WORKING PAPER · NO. 2020-89

\title{
U.S. Banks and Global Liquidity
}

Ricardo Correa, Wenxin Du, and Gordon Liao

JUNE 2020 


\title{
U.S. Banks and Global Liquidity*
}

\author{
Ricardo Correa ${ }^{\dagger} \quad$ Wenxin $\mathrm{Du}^{\ddagger} \quad$ Gordon Liao $^{\S}$
}

First Draft: December 2019

This Draft: June 2020

\begin{abstract}
We characterize how U.S. global systemically important banks (GSIBs) supply shortterm dollar liquidity in repo and foreign exchange swap markets in the post-Global Financial Crisis regulatory environment and serve as the "lenders-of-second-to-lastresort". Using daily supervisory bank balance sheet information, we find that U.S. GSIBs modestly increase their dollar liquidity provision in response to dollar funding shortages, particularly at period-ends, when the U.S. Treasury General Account balance increases, and during the balance sheet taper of the Federal Reserve. The increase in the dollar liquidity provision is mainly financed by reducing excess reserve balances at the Federal Reserve. Intra-firm transfers between depository institutions and broker-dealer subsidiaries within the same bank holding company are crucial to this type of "reserve-draining" intermediation. Finally, we discuss factors that contributed to the repo spike in September 2019 and the subsequent response of U.S. GSIBs to recent policy interventions by the Federal Reserve.
\end{abstract}

Keywords: Liquidity, Global Banks, Repos, Reserves, Covered Interest Rate Parity JEL Classifications: G2, F3, E4

*We thank seminar and conference participants at the AEA, Chicago Booth, the Federal Reserve Board, Imperial (Zoom), PBCSF (Zoom), Princeton (Zoom), and Yale SOM (Zoom) for helpful comments. We thank Markus Brunnermeier, Tyler Muir, James Clouse, Patrick McCabe and Mike Hsu for helpful comments. We are grateful to Luke Pettit, Thomas Doherty, Phillip Weed, and Brian Hefferle for their insights into the FR2052 data and advice on liquidity regulations and to Vickie Chang and Martin Sicilian for their excellent research assistance. The views in this paper are solely the responsibility of the authors and should not be interpreted as reflecting the views of the Board of Governors of the Federal Reserve System or any other person associated with the Federal Reserve System. All remaining errors are our own.

${ }^{\dagger}$ Correa: Board of Governors of the Federal Reserve System. Email: ricardo.correa@frb.gov.

${ }^{\ddagger} \mathrm{Du}$ : University of Chicago Booth School of Business and NBER. Email: wenxin.du@chicagobooth.edu.

§Liao: Board of Governors of the Federal Reserve System. Email: gordon.y.liao@frb.gov. 


\section{Introduction}

Recent rate spikes in the U.S. repurchase agreement (repo) markets and the failure of covered interest rate parity (CIP) point to frictions in global dollar intermediation. Financial intermediaries with broad access to dollar deposits and wholesale funding markets can lend dollars to market participants without ready access to dollar funding and earn an intermediation spread. Among all the financial intermediaries, large U.S. banks stand out as natural intermediaries for global dollar funding due to their access to the broadest dollar deposit base, high levels of dollar excess reserve balances, extensive global operations, and active foreign exchange spot and derivative services.

In this paper, through the lens of large U.S. banks, we provide an empirical characterization of how dollar funding is intermediated by U.S. banks and investigate the drivers for these intermediation activities. We find that large U.S. banks moderately increase their dollar funding liquidity provision in response to an increase in dollar intermediation spreads, and finance the additional liquidity provision mainly by reducing their excess reserve balances at the Federal Reserve (or the Fed). Our results shed light on the dynamic interplay among money market rates, banks' balance sheet constraints, and the conduct of U.S. monetary policy in the post-Global Financial Crisis (GFC) regulatory environment. In particular, we highlight the trade-offs faced by policymakers between financial regulations and the effectiveness of monetary policy implementation, and the central role of bank reserves to help mitigate these trade-offs.

This empirical characterization of U.S. banks' short-term dollar liquidity provision could not be performed in the past due to the absence of high-frequency balance sheet data broken down by currencies and counterparties. As a part of the regulatory effort to calculate the Basel III liquidity coverage ratio (LCR), the Federal Reserve started to collect detailed daily consolidated bank balance sheet information (and for material entities) by currency for the largest U.S. banks in the FR2052a Complex Institution Liquidity 
Monitoring Report, starting in December 2015. We use aggregate data from the FR2052a report for six global systemically important banks (GSIBs) headquartered in the United States: Bank of America, Citigroup, Goldman Sachs, JP Morgan, Morgan Stanley, and Wells Fargo to shed light on the global dollar intermediation activities of the largest U.S. banks. $^{1}$

We focus on two types of secured short-term dollar liquidity provision: dollar lending via repurchase agreements (known as repos) or dollar lending via the foreign exchange (FX) swap market. In a repo agreement, a cash loan is collateralized by securities such as Treasury securities. The borrower receives cash in exchange for posting securities as collateral at the inception of the trade with a promise to repurchase the securities with cash at maturity. Dollar lending via FX swaps can also be viewed as a form of secured lending collateralized by foreign currency - the borrower receives dollars and posts foreign currency at the spot exchange rate against a bank counterparty at the inception of the trade and promises to repurchase the foreign currency with dollars at the forward exchange rate at maturity. The foreign currency that the bank receives from the FX swap counterparty is either deposited at the corresponding foreign central bank or on-lent to borrowers.

With the detailed balance sheet data for U.S. GSIBs by currency and instrument, we classify the mechanism of short-term dollar liquidity provision into two channels matched-book intermediation and reserve-draining intermediation. In matched-book intermediation, an increase in the dollar reverse repo position or the FX swap lending position is financed by a corresponding increase in liabilities such as repo borrowing. As a result, the size of the bank balance sheet expands by the same amount as the increase in dollar lending. In reserve-draining intermediation, increases in reverse repo or FX swap lending positions are financed by reducing "drainable" excess reserve balances at

\footnotetext{
${ }^{1}$ There are currently eight GSIBs in the United States. We exclude the Bank of New York Mellon and State Street from our sample due to their specialization in the custodian business.
} 
the Fed. The overall size of the balance sheet stays constant under this channel, but the composition of bank assets changes in the direction of more dollar lending and less reserve balances.

Both methods of intermediation incur different balance sheet costs and make different regulatory requirements more binding. In particular, more matched-book intermediation increases the size of the bank balance sheet and makes the Basel III leverage ratio requirement more binding. More reserve-draining intermediation reduces banks' intraday liquidity, necessitates intra-firm credit between the depository financial institution and the broker-dealer affiliate within the bank holding company (BHC), and may also unevenly distribute liquidity among subsidiaries and jurisdictions, making it more difficult to meet the resolution planning rules. In return for providing these dollar liquidity services, banks receive an intermediation spread (averaging to about 10-25 basis points outside quarter-ends) to offset the shadow cost of these balance sheet constraints.

To assess how these intermediation strategies are associated with the changes in intermediation spreads, we analyze the U.S. GSIBs' balance sheet responses to three types of dollar funding shortages. In particular, we focus on quarter-ends, on days with increases in Treasury General Account (TGA) balances, and on days with reductions in the Federal Reserve's System Open Market Account (SOMA) portfolio. First, quarter-ends are associated with spikes in intermediation spreads because non-U.S. banks reduce their lowmargin balance-sheet-intensive arbitrage and intermediation activities to "window-dress" leverage ratios on regulatory-reporting dates. ${ }^{2}$ Second, an increase in the Treasury's TGA balance at the Federal Reserve, either due to an increase in the net issuance of Treasury securities or higher tax payments (lower expenses), reduces cash (reserves) from the banking system. Additionally, increases in the net issuance of Treasury securities also increases the financing needs for those Treasury securities. We find that an increase in the TGA

\footnotetext{
${ }^{2}$ In most non-U.S. jurisdictions, the Basel III leverage ratio is calculated using quarter-end snapshots of bank balance sheets. For U.S. banks, the leverage ratio is calculated based on the daily average of bank assets.
} 
balance is significantly associated with wider repo and FX swap spreads. Third, an increase in the Federal Reserve's SOMA portfolio increases the availability of cash in the banking system and reduces the share of Treasury securities that need financing, and thus, has the opposite effect of a TGA balance increase. In our main sample period, the Federal Reserve reduced its SOMA portfolio holdings (between October 2017 and September 2019), tightening dollar funding conditions.

We show that U.S. GSIBs modestly increase their short-term dollar lending in repo and FX swap markets during these three types of dollar-shortage events. Importantly, reserve-draining intermediation was the dominant channel for U.S. GSIBs to increase their dollar liquidity provision in our sample period. In other words, the additional lending from U.S. GSIBs was largely financed by a reduction in reserve balances at the Fed rather than additional repo borrowing or deposit inflows.

In terms of economic magnitudes, focusing on quarter-ends, we find that U.S. banks reduce their reserve balances by about $\$ 60$ billion, and increase their net reverse repo positions by $\$ 40$ billion and dollar lending in the FX swap market by $\$ 20$ billion. The increase in the net reverse repo is primarily driven by a reduction in the repo position while holding the reverse repo position roughly unchanged. Using a multivariate regression controlling for quarter-ends, daily fluctuations in the TGA balance and the SOMA portfolio, we find that in response to a one-standard-deviation change in the daily TGA balance (about $\$ 20$ billion), U.S. GSIBs significantly reduce their reserve balances by about $\$ 3.6$ billion, while increasing their net repo lending by $\$ 7.4$ billion and FX lending by $\$ 6.2$ billion. The impact of daily fluctuations in the SOMA holdings is also significant for intermediation activities and generally works in the opposite way as the TGA fluctuations.

We find additional evidence for the reserve-draining intermediation channel by studying the intra-firm liquidity flows within the BHC. Given that most of the short-term liquidity provision is done by broker-dealers, but only depository institutions can hold reserves, intra-firm transfers between broker-dealers and depository institutions are cru- 
cial. To keep the reverse repo lending position steady and to expand the dollar lending in the FX swap market, the broker-dealer arm increases internal repo borrowing from the non-broker dealer arm of the bank. The non-broker dealer arm of the bank (depository institution), in turn, finances the intra-firm transfer through a reduction in reserve balances. ${ }^{3}$ The shared usage of reserves between depository entities and the affiliated dealers highlights the synergy and the importance of having both banks and broker-dealers organized under the same BHC structure.

Furthermore, we show that the distribution of reserves among U.S. GSIBs, foreign banks, and other U.S. banks react strongly to dollar funding conditions. Holding the size of the Fed's assets constant, a reduction in the reserve balance of U.S. GSIBs must translate into an increase in the reserve balance of other banks in the system or an increase in some non-reserve liabilities of the Federal Reserve. ${ }^{4}$ Using daily data on reserve balances for all banks, we find that U.S. GSIBs and foreign banks significantly reduce their reserve balances in response to a dollar funding shortage, while other U.S. banks become the recipients of these reserves outflows. Our results suggest that large non-U.S. global banks are also potentially conducting significant amounts of reserve-draining intermediation in dollar funding markets.

The central role of reserves to absorb large dollar funding shocks helps us better understand the repo rate spike in September 2019. On September 16, 2019, the TGA balance increased by around $\$ 83$ billion as a result of a large Treasury auction settlement and corporate tax payments. The repo rate increased up to $10 \%$ the following morning, and the implied dollar rate from the FX swap market increased up to 6\%. The large spikes in funding rates occurred against the backdrop of the total amount of reserves

\footnotetext{
${ }^{3}$ We note that intra-firm transfers that are used to accommodate cash demands at the entity level are mainly achieved through internal repo transactions, as such transactions protect individual entities from a resolution planning standpoint. Additionally, this type of transactions are exempted under certain circumstance from the Regulation W quantitative limits on transactions between depository institutions and affiliates within a BHC.

${ }^{4}$ The three most important non-reserve liability items are currency in circulation, reverse repo positions of non-banks at the Fed, and the TGA.
} 
in the banking system reaching multi-year lows since the Fed started its balance sheet normalization (or taper) process in October 2017. A low level of reserves impairs reservedraining intermediation. Interestingly, we find that the U.S. GSIBs' one-day change in their dollar intermediation activities was comparable to estimates from the sample before the event. In contrast, foreign banks reduced their reserve balances by about $\$ 26$ billion less on September 16, 2019 compared to previous episodes with changes in TGA balances. This finding points to a contraction in foreign banks' intermediation activity as a likely trigger for the large spike in funding rates.

We also examine the response of U.S. GSIBs' to the repo facility launched by the Fed in the aftermath of the repo rate spike in September 2019. We find that primary dealer subsidiaries of U.S. GSIBs increase their repo borrowing from the Fed when funding conditions are tight, with this Fed liquidity partly substituting their internal borrowing from depository institutions as part of the reserve-draining intermediation channel. Overall, liquidity from the Fed repo facility helps U.S. GSIBs to boost their dollar lending in the repo and FX swap markets.

Our documented channel of reserve-based liquidity provision post-GFC stands in contrast with the pre-GFC regime. Before the GFC, banks operated in the scarce reserves environment and financed their immediate cash needs by either borrowing in an actively traded federal funds market or by accessing Fed intraday credit in the form of overdrafts. The Fed actively managed the supply of reserves in the system through open market operations to target the federal funds rate. Short-term money markets were very integrated, as financial intermediaries were able to effectively arbitrage across different market segments in the absence of significant regulatory constraints on their balance sheet. After the GFC, regulatory oversight became tighter to build resilience in the financial system. Relatedly, banks now face higher balance sheet costs to intermediate across different money market segments. Reserve-based liquidity provision has become the main response of large U.S. banks to dollar funding shortage, as it is neutral to key Basel III regulatory ratios, 
such as the Leverage Ratio (LR) and the LCR. Nevertheless, this intermediation strategy is still constrained by banks' requirements to hold reserves for liquidity stress tests and resolution planning purposes.

Frequent and acute dollar shortages pose new challenges not only for banks' liquidity management but also for the implementation and transmission of U.S. monetary policy. The ongoing benchmark transition process from the survey-based London Overnight Borrowing Rate (LIBOR) to the market-based Secured Overnight Financing Rate (SOFR) will link trillions of dollars of floating-rate debt and derivative contracts to the repo rate. This transition would accentuate the pass-through effects on the broader economy due to rate fluctuations arising from quarter-ends, TGA swings, and SOMA changes. Therefore, understanding global banks' role in leaning against these factors is of critical importance.

Lastly, as the Federal Reserve massively builds up its balance sheet in response to the COVID-19 pandemic, banks are again accumulating an abundance of reserves critical for the supply of liquidity, particularly in times of distress. Going forward, the lessons learned from the earlier episode of Federal Reserve balance sheet normalization before the COVID-19 pandemic can inform future monetary policy and its interaction with global dollar intermediation.

\section{Related Literature}

Our paper is related to several strands of the literature. The role of banks in supplying liquidity through their issuance of demand deposits has been widely recognized in earlier studies that emphasize liquidity transformation (Diamond and Dybvig, 1983), information-insensitive claims (Gorton and Pennacchi, 1990), and synergies between loans and deposits (Kashyap, Rajan, and Stein, 2002). Relative to this literature, we focus on the post-crisis Basel III regime that differs in two important ways. First, the demand

shocks typically associated with deposit withdrawals are modeled as idiosyncratic shocks, whereas the post-crisis regime is characterized by large liquidity demands that are sys- 
tematic, absent of bank runs. Rather than satisfying idiosyncratic deposit withdrawals, U.S. GSIBs deploy reserve buffers to accommodate TGA cash withdrawals, SOMA portfolio changes, and contractions in foreign banks' liquidity provision. These large demand shocks in the post-crisis regime have notable pricing impacts on funding spreads and elicit strong responses from banks. Second, in contrast to the earlier scarce reserve regime where the central bank provided liquidity by making daily adjustments in open-market operations, the post-crisis era of large bank reserve holdings make the largest banks the "lenders-of-second-to-last-resort." These banks affect the overall provision of short-term financing and the equilibrium short-term interest rate available to a large fraction of the market.

Another strand of the literature has also examined the deposit-taking role of banks. Drechsler, Savov, and Schnabl (2017) study banks' pricing power in deposit-taking that affects the transmission of monetary policy. In our paper, we focus on the immediately scalable components of banks' balance sheets that can be adjusted on an overnight or intraday basis, which contrasts with retail deposits that are slower to adjust. The financing provided by these scalable components of banks' balance sheets are important bedrocks of the financial system.

Outside of the study of traditional banking, the GFC has led to a separate line of inquiry into the role of non-depository financial institutions, generally referred to as "shadow banks", that engage in repo financing and liquidity transformation (Gorton and Metrick, 2012; Krishnamurthy, Nagel, and Orlov, 2014). The possibility of rapid evaporation of short-term financing is reminiscent of bank runs. Related to this theme, Hanson, Shleifer, Stein, and Vishny (2015) models the comparative advantage of traditional commercial banks that rely on deposit to hold illiquid fixed-income investments, compared to shadow banks that rely on run-prone short-term financing to hold relatively liquid assets. Our work suggests that U.S. GSIBs satisfy both characterizations, with a strong synergistic relationship between broker-dealers' role in short-term liquidity provision and the traditional 
banking function of deposit taking. The use of internal liquidity management between these affiliated institutions allows them to use the BHC's reserves to supply short-term funding to the broader economy and to maintain a stable price of funding. These findings are consistent with studies highlighting the importance of banks' internal liquidity management to absorb monetary and other types of shocks (Campello, 2002; Cetorelli and Goldberg, 2012), while using better information on the high-frequency magnitudes of these transactions.

A related line of inquiry that has focused on short-term borrowings and the financing of assets, emphasizes the supply of leverage by broker-dealers as a key determinant of asset prices both theoretically (Brunnermeier and Pedersen, 2008; He and Krishnamurthy, 2013; Adrian and Shin, 2010) and empirically (Adrian, Etula, and Muir, 2014; He, Kelly, and Manela, 2017; Du, Hébert, and Huber, 2019). Relative to these papers, our paper takes a bottom-up approach and examines the underbelly of intermediary leverage, by focusing on the role of GSIBs in intermediating short-term financing that supports the leverage of other financial institutions and determines asset prices.

A large growing literature has also focused on CIP deviations post-GFC. For example, Du, Tepper, and Verdelhan (2018) highlight persistent CIP deviations in the post-crisis period and periodic increases in these deviations nearing quarter-ends. Liao (2020) examines financial and non-financial corporates arbitraging long-term CIP deviations through currency-hedged borrowing in different currencies. Anderson, Du, and Schlusche (2019) calculate the amount of potential capital of global banks to arbitrage CIP deviations. Liao and Zhang (2020) examine the impact of hedging demand and global imbalance on CIP deviations. ${ }^{5}$ Our paper provides the first granular account of balance sheet adjustments of U.S. GSIBs relating to CIP deviations.

\footnotetext{
${ }^{5}$ In addition, Du, Im, and Schreger (2018) and Jiang, Krishnamurthy, and Lustig (2018, 2019) discuss the U.S. Treasury convenience yield through the lens of CIP deviations for government bond yields.
} 
Finally, the turmoil in the repo market in September 2020 and the Federal Reserve's operational framework under "ample" reserves have prompted many commentary pieces from market observers. Pozsar $(2017,2019)$ voiced concerns with excess balance sheet normalization prior to the repo market turmoil and detailed potential liquidity concerns associated with Treasury settlements. Gagnon and Sack (2019) have made several suggestions focusing on the Federal Reserve's operational framework including the setting of a standing repo facility, higher reserve levels, and explicit directives to control the repo rate. Tarullo (2019) highlights several questions yet to be addressed with the current monetary policy and regulatory frameworks. Avalos, Ehlers, and Eren (2019) attributes part of the repo turmoil to hedge funds' use of repo. Afonso, Cipriani, Copeland, Kovner, La Spada, and Martin (2020) provides a detailed account of the event and highlights the role of reserves and interbank market frictions. Relative to these writings, we provide a comprehensive approach to characterize the largest U.S. banks' liquidity provision in

the post-GFC regime. We also bring quantitative evidence from balance-sheet shifts to understand the repo market turmoil.

\section{Data Description and Summary Statistics}

\subsection{Daily Bank Balance Sheets for U.S. GSIBs}

We construct detailed bank balance sheets at the daily frequency using data collected by the Federal Reserve in the FR2052a, Complex Institution Liquidity Monitoring Report. These data are used for the calculation of the Basel III LCR, which requires that banks hold enough high quality liquid assets to fund net expected cash outflows for 30 days. These bank-level data contain a detailed breakdown of individual banks' asset inflows and liability outflows on a consolidated basis, as well as by material subsidiary entities. Banks with $\$ 700$ billion or more in total consolidated assets or $\$ 10$ trillion or more in 
assets under custody are required to report on each business day beginning in December 2015. The collection of month-end reports from these entities extends to January 2015.

Our analysis focuses on the aggregate data for six U.S. GSIBs: Bank of America, Citigroup, Goldman Sachs, JP Morgan, Morgan Stanley, and Wells Fargo. We exclude State Street and Bank of New York Mellon in our sample as these two banks' large custodian functions are reported together with other business lines in the filings, making it difficult to distinguish the liquidity provision functions of the banks as defined in the following section.

As the data collection is designed for LCR assessment rather than balance sheet reporting, we perform a manual mapping of the inflow and outflow product categories collected in FR2052a to asset and liability line items in the quarterly call reports collected through FR Y-9C forms at the consolidated bank holding company level. The balance sheet assembly and matching process is meticulous and achieved through iterative comparison with FR Y-9C. The FR2052 data is mainly composed of inflow items that correspond generally to assets and outflow items that correspond generally to liabilities. However, there are caveats to these generalizations. We exclude a number of the inflow and outflow categories in the LCR assessment that are off-balance sheet or contingency facilities, e.g. loan or liquidity facilities on which either the banks or their clients can draw on. For some inflow and outflow LCR items, we rely additionally on the collateral type reported for the proper assembly of the balance sheet snapshots. ${ }^{6}$

There are several novel aspects of the LCR assessment data that relates to our analysis. First, the data capture the global activities of reporting U.S. based banks, which allows for a comprehensive analysis of these institutions' exposure in different currencies and locations. Second, the data is collected daily and as such, offers a look into the highfrequency changes that these institutions make to their balance sheets. Third, the data

\footnotetext{
${ }^{6}$ We discuss the comparison between FR2052a and FR Y-9C in greater detail in Appendix A. Appendix Figure A1 shows that the key balance sheet items from the two data sources are broadly in line.
} 
allows us to assess the intermediation activities at the consolidated level and the material legal entity level. This allows us to assess whether banks move funds across material entities to manage their liquidity, as a result of specific events. Last, the granularity of the inflow and outflow data also provides a view into hard to find details about bank balance sheet items, including the remaining maturity and the collateral type used, when it is applicable.

\subsection{Summary Statistics of Balance Sheets by Currency}

Figure 1 shows the balance sheet of dollar-denominated assets and liabilities aggregated across the six banks in our sample. We can see that the overall assets and liabilities of U.S. banks are broadly equivalent in size, with the assets averaging to $\$ 7.4$ trillion and liabilities averaging to $\$ 7.2$ trillion. The gap in dollar-denominated assets and liabilities only averages to $4 \%$ of total assets. Loans represent the largest asset category and deposits represent the largest dollar-denominated liability.

Figure 2 shows the evolution of assets and liabilities denominated in euros (EUR), yen (JPY), sterling (GBP), and Australian (AUD) dollars, respectively. The size of all foreign-currency-denominated assets is about $\$ 1.7$ trillion and the average size of all foreign currency denominated liabilities is about $\$ 1.4$ trillion. The foreign currency funding gap, or the difference between assets and liabilities denominated in foreign currencies, is about to $\$ 300$ billion, or $17 \%$ of the size of total foreign currency assets. ${ }^{7}$ In contrast to the dollardenominated balance sheet items, the foreign currency balance sheets have a markedly lower fraction of loans in total assets and a lower fraction of deposits in total liabilities. Reverse repos and repos represent the largest balance sheet items denominated in foreign currency.

\footnotetext{
${ }^{7}$ In Section 6.1, we discuss the foreign currency funding gap as a proxy of total dollar lending in the FX swap market.
} 


\section{Dollar Lending in Repo and FX Swap Markets}

In this section, we first describe two types of dollar liquidity provision in repo and FX swap markets. We then introduce two types of intermediation methods: matched-book and reserve-draining intermediation, which are used to finance the provision of short-term dollar liquidity.

\subsection{Definition and Measurement}

We focus on the two most important types of collateralized short-term lending done by U.S. GSIBs: dollar lending in the repo market and dollar lending in the FX swap market. These two types of lending are the most liquid and scalable components of bank's overall dollar lending. As opposed to traditional bank loans to businesses and households, banks can easily change the scale of these positions on a daily basis.

Figure 4 shows schematically these two types of dollar lending. As shown in Panel A, at the inception of a dollar repo loan, a bank (e.g., JP Morgan) lends dollars against some collateral, most commonly U.S. Treasury securities. At maturity, the bank receives the principal and interest payment in dollars and returns the collateral. Repo lending is referred to as a reverse repo position on the bank's balance sheets. We can directly observe the amount of reverse repo positions denominated in dollars from our constructed balance sheet. ${ }^{8}$

As shown in Panel B of Figure 4, to lend dollars in the FX swap market (e.g., the dollar-yen swap market), at the inception of the trade, the bank lends dollars through an FX swap dealer, receives yen in exchange at the spot exchange rate, and on-lends the yen. In addition, the bank promises to buy dollars for yen at the forward exchange rate. At maturity, the bank receives the yen principal and interest payment and fulfills the terms

\footnotetext{
${ }^{8}$ We also consider fixed income security lending and borrowing positions that are much smaller in size relative to repo and reverse repo positions but are functionally similar in our analyses.
} 
of the forward contract by exchanging yen for dollars. Dollar lending in the FX swap market is collateralized in the sense that the yen is effectively posted as collateral for dollar lending. Furthermore, the bank has the option to on-lend the yen without credit risk, for example, by depositing the yen at the Bank of Japan's deposit facility or lending it in the Japanese repo market backed by Japanese government bonds.

The challenge to measure dollar lending via the FX swap market is that the position is off balance sheets and not directly observable. However, given that dollar lending via the FX swap market is accompanied by foreign-currency on-lending on balance sheets, we can construct an empirical proxy for FX lending positions based on balance-sheet items. Our benchmark measure for short-term FX swap lending (Short-Term FX Swap Lend) is equal to the sum of net repo lending in foreign currency and excess reserve balances in foreign currency:

Short-Term FX Swap Lend = FC Reverse Repo - FC Repo + FC Excess Reserve.

The assumption behind this measure is that banks choose secured foreign currency onlending to minimize their credit risk so that an increase in the short-term dollar lending in the FX swap market (e.g. for the dollar-yen FX swap) is associated with an increase in the reverse repo position in yen (not matched by an increase in the repo position in yen) or an increase in the reserve balances at the Bank of Japan. While the high-frequency variation in our Short-Term FX Swap Lend measure provides relevant information about the fluctuations in short-term dollar lending in the FX swap market, the level of ShortTerm FX Swap Lending could overstate the amount of FX swap lending. This is because banks may hold excess reserves in foreign currency for reasons other than supporting dollar lending in the FX swap market. In Section 6.1, we present robustness checks for our main results using an alternative proxy of FX swap lending that takes the difference between total foreign currency assets and foreign currency liabilities. 
Figure 3 shows the amount of reverse repo positions, our proxy for short-term dollar lending in the FX swap market, along with the total reserve balances at the Federal Reserve for our sample of U.S. GISBs. We can see that reverse repo positions is the largest item totaling over $\$ 1$ trillion. Our proxy for FX swap lending is significantly lower and averages to about $\$ 300$ billion in our sample period. It is worth noting that since late 2017, when the Federal Reserve started reducing the size of its balance sheet, the decline in reserves balances has been associated with a significant increase in the reverse repo position.

\subsection{Matched-book and reserve draining intermediation}

How do U.S. GSIBs finance their short-term dollar liquidity provision? We now discuss two types of intermediation methods, matched-book and reserve-draining, which allow U.S. GSIBs to scale up or down short-term dollar lending in the repo and FX swap markets at a high frequency. We illustrate these two intermediation methods in Figure 5.

To start, Panel A of Figure 5 presents baseline balance sheet that consists of dollardenominated short-term scalable assets, namely reverse repos (RRP), short-term FX swap lending (FX Lend), and drainable excess reserve balances. ${ }^{9}$ The last item, drainable excess reserves, measures excess reserves that the bank holds at the Federal Reserve beyond those determined by reserve requirements and other regulatory demands. Postcrisis liquidity regulations have increased banks' demand for reserves, over those usually maintained for reserve requirement purposes. However, the exact amount of drainable reserves is unknown, but is certainly lower than total excess reserve balances, as shown in Figure 3. On the liability side of our scalable balance sheet, we have repos and deposits,

\footnotetext{
${ }^{9}$ By combining the foreign currency on-lending and an FX swap, we treat synthetic dollar lending in the FX swap market as an on-balance-sheet item.
} 
which fund reverse repo, FX swap lending, and drainable excess reserve positions. ${ }^{10}$ As presented in Figure 1, U.S. GSIBs have smaller repo positions compared to their reverse repo positions, so a certain amount of deposits is needed to support the short-term dollar liquidity provision. However, since deposits are rather sticky, the bank cannot rely on deposits to scale their liquidity provision at a high frequency.

The first intermediation method, matched-book intermediation, is illustrated by Panel B of Figure 5, which features simultaneous changes in the bank's assets and liabilities. For example, if the bank wants to lend additional dollars in the repo market, it needs to borrow additional dollars in the repo market. On the bank's balance sheet, we can see that an increase in the reverse repo position is matched by the same increase in the repo position. Any matched-book intermediation transactions result in a larger balance sheet for the bank.

The second intermediation method, reserve-draining intermediation, is illustrated by Panel $\mathrm{C}$ of Figure 5. It features a change in the composition of assets while maintaining the overall size of the balance sheet unchanged. In this case, the bank can "drain" reserves to finance an expansion of repo lending, without additional borrowing. On the bank's balance sheet, we can see that the increase in the reverse repo position is matched by a reduction in the drainable reserve balance by the same amount. There are no changes to banks' liabilities.

Intra-firm transfers between depository institutions and broker-dealers within the BHC play a central role in reserve-draining intermediation. As shown in Figure 6, only depository institutions have reserve accounts at the Federal Reserve, but most of the reverse repo and repo positions are booked on the broker-dealers' balance sheet. The mechanics of the reserve-draining intermediation is that the depository institutions reduce their

\footnotetext{
${ }^{10}$ We purposely exclude unsecured wholesale funding instruments (such as fed funds, eurodollars, commercial paper and certificate of deposits) from the liabilities because U.S. GSIBs' reliance on these sources of unsecured wholesale funding is small during our sample period based our data. This fact is also separately documented in Anderson et al. (2019).
} 
reserve balance and lend the cash to a broker-dealer within the same BHC through an internal repo position, the broker-dealer then uses the internal repo from the depository institution to finance its additional external repo lending. After netting out internal repo positions, the overall size of the BHC's balance sheet remains unchanged after additional reserve-draining intermediation. ${ }^{11}$

Matched-book intermediation and reserve-draining intermediation have different regulatory implications. The most important difference is that matched-book intermediation increases the overall size of the bank balance sheet, but reserve-draining intermediation leaves the overall balance sheet size unchanged at the BHC level. Assuming that bank equity cannot be adjusted in the short run, matched-book intermediation worsens the Basel III leverage ratio, and reserve-draining intermediation has no impact on the leverage ratio for the BHC. Therefore, for banks constrained in terms of their leverage ratio, reserve-draining intermediation is often preferred. ${ }^{12}$

However, reserve-draining intermediation can be constrained by additional regulatory and internal risk management practices, especially regarding intraday liquidity and how liquidity can be allocated across material entities and jurisdictions. In addition to Regulation W, resolution planning rules require U.S. GSIBs to hold sufficient liquidity in each material legal entity on an ongoing basis to ensure a successful resolution in case of bankruptcy. Reserve-draining intermediation shifts the distribution of liquidity across material legal entities and jurisdictions, which can bind resolution planning requirements. We provide a detailed discussion of the resolution planning rules in Section 7.2. Furthermore, reserves have better intraday liquidity than repo and FX swap lending (which are

\footnotetext{
${ }^{11}$ Regulation W, which implements sections 23A and 23B of the Federal Reserve Act, establishes restrictions on transactions between depository institutions and its affiliates. The regulation sets quantitative limits on transactions that are covered by the rules. Importantly, transactions that are collateralized by U.S. government securities are not subject to the quantitative limits (equivalent to $10 \%$ of capital stock and surplus).

${ }^{12}$ For the Basel III LCR, matched-book intermediation is LCR-neutral if the change in the repo and reverse positions have the same maturity and collateral. Reserve-draining intermediation is also LCRneutral if the increase in the reverse repo position is collateralized by U.S. Treasury securities, as reserves and Treasury securities both count towards Level 1 high quality liquidity assets.
} 
locked at least overnight), potentially reducing the incentive for the depository institution to use them to fund their transactions with non-depository affiliates within the BHC.

\section{Dollar Funding Shortages and Response of U.S. GSIBs}

In this section, we assess the response of U.S. GSIBs to high-frequency fluctuations in dollar funding and cash liquidity demand. In particular, we examine three types of events:

1) contraction of dollar intermediation by foreign banks on period-end regulatory reporting dates, 2) large fluctuations in TGA balances, and 3) changes in the SOMA portfolio holdings. We find that all three types of fluctuations have a substantial impact on the scarcity value of the dollar and elicit responses from the U.S. GSIBs as they optimize their balance sheets. We first describe the three types of dollar funding events, their effects on the intermediation spreads, and the U.S. GSIBs' balance sheet response. Finally, we also describe changes in the distribution of reserves in the entire banking system among U.S. GSIBs, foreign banks, and smaller U.S. banks in response to these dollar funding shortages. All the analyses are based on the sample from December 15, 2015, to August 31, 2019, prior to the repo rate spike in September 2019.

\subsection{Three Types of Dollar Funding Shortage}

We focus on three types of events that are associated with changes in dollar funding conditions: quarter-ends, fluctuations in the TGA balance, and fluctuations in the holdings of the Federal Reserve's SOMA portfolio.

First, dollar funding conditions are particularly tight at quarter-ends. The quarter-end liquidity premium predominately arises due to a significant contraction in foreign banks' dollar intermediation activities to meet regulatory requirements in their own jurisdictions Du et al. (2018); Cenedese, Della Corte, and Wang (2019); Egelhof, Martin, and Zinsmeiste (2017). These requirements are typically measured using period-end snapshots of 
banks' balance sheets. Of particular importance, in most non-U.S. jurisdictions the Basel III LR is assessed using banks' balance sheet size at quarter-end. ${ }^{13}$ This reporting requirement incentivizes foreign banks to reduce their dollar lending in the repo and FX swap markets on quarter-ends in order to have better reported consolidated LRs, contributing to spikes in short-term intermediation spreads. In contrast to the foreign banks, U.S. banks calculate the leverage ratio based on the daily-average of assets in each quarter.

Second, fluctuations in the TGA account balance are also significantly correlated with dollar funding conditions. The TGA contains cash balances that the U.S. Treasury holds at the Federal Reserve. Other things being equal, an increase in the TGA balance corresponds to a reduction in the overall cash for the entire banking system, making dollar liquidity more scarce. Similarly, Hamilton (1997) has used Treasury cash balances in commercial banks to identify liquidity shocks. ${ }^{14}$ Since May 2015, the TGA balance has been particularly volatile, ranging from a minimum of $\$ 23$ billion to a high of $\$ 440$ billion. The weekly changes in the TGA balance have a standard deviation of $\$ 40$ billion, with a maximum weekly change exceeding $\$ 100$ billion. Appendix Figure A2 presents the time series of the TGA balance. ${ }^{15}$

Third, fluctuations in the Fed SOMA portfolio also affect dollar funding conditions. In our sample, between October 2017 and August 2019, the Federal Reserve reduced its Treasury holdings at the rate of $\$ 35$ to $\$ 50$ billion a month, a process known as the balance sheet normalization or taper. A reduction in the SOMA's Treasury holdings corresponds

\footnotetext{
${ }^{13}$ In addition to quarter-end reporting, banks in some jurisdictions follow Basel III guidelines for calculating the LR using month-end averages of banks' assets within a quarter. U.K. banks switched from three month-end-averaging for the LR calculation to daily-averaging beginning in 2018 .

${ }^{14}$ The methodology in Hamilton (1997) exploits the forecasting error in Treasury cash holdings in private banks, a setup specific to the pre-GFC regime in which the Federal Reserve conducted daily open market operations to control the Fed Funds rate based on forecasts of banking reserves.

${ }^{15}$ Prior to 2009, the Treasury held most of its cash balances in commercial bank deposit accounts through the Treasury Tax and Loan program. The Treasury shifted to holding cash balances at the Federal Reserve in the fall of 2008 to facilitate the Fed's large expansion of lending to financial firms (Santoro, 2012). In May 2015, the Treasury expanded its TGA balance to protect against "a potential interruption in market access," with a minimum balance of $\$ 150$ billion (Treasury Quarterly Refunding Statement, May 2015).
} 
to a reduction in the overall reserve balance for the banking system and an increase in the Treasury securities held by financial market participants, likely increasing financing needs and tightening funding conditions.

\subsection{Impact on the Intermediation Spreads}

We first present the intermediation spreads that the U.S. GSIBs can earn by increasing their dollar lending through reverse repo positions. The exact spread depends on the intermediation method. For matched-book intermediation, the spread that the bank can earn is determined by the difference between the U.S. GSIBs' funding cost in the repo market and its lending rate in the reverse repo market. We use the triparty Treasury repo spread as the proxy for GSIBs' repo funding rate and the General Collateral Financing $(\mathrm{GCF})$ repo rate as the proxy for their lending rate in the reverse repo market. ${ }^{16}$ Alternatively, for the reserve-draining intermediation, the bank earns an intermediation spread captured by the difference between the reverse repo lending rate and the opportunity cost of not holding reserves, which equals the foregone interests on reserves (IOR). We use the GCF-IOR spread as the repo spread for reserve-draining intermediation. We also present results on an additional spread measure using SOFR minus IOR to show the impact on the benchmark rate that is set to replace LIBOR.

We measure the intermediation spread for lending dollars in the FX swap markets, as the CIP deviations between overnight central bank deposit rates. We conduct a meticulous calculation for the overnight FX swap rate following a strict set of market conventions, the first time in the literature to our knowledge, in order to be as analogous as possible to an overnight dollar reverse repo. ${ }^{17}$ In the subsequent analysis, we present spreads based

\footnotetext{
${ }^{16}$ The triparty repo market is where large, high-quality, dealers borrow from U.S. money market funds, and the GCF repo market is where large dealers lend to smaller dealers. As a result, the GCF-triparty repo spread measures the compensation that large dealers earn when providing matched book intermediation.

${ }^{17}$ To calculate overnight FX-implied dollar funding rate, we use the following formula:

$$
r_{\text {implied }}=\left(\left(1+r^{*} * N / d\right) *\left(S-\phi_{T N} / D\right) /\left(S-\phi_{T N} / D-\phi_{O N} / D\right)-1\right) *(d / N),
$$
}


on reserve-draining intermediation transactions. The matched-book FX swap spreads are similar in levels. Our overnight FX IOR spread reflects additional profits that banks can earn by moving excess reserves from the Fed to the ECB or the BOJ, while fully hedging FX risk using overnight FX swaps.

Panel (A) of Figure 7 shows these two repo intermediation spreads. We can see that the GCF-triparty spread is almost always positive. Outside the large spikes on period ends, the GCF-triparty spread is on average about 10 basis points in our sample period. In contrast, the GCF-IOR spread was negative until early 2018 and then became positive and of similar magnitude compared to the GCF-triparty repo spread. The sign-switch for the GCF-IOR spread likely reflects the fact that as the amount of drainable reserves declined for large banks, constraints on intraday liquidity became more binding. As a result, banks started to charge a positive intermediation spread between the reverse repo rate and the IOR.

Panel (B) of Figure 7 shows the spread between the swapped BOJ and ECB deposit rates in dollars and the IOR paid by the Federal Reserve. Excluding the large periodend spikes, the average FX swap spreads are 15 and 25 basis points for the yen and the euro, respectively, despite the BOJ's and the ECB's negative deposit rates. Once we swap these negative deposit rates into dollars overnight, they are more attractive than the IOR paid by the Federal Reserve. Unlike the GCF-IOR spread, the FX swap spread based on central bank deposit rates is largely positive throughout our sample, including in the earlier sample when the drainable excess reserves at the Federal Reserve were more abundant. This finding suggests that dollar lending in the FX swap market, financed via

where $r_{\text {implied }}$ is the FX-implied dollar rate, $r^{*}$ is the non-dollar interest rate on reserve, $S$ is the spot exchange rate, $\phi_{T N}$ and $\phi_{O N}$ are the forward points on the overnight and tomorrow next contracts, $d=360$ is the day count convention, $D$ is the forward point multiplier, and $N$ is the number of calendar days from valuation to settlement date following FX holiday calendar conventions. This formula is more involved than the textbook forward and spot relation since the market convention in FX is that the spot exchange rate is quoted to settle on $T+2$, effectively making spot contracts a two-day forward exchange rate. To obtain the overnight implied rate, it is important to adjust the spot exchange rate to a hypothetical contract that settles at $T$ rather than $T+2$. 
draining excess reserves, is constrained by banks' ability or willingness to allocate liquidity across jurisdictions.

Table 1 shows regression results capturing the relation between quarter-ends, fluctuations in the TGA balance, and SOMA portfolios and the intermediation spreads. The first four columns show effects on daily changes in various repo spreads, and the last two columns show the effects on daily changes in the FX swap spreads. The independent variables are $Q e n d_{t}$ and $Q$ start $_{t}$ indicator variables, which denote the last and the first business day of the quarter, daily changes in the TGA balance, $\Delta T G A_{t}$, and daily changes in the SOMA holding of Treasury securities, $\triangle S O M A_{t}$.

We can see clear quarter-end effects on intermediation spreads, as captured by the coefficients on the quarter-end and quarter-start indicator variables. On the last day of the quarter, repo spreads increase between 8 to 30 basis points. FX swap spreads increase over 100 basis points and 400 basis points for the dollar-euro and the dollar-yen swap, respectively. These quarter-end spikes quickly normalize after the end of the quarter, as indicated by negative coefficients on Qstart $_{t}$ of similar magnitude compared to the coefficients on $Q e n d_{t}{ }^{18}$ Furthermore, fluctuations in the TGA balance, $\Delta T G A_{t}$ are also significantly positively correlated with intermediation spreads. In particular, a 100 billion increase in the TGA balance increase the repo spreads between 4 and 7 basis points, and FX swap spreads by 25 and 41 basis points. Finally, changes in the SOMA portfolio, captured by the coefficient on $\triangle S O M A_{t}$, are generally negatively correlated with dollar intermediation spreads. Therefore, as the Fed decreased the size of its SOMA portfolio (negative $\triangle S O M A_{t}$ ), intermediation spreads increased.

\footnotetext{
${ }^{18}$ Standard event-study style charts showing the effect of period-ends on intermediation spreads are shown in Appendix Figure A3.
} 


\subsection{U.S. GISBs' Response to Dollar Funding Shortages}

Having documented the price response to dollar funding shortages, we examine the response of the U.S. GSIBs through their intermediation activities. We focus on the same three types of funding events discussed above: quarter-end, TGA changes, and SOMA taper.

\subsubsection{Quarter-end Event Study}

We begin by describing the quarter-end dynamics since their well-defined timing allow us to visualize the impact of funding shortage on U.S. GSIBs' activities using an event study approach. ${ }^{19}$ Figure 8 presents the changes in U.S. GSIBs' scalable balance sheet items near quarter-ends. On these dates, the aggregated U.S. GSIBs' balance sheet shows a sharp decline in dollar reserve holdings by around $\$ 60$ billion (top left). This cash reserve drain is used by these institutions to maintain their reverse repo lending at roughly the same level (top right) while reducing their reliance on dollar repo funding by around $\$ 40$ billion (bottom left). ${ }^{20}$ This reduced reliance on repo financing is possibly due to the higher quarter-end cost of funding discussed above. The remaining $\$ 20$ billion of cash reserve drainage appears to be used to support an expansion of their FX swap lending, which is mostly represented by an increase in non-dollar reserves held at foreign central banks with associated FX swaps. The relative amount of intermediation in the domestic repo market versus the FX swap market likely reflects different fees from intermediation. As the FX IOR basis generally spikes higher than repo-IOR basis, given a set amount of

\footnotetext{
${ }^{19}$ We focus on the quarter-end dynamics since the dominant factor for the funding scarcity in these periods emanates from foreign banks, and as such, U.S. GSIBs take on a more reactive role. We show similar patterns for the year-end and month-end dynamics in the Appendix Figures A4 and A5. In particular, funding constraints are especially acute on year-ends when the contraction in funding from foreign banks is compounded by the adjustment in GSIBs' balance sheets due to the scoring that takes place predominately at year-end to determine the capital surcharge for these institutions.

${ }^{20}$ The steady reverse repo position of the U.S. GSIBs on quarter-ends is a direct contrast to a sharp reduction in the reverse repo position of foreign banks. Using the limited daily data reported from foreign banks in 2052a, Appendix Figure A6 shows a $\$ 40$ billion contraction in the aggregate reverse repo position of the U.S. operations of the 4 foreign banks.
} 
reserve draining, it is intuitive that U.S. GSIBs would choose to expand FX swap lending while maintaining the same level of reverse repo lending.

Figure 9 presents quarter-end event studies that describe how U.S. GSIBs manage liquidity within the BHC to maintain and increase the liquidity provision to third-parties (as illustrated in Figure 6). At quarter-ends, the broker-dealer arms of U.S. GSIBs provide around the same level of reverse repo lending to clients while reducing external borrowing in the repo market (bottom and top left panels). To replace costly external funding, broker-dealers turn to internal funding from non-broker-dealer entities in the same BHC (top right). This internal transfer is made possible by the non-broker-dealer entities (depository institutions) that drain reserves from their Federal Reserve accounts (bottom right). Market observers have previously hypothesized that such use of reserves by banks to finance short-term lending, termed "fracking", amounted to sterilization in FX swaps (Pozsar, 2017). Our findings provide micro-evidence that is consistent with these claims while documenting the important role of liquidity management within BHCs to absorb high-frequency liquidity shortages (Cetorelli and Goldberg, 2012).

\subsubsection{Regression Analysis with Quarter-Ends, TGA and SOMA Variations}

Table 2 presents quantity regressions for intermediation activities with the same structure as those reported before for funding spreads. We first quantify the quarter-end effects, as visualized in the event study. The last day of the quarter, as indicated by the dummy variable $Q e n d_{t}$, is associated with a $\$ 26$ billion contraction in aggregate U.S. GSIB reserve balances (column 1). Similar to the event study, reverse repo lending is largely unchanged (column 2) while repo borrowing by these banks declines by around $\$ 30$ billion (column 2), resulting in a net increase in reverse repo lending (gross reverse repo minus repo, column 4). FX lending activities also increase by around $\$ 10$ billion (column 5 ). These coefficients have smaller magnitudes than the multi-day responses shown in Figure 8. This is in part due to the fact that the adjustment for short-term intermediation activities with 
maturities greater than overnight can take place a few days before the quarter-ends. ${ }^{21}$ The last two columns (columns 6 and 7) show two additional balance sheet items that exhibit some frequent variations — deposit and outright treasury holdings. Both of these are relatively stable on quarter-ends.

The quarter-start variable, Qstart , exhibits changes that are largely the reverse of Qend $_{t}$, with the exception that deposit flow is positive and significant while repo borrowing shows little sign of reversing the quarter-end decline. This is likely related to periodic payroll-related deposit inflows occurring at the beginning of the month, which reduces the banks' need for repo financing. ${ }^{22}$

The regression coefficient on $\Delta T G A_{t}$ for reserves (column 1) indicates that each dollar of TGA balance increases is funded with around 18 cents of reserve drainage for our sample of U.S. GSIBs, controlling for other factors (the unconditional univariate coefficient is around 0.30). Both repo and reverse repo positions are reduced, but the decline in repo borrowing is larger, leading to a small increase in net reverse repo lending (columns 2-4). Similar to the quarter-end results, the coefficients suggest that U.S. GSIBs prefer to maintain lending at the higher intermediation spreads but reduce their financing costs by shrinking their repo borrowings. Instead of repo market financing, the banks rely on reserves drainage to make up for the reduced repo borrowing. Additionally, the banks also lend out more dollars through FX swaps as indicated by column 5. Concurrently, U.S. GSIBs experiences small deposit outflows (column 6), which likely reflect a transfer from depositors' account to the TGA account to finance the increase in the TGA balance. Finally, U.S. GSIBs increase their outright Treasury holdings (column 7), which

\footnotetext{
${ }^{21}$ It is also possible that large banks have some difficulty in fully adjusting their balance sheets in just a single day. The inability of banks to adjust their balance sheet despite their natural role in intermediation and arbitrage activities in response to large increases in funding spreads speak to papers on slow-moving capital and asset price dynamics (Duffie, 2010; Greenwood, Hanson, and Liao, 2018).

${ }^{22}$ To be clear, for deposits to increase across the banking system, the payroll payments made by the corporate sector must originate from non-deposit sources such as money-market fund holdings. Moreover, inflows and outflows out of deposit accounts are largely passive at the daily frequency, though banks can adjust the interest paid on deposit accounts over a longer horizon to attract and compete for deposits with other banks and money market funds.
} 
is responsive to the increases in TGA balances attributed to new Treasury issuance as opposed to tax receipts (Section 6.2 presents this decomposition of TGA). Taken together, U.S. GSIBs draw down reserves to fund repo and FX swap lending during TGA balance increases, and outright purchases of Treasurys also increases in response.

Finally, the change in SOMA Treasury holdings is also significantly associated with intermediation activities. An increase in $\triangle S O M A_{t}$ works in the opposite way as an increase in the TGA balance, as an increase in $\triangle S O M A_{t}$ eases overall funding conditions. U.S. banks provide less dollar intermediation in response to an increase in $\triangle S O M A_{t}$ through an increase in reserve holdings and a reduction in net reverse repo lending and FX swap lending. Deposits and Treasury holdings also fall.

Comparing the responses across balance sheet items due to TGA and SOMA fluctuations reveals two additional insights. First, the amount of reserve drainage roughly matches the cash used to provide short-term funding and outflows due to deposit and Treasury holdings. This finding confirms that we are capturing the most scalable components of the balance sheet. Second, the relative coefficients of dollar deposits and reserves reveal the active role that U.S. GSIBs play in providing short-term funding intermediation. Absent these intermediation activities, the reduction in reserves should match the outflow of deposits that goes towards an increase in the TGA balance.

The intra-office flows for TGA- and SOMA-related cash liquidity shortage again mirror the findings from the quarter-end study. Table 3 shows that broker-dealers' subsidiaries reduce their repo borrowing from third-parties and increase their internal repo borrowing from non-broker-dealer affiliates (depository institutions) within the BHC when the TGA balance increases. The non-broker-dealers finance the intra-office transfer by draining their excess reserve balances. An increase in the Fed's SOMA holdings eases liquidity strains and reverses the flow of cash — broker-dealers reduce their internal borrowing from deposit holding subsidiaries which in turn increases their reserve holdings. One difference 
in the case of SOMA balance changes is that the easing of dollar funding conditions is large enough that the broker-dealers also reduce their external repo financing needs.

\subsection{Reserve Distribution among U.S. GSIBs, Foreign and Other U.S. Banks}

The previous subsection highlights the crucial role of reserves in the U.S. GSIBs' dollar intermediation strategy. These institutions substitute excess reserves at the Fed for repo or FX lending as intermediation spreads increase. However, from an aggregate financialsystem-perspective, the overall level of bank reserves is determined by the size of Federal Reserve's assets, holding other non-reserve liability items of the Federal Reserve constant. ${ }^{23}$ Any decrease in the reserve holdings of some institutions has to end up in other institutions' balance sheets. The distribution of reserves across institutions in the system may have implications for the level of aggregate financial intermediation activities. Moreover, data on reserve holdings can also shed light on whether other institutions conduct reserve-dependent intermediation strategies similar to those followed by the six U.S. GSIBs.

To conduct our tests, we use information collected by the Federal Reserve on daily reserve balances at financial institutions. Besides the six U.S. GSIBs, we create two additional groups composed of foreign financial institutions and other domestic institutions. ${ }^{24}$ As shown in Figure 10, reserve balances for the U.S. GSIBs and the foreign banks have trended down in the last couple of years, consistent with the normalization process of the Federal Reserve's balance sheet. This trend is less pronounced for the domestic banks, which have held relatively stable balances of reserves in recent years.

We also collect information on balances at the overnight reverse repurchase agreement facility (ON RRP). This facility is used by the Federal Reserve to control the federal

\footnotetext{
${ }^{23}$ Appendix Figure A7 shows the evolution of the Federal Reserve balance sheet post-GFC.

${ }^{24}$ We include Bank of New York Mellon and State Street in the group of other domestic institutions. We also note that only foreign BHCs with U.S. branches and subsidiaries can hold reserves at the Federal Reserve, and these branches and subsidiaries hold reserves for their ultimate parent BHCs.
} 
funds rate by selling securities to eligible counterparties with an agreement to repurchase them the next day. Thus, an increase in ON RRP transactions drains reserves from the system, which should mirror the change in reserves at the three groups of banks previously described.

In Table 4, we estimate the same specifications as in Table 2, using the change in the reserve balances of financial institutions and the change in the ON RRP as the dependent variables. The results in column 1 are similar to those presented in column 1 of Table $2 .{ }^{25}$ Focusing on the coefficients on the quarter-end $\left(Q e n d_{t}\right)$ and quarter start $\left(Q s t a r t_{t}\right)$ dummies, we find that at quarter ends, both reserves at the U.S. GSIBs and foreign banks decrease substantially, with most of those balances moving to the domestic banks or the ON RRP. As noted previously, the drop in reserves balances at the U.S. GSIBs is drive by their intermediation strategy, where they substitute reserves for repo and FX lending.

In the case of the foreign banks, the drop in reserves on quarter-ends is larger, which is likely driven by at least two factors. First, as noted previously, regulations that govern the disclosure of banks' leverage ratios incentivize foreign banks to shrink the size of their balance sheets at quarter ends. In particular, Anderson et al. (2019) show that foreign banks are actively engaged in the IOR arbitrage and significantly contract their IOR arbitrage positions on quarter-ends. U.S. banks do not engage in much IOR arbitrage. ${ }^{26}$ Second, foreign banks could also be conducting some reserve-draining intermediation as is the case for the U.S. GSIBs.

The shift of reserves from large U.S. GSIBs and foreign banks to smaller U.S. banks and the ON RRP facility at quarter ends reduces the level of aggregate financial intermediation. As the smaller banks participate less in lending via the wholesale funding

\footnotetext{
${ }^{25}$ As this data on daily reserve holdings is collected separately from the FR2052a, the sample size differs slightly. Nonetheless, these data validates the result on the reserve holdings of the six U.S. GSIBs from the FR2052a report.

${ }^{26}$ The IOR arbitrage involves borrowing in the overnight private money markets, such as the federal funds or eurodollar markets, and then depositing the proceeds at the Federal Reserve, earning the IOR rate. U.S. banks face additional regulatory costs, such as the insurance premium charged by the Federal Deposit Insurance Corporations, which disincentives this activity.
} 
markets and the ON RRP absorbs cash from the banking system, the effective amount of dollar cash lent out by banks declines. This reserve redistribution can have implications on the aggregate pricing of funding, as evidenced by the significant effects on funding spreads observed on quarter ends.

The two additional types of events that we noted in the previous sections are the changes in TGA balances and in the Federal Reserve's SOMA portfolio. In table 4, we observe that the coefficient on the foreign and smaller domestic banks is each about negative 0.4 and the coefficient on U.S. GSIBs is around negative 0.2. ${ }^{27}$ As discussed in Section 4.3.2, a larger reduction in reserves than the deposit outflows for U.S. GSIBs is a signal for reserve-draining intermediation activities. For foreign banks and smaller domestic banks, we do not have direct daily data on their dollar deposits. However, given that foreign banks in the U.S. do not have a significant deposit base, and that most of the smaller domestic banks are primarily funded with deposits, the very negative coefficients on TGA for foreign banks and smaller domestic banks likely reflect different drivers: foreign banks might also engage in reserve-draining intermediation, whereas other smaller domestic banks passively accommodate deposit outflows to pay for TGA increases. ${ }^{28}$ Lastly, in response to a reduction in the SOMA portfolio holdings $\left(\triangle S O M A_{t}<0\right)$, we find that only U.S. GSIBs and foreign banks reduce their reserve balances, with the effect larger and more statistically significant for foreign banks. Smaller domestic banks increase their reserve holdings. ${ }^{29}$

\footnotetext{
${ }^{27}$ We note that the sum of the coefficients on TGA across the three types of banks adds up to around negative one, which suggests that the TGA variations are generally uncorrelated with changes in other non-reserve liability items of the Federal Reserve.

${ }^{28}$ As businesses or households use their deposits to, for example, pay their taxes, banks use reserves to credit the government while debiting the deposit accounts.

${ }^{29}$ We note that the take-up at the ON RRP facility has a negative coefficient on $\triangle S O M A_{t}$. However, this negative coefficient largely captures some period-end dynamics not fully absorbed by the quarter-end dummies. Once we control for the month-end and month-start dummies, the coefficient $\triangle S O M A_{t}$ on the ON RRP becomes positive and significant, consistent with the notion that the Fed taper reduces the spare cash parked in the ON RRP facility.
} 
In sum, beyond the six U.S. GSIBs, it appears that foreign banks also conduct reservebased intermediation activities, as shown by similar patterns in the changes of reserve balances. In contrast, smaller domestic banks that are less involved in these markets are at the receiving end of those reserves. A similar pattern is observed for the ON RRP facility. The redistribution of reserves has implications for the overall level of financial intermediation and therefore various dollar funding spreads. We will return to these distributional issues in our analysis of the repo rate spike in September 2019 in Section 5.

\section{Repo Spike in September, 2019 and U.S. GSIBs' Response to Fed Liquidity Support}

As highlighted in the previous Section 4.4, increases in TGA balances and decreases in Fed SOMA holdings tighten funding conditions and affect both the price and quantity measures of dollar intermediation. In this section, we examine the funding crunch that took place in mid-September 2019 and the immediate aftermath, when the Federal Reserve re-established its repo facility and increased its purchases of Treasury bills. These actions were first intended to improve conditions in money markets and to maintain the federal

funds rate within the target range following the mid-September event, but were then maintained to provide an extraordinary amount of liquidity support to the economy during the COVID-19 pandemic.

\subsection{September 2019 repo rate spike}

The September 2019 funding crunch occurred when the TGA balance increased over $\$ 100$ billion, as corporate tax payment coincided with large Treasury issuance settlements. This funding crunch happened against the backdrop of declining aggregate reserve levels as the Fed normalized the size of its balance sheet by, as noted previously, reducing the size of its SOMA holdings. Reserves across all banks reached their multi-year lows. On Monday, 
September 16, the TGA balance increased by $\$ 83$ billion, and the benchmark SOFR-IOR spread ended the day 23 basis point higher — a four-standard deviation increase. On September 17, the overnight repo rate spiked to a high of $10 \%$ and the volume-weighted SOFR benchmark settled at $5.25 \%-3.15 \%$ above the interest paid on reserves. The repo market stress also strongly spilled over to the FX swap market, which priced the implied dollar funding rates at above 5\% intraday. Figure 11 shows the intraday movements in the overnight repo rate and the implied dollar funding rates from the FX swap market. A detailed discussion of intraday movements in these rates is provided in Appendix Section B.

Despite the large market reaction over a two-day period, the TGA balance increase was long anticipated. In late July 2019, as it became increasingly clear that Congress would pass a budget deal to lift the debt ceiling, the Treasury Department announced that it would raise the TGA balance to $\$ 350$ billion by the end of September. ${ }^{30}$ Two days later, the Federal Reserve announced that it would conclude its balance sheet normalization, with the FOMC meeting minutes mentioning an expected increase in the TGA balance that would drain reserves. The TGA balance gradually increased throughout August and early September before increasing by over $\$ 100$ billion cumulatively between September 13th and 16th due to a combination of Treasury issuance settlement and corporate tax payments.

The price of secured dollar funding reacted strongly to the TGA balance increase compared to previous episodes. Figure 12 shows that the SOFR-IOR spread typically increases on days when there are large positive movements in the TGA balance and declines on days with large TGA balance reductions. The changes in SOFR-IOR on both September 16 and 17 were outsized relative to the TGA increase. ${ }^{31}$

\footnotetext{
${ }^{30}$ Treasury Quarterly Refunding Statement, July 31, 2019.

${ }^{31}$ Furthermore, the multivariate comparison of the predicted versus actual spread changes based on coefficients estimated in Table 1 shows that the changes in SOFR-IOR were 20 basis points higher than the estimated fit on September 16 and 282 basis points higher than the fit on September 17. This outsized price reaction raises questions on the activities of intermediaries.
} 
Using information for the GSIBs in our sample, we find that the one-day response of these institutions to the large TGA increase on September 16 was generally consistent with their typical reaction to TGA shocks. ${ }^{32}$ Panel A of Figure 13 shows the one-day changes in select balance sheet items on September 16 compared to the predicted range of response based on coefficient estimates in Table 2. The actual response is within the 95\% confidence interval of the predicted response for most balance sheet items. Reserves declined around $\$ 22$ billion, which is slightly lower than the predicted decline. Dollar lending against foreign cash collateral, FX Lend, increased slightly above the top of the predicted range while net repo lending against security collateral remained roughly constant. The difference in the willingness of U.S. GSIBs to lend against foreign cash collateral and security collateral possibly speaks to the abundance of Treasury collateral due to new issuance.

While we cannot expand our analysis to non-U.S. GSIBs due to the lack of FR2052a reporting for these institutions, our reserve-based intermediation channel nonetheless helps us to shed light on the likely culprit of the September 2019 funding crunch. Panel B of Figure 13 presents the estimated versus actual changes in reserve holdings at the Federal Reserve for the same three groups of banks described in Section 4.4: our sample of U.S. GSIBs, foreign banks, and other smaller domestic banks. The predicted changes are based on Table 4. The results show that in contrast to U.S. GSIBs, which drained reserves slightly more than predicted, foreign banks significantly under-reacted to the TGA increase on the 16th. Foreign banks reduced their total reserve balance by $\$ 14$ billion on the 16th, compared to a predicted change of $\$ 40$ billion. Other smaller domestic banks' reserve behavior on the day is quite in line with our prediction. Furthermore, on September 17, 2019, foreign banks increased their reserves by $\$ 58$ billion, an amount that

\footnotetext{
${ }^{32}$ We focus on the one-day change from Friday, September 13 to Monday, September 16, despite the fact that the largest price action occurred on September 17. This is because the Fed intervened in the morning of September 17 and our balance sheet numbers as of the end of day on September 17 already reflect the Fed's intervention.
} 
is roughly on par with the total draw on the Fed repo facility reinstated for the first time since the GFC on that same day. In contrast, U.S. GSIBs drained their reserves further by $\$ 14$ billion. This provides an additional signal that foreign banks might have hit the limit of drainable reserves and contracted their dollar intermediation on the 16th.

In addition to the likely breakdown of reserve-based intermediation to absorb a large TGA shock due to the lack of drainable reserves, structural shifts in the broker-dealers' own Treasury financing needs might have also contributed to the dollar funding shortage. In particular, against the backdrop of the Federal Reserve's balance sheet normalization process and gradual reserve declines in banking entities, the broker-dealer arms of the banks transitioned from net lending to net borrowing in the repo market. Their extra financing needs were used to support accumulation of Treasury holdings in an environment with a flat to negative yield curve that reduced end-buyers' demand for Treasury securities. Moreover, the dealers' repo financing was increasingly reliant on posting lower-quality collateral and shortening the maturity of borrowing, characteristics that are indicative of a funding crunch. We discuss these developments in more details in Appendix C.

\subsection{The Fed Repo Facility and post-September 2019 events}

The acute funding shortage in September 2019 prompted the Federal Reserve to reinstate its repo lending facility that had been inactive since the GFC. As the repo rate spiked to a high of $10 \%$ on September 17, 2019, the Fed established a repo facility with up to $\$ 75$ billion in initial drawing capacity. After this event, the Fed carried out daily overnight and term repo auctions through year-end 2019 and into 2020. The onset of the COVID-19 market turmoil in March 2020 led to another funding crunch with the GCF-IOR spread increasing to a high of 76 basis points and FX overnight funding spreads increasing by as much as 6\%. Appendix Figure A8 shows the evolution of funding spreads since September 2019. 
Primary dealers are the only private sector counterparties that are allowed to borrow at the Fed repo facility. ${ }^{33}$ The red line in Figure 14 plots the U.S. GSIBs' take-up at the Fed repo facility (through their primary dealer subsidiaries). The repo facility takeup is high when the funding condition is tight. We see solid take-up reaching around $\$ 80$ billion in the immediate aftermath of the September 2019 repo spike. The takeup reached a pre-COVID peak at $\$ 120$ billion on December 31, 2019, and later peaked at $\$ 170$ billion during the COVID-related market turmoil in March 2020. Furthermore, the Fed repo facility possibly reduced the need for broker-dealers to draw on the BHC's internal liquidity from affiliated depository entities and supported a substitution away from reserve-based intermediation to matched-book intermediation. The blue line in Figure 14 plots the broker-dealers' net internal borrowing from depository institutions. Increases in the usage of the Fed repo facility tend to match declines in repo borrowing from internal sources within the BHC.

The repo facility was effective in enabling banks to on-lend official liquidity support through matched-book intermediation. Table 5 shows regression results of daily changes in the U.S. GSIBs' dollar intermediation activities on changes in Fed repo take-up. Each dollar increase in the bank's Fed repo facility use is correlated with a net increase in repo lending of around 75 cents and FX-swap-based dollar lending of around 25 cents. Consistent with our baseline result, the net increase in repo lending is predominantly driven by the bank's reduction of borrowing from cash lenders and a somewhat smaller increase in reverse repo lending to other counterparties.

Lastly, recent events have heightened financial institutions' cash demand uncertainties because of the rapid increase in the TGA balance, which reached over a $\$ 1$ trillion dollars in April 2020. The COVID-19 fiscal measures led to a surge in cash flowing through the TGA as a result of asynchronous debt issuance and fiscal payouts. We find that despite

\footnotetext{
${ }^{33}$ On March 31, 2020, the Fed established an additional repo facility for foreign and international monetary authorities.
} 
the ample Fed liquidity support, unprecedented TGA balance changes continue to impact funding spreads and large bank's intermediation activities. We present results for our baseline price and balance sheet regressions in the post-September 2019 sample period in Appendix Tables A1 and A2. In particular, we see that fluctuations in the TGA balance remain significantly correlated with the repo spreads and dollar intermediation activities.

\section{Robustness Checks}

\subsection{Alternative Measure of FX Swap Lending}

As a robustness check, we use an alternative proxy for FX swap lending (Total FX Swap Lend), which takes the difference between foreign currency assets and foreign currency liabilities:

$$
\text { Total FX Swap Lend = FC Total Assets - FC Total Liabilities. }
$$

Assuming that U.S. GSIBs fully hedge the currency risk of its assets and liabilities, then the gap between foreign currency assets and liabilities on balance sheets must be matched by dollar lending in the FX swap market off-balance sheets. Similar measures have been used in the literature to measure non-US banks' dollar borrowing in the FX swap market (for example, McGuire and Von Peter (2009) and Fender and McGuire (2010)). Compared to Short-Term FX Swap Lend, Total FX Swap Lend also capture long-term dollar lending in the FX swap market. Table A3 shows that the regression results based on the alternative FX lend measure are very similar to those based on our benchmark short-term FX-lending measure.

To assess whether U.S. GSIBs indeed hedge the foreign currency funding gap, we note that U.S. bank supervisors do not systematically collect data on the FX derivatives exposure by currency for banks' banking book. However, the FX swap exposure on banks' 
trading book can be inferred from the FR Y14Q Capital Assessment and Stress Testing

form. In Appendix D, we show that the foreign currency funding gap is directionally in line with the estimated FX swap exposure for long dollar positions in banks' trading books.

\subsection{Decomposition of TGA fluctuations}

In this subsection, we decompose daily fluctuations in the TGA balance, $\triangle T G A_{t}$, into two components. The first component summarizes daily changes in the net issuance of Treasury securities, denoted by $\Delta T S Y_{t}^{\text {Issue }}$. The second component reflects daily changes in the TGA account unrelated to the net Treasury issuance, denoted by $\Delta T G A_{t}^{\text {Other }}$. Therefore, we have that

$$
\Delta T G A_{t}=\Delta T S Y_{t}^{\text {Issue }}+\Delta T G A_{t}^{\text {Other }}
$$

Since the six banks in our sample have broker-dealer subsidiaries that are designated primary dealers for Treasury securities, we might expect $\Delta T G A_{t}$ and $\Delta T G A_{t}^{\text {Other }}$ to have different impacts on their dollar intermediation activities.

Table A4 shows regression results for intermediation spreads. We can see that TGA increases unrelated to Treasury issuance, $\Delta T G A_{t}^{\text {Other }}$, raise the repo and FX swap intermediation spreads, with larger and more significant impact on the FX swap spreads. An increase in the overall Treasury net issuance, $\Delta T S Y_{t}^{I s s u e}$, significantly increases repo intermediation spreads. The effect of $\Delta T S Y_{t}^{\text {Issue }}$ on the FX swap spread is not statistically significant.

Table A5 shows the analogous quantity regressions for intermediation activities. In response to an increase in $\Delta T G A_{t}^{\text {Other }}$, U.S. GSIBs contract both repo and reverse repo positions by a similar magnitude, leaving the net reverse repo position roughly unchanged (columns 2-4). However, U.S. GSIBs increase their dollar liquidity provision in the FX 
swap market significantly (column 5). Similar to the results in Table 2, this increase in the FX swap lending is mainly financed via reserve-draining (column 1). Meanwhile, U.S. GSIBs experience deposit outflows (column 6) in these episodes, which likely reflect a transfer from depositors' accounts to the TGA account to finance the increase in the TGA balance. However, the magnitude of the deposit outflow is significantly smaller than the reduction in the reserve balance, suggesting that reserves fall beyond a simple passive cash transfer between depositors and the TGA. Finally, U.S. GSIBs increase their unencumbered Treasury holdings (column 7). We find a few different results when assessing the relationship between the net issuance of Treasuries, $\Delta T S Y_{t}^{\text {Issue }}$, and U.S. GSIBs' intermediation activities. In contrast to $\Delta T G A_{t}^{\text {Other }}$, an increase in $\Delta T S Y_{t}^{\text {Issue }}$ significantly increases U.S. bank reverse repo lending, leaves the repo position largely unchanged, and thus results in a significant increase in the net reverse repo lending (columns 2-4). The Treasury net issuance has little effect on FX lending (column 5).

Taking stock of these pricing and quantity results in Tables A4 and A5, we can determine that an increase in both components of the TGA balance tighten funding conditions, with the $T G A_{t}^{\text {Other }}$ affecting the FX swap market and $T S Y_{t}^{\text {Issue }}$ affecting the repo market more significantly. In response, U.S. GSIBs moderately increase their dollar liquidity provision. In particular, reserve-draining intermediation is used to finance an increase in TGA $A_{t}^{\text {Other }}$.

\subsection{Outright Treasury holdings vs. repo-financed Treasury holdings}

As noted previously, the six U.S. GSIBs in our sample have broker-dealer subsidiaries that are designated primary dealers for Treasury securities. Primary dealers are required to participate in all Treasury auctions and are the direct counterparties of the Fed to purchase Treasury securities during the Fed balance sheet taper. In this subsection, we provide a closer look at Treasury holdings' of the U.S. GSIBs. 
In our previous analysis, we examined the response of outright holdings of Treasury securities in the dollar funding shortage. In addition, U.S. GSIBs can also change their Treasury holdings financed via repos. We measure the amount of repo-financed Treasury holdings as the amount of "non-rehypothecated" repo positions backed by U.S. Treasury collateral. $^{34}$

Table A6 shows the regression results for repo-financed Treasury holdings. We find that U.S. GSIBs' repo-financed Treasury holdings increase with the net issuance of Treasury securities and decrease with Fed SOMA portfolio holdings. Together with the outright Treasury holdings, for each $\$ 100$ billion increase in the Treasury net issuance, U.S. GISBs increase their total Treasury holdings by $\$ 7$ billion, half of which is through outright holdings and the other half is through repo-financing. The effect of Fed's balance sheet taper on U.S. GSIBs' Treasury holdings is significantly larger. For each $\$ 100$ billion taper of the SOMA portfolio, U.S. GSIBs increase Treasury holdings by $\$ 30$ billion, $\$ 12$ billion of which is through outright holdings and $\$ 18$ billion of which is through repo-financing. The amount of U.S. GSIBs' own Treasury financing needs could help explain the large price effects of $\triangle S O M A$ on various repo spreads in Tables 1 and A4.

\section{Discussions}

In previous sections, we show that reserve-draining intermediation has become the dominant intermediation strategy for U.S. GSIBs in response to dollar funding shortages. However, the modest increase in dollar liquidity provision by U.S. GSIBs is clearly not sufficient to smooth out large and frequent spikes in dollar funding rates. Frequent and acute dollar shortages challenge the effectiveness of U.S. monetary policy implementation and pose considerable financial stability risk. In this section, we discuss why global

\footnotetext{
${ }^{34}$ In contrast, if the Treasury-backed repo position is "rehypothecated", the bank re-pledges the Treasury collateral and no longer possesses the Treasury securities.
} 
banks favor reserve-draining intermediation and the constraints in scaling up this type of intermediation.

\subsection{Why reserve-draining intermediation?}

Reserve-draining intermediation is a new type of intermediation activity conducted by global banks post-GFC. The GFC triggered a rapid change to the conduct of monetary policy. Large scales asset purchases by the Fed financed by reserves created an ample reserve environment for global banks, which is a pre-condition for the reserve-draining intermediation to take place. In the pre-GFC period, the Federal Reserve operated in a monetary policy framework with scarce reserves (Kroeger, McGowan, and Sarkar (2018)), with banks relying on the interbank market to satisfy their reserve requirements (Kim, Martin, and Nosal, 2018). The amount of drainable excess reserves in the financial system was zero, and reserve-draining intermediation was not feasible.

Under the post-GFC ample reserve environment, leverage-constrained global banks have preferred reserve-draining intermediation over matched-book intermediation due to the stronger capital regulations that increase the cost of balance sheet expansions. The new Basel III framework and the Dodd-Frank Act changed the minimum capital requirement levels and introduced additional buffers for U.S. banking organizations (Walter (2019)). Of particular importance for U.S. GSIBs, the new requirements included a more stringent leverage ratio (enhanced supplementary leverage ratio or eSLR) and a GSIB surcharge applied on top of the other risked-based capital requirements.

The eSLR potentially limits the dollar intermediation activities of U.S. banks by raising the cost to the bank of increasing the size of its balance sheet, as all exposures are treated equally for the calculation of the ratio. The constraint on the size of the bank balance sheet may bind if banks need to conduct their intermediation activities through matchedbook operations. Similar constraints could arise with the GSIB capital surcharge, whose calculation depends on several factors, but the size of the balance sheet is an important 
component. The preference for reserve-draining intermediation could be potentially traced to the binding nature of the eSLR and the GSIB surcharge. In a counterfactual setting without these requirements, U.S. GSIBs would potentially be able to provide more dollar intermediation through matched-book transactions, but at the cost of diminished financial resiliency due to lower capital ratios.

Besides capital regulations, liquidity regulations also help explain the dominance of reserve-draining intermediation. The LCR penalizes reliance on "runnable" liabilities, notably unsecured funding from financial institutions. As a result, banks also reduce their supply of these runnable liabilities to other financial institutions, such as overnight and transaction deposits (Roberts, Sarkar, and Shachar, 2018). A lower level of unsecured interbank transactions in turn induced banks to hold more reserves to satisfy their liquidity needs on an intraday basis (Kim et al., 2018).

\subsection{Constraints facing reserve-draining intermediation}

In an ample reserve environment, it appears that banks have a large amount of excess reserves on their balance sheets, beyond the traditionally required reserve requirement. However, not all these excess reserves are drainable. Banks' demand for reserves depends on regulatory requirements and their own preference for holding reserves versus other high-quality liquid assets such as Treasury securities. These factors affect the degree of reserve-draining that banks can conduct conditional on the level of overall reserves in the system.

In particular, the new post-GFC resolution framework may have some relevant implications for reserve-draining intermediation. As part of section 165(d) of the Dodd-Frank Act, large banks are now required to submit annual plans for resolution proceedings under a hypothetical bankruptcy. These plans are assessed on qualitative and quantitative bases. The latter set of rules has led to the creation of Resolution Liquidity Adequacy Positioning (RLAP). Under RLAP, banks are subject to the expectation that they have enough 
liquidity in material entities to meet potential stress-induced outflows. Such outflows are not only due to localized stress but also to the prospect of local regulators outside the United States requiring incremental liquidity in their jurisdiction (ring-fencing). Stated more broadly, banks are now expected to be able to meet outflows at the material entity or local level, without having to rely on cross-entity or cross-jurisdiction transfers in a time of stress.

As we noted in earlier sections, reserves are held in the depository institution within the BHC. The extent of reserve-draining intermediation crucially depends on the amount of these reserves that can be used to finance other parts of the BHC, such as the affiliated broker-dealers. If the RLAP requirement is binding at the material entity level, these intragroup flows may only represent a fraction of the intragroup transfers that would have been conducted without these constraints. For example, RLAP may limit the movement of liquidity across material entities based in the United States, which limits repo lending financed via draining reserves. In addition, in the case of supporting dollar lending in the FX swap market, additional reserve-draining intermediation reduces banks' liquidity buffers in their U.S. material legal entities, which could also make the RLAP requirements more binding.

It is important to note, that RLAP requirements are based on the banks internal liquidity stress testing models. Thus, it is difficult to identify whether the RLAP requirement indeed affects intragroup liquidity management, or if the binding constraint for the flow of liquidity is explained by banks' business models and their risk tolerance. Beyond RLAP, banks may also decide to maintain liquidity in certain legal entities, even in the absence of regulatory constraints, to enhance their resiliency. ${ }^{35}$ This would also limit the overall level of reserve draining.

\footnotetext{
${ }^{35}$ In addition, it is also quite plausible that not all liquidity management decisions are made at the $\mathrm{BHC}$ level. Individual entities can have sufficient autonomy in making their own decisions.
} 
Lastly, besides constraints on intragroup flows, the preference for reserves over Treasury securities in the high-quality liquid asset (HQLA) portfolios also matters for reservedraining intermediation. In terms of the composition of the HQLA portfolio for the LCR requirement, even though reserves and Treasury securities are both considered Level 1 HQLAs, banks may still prefer to hold reserves instead of Treasury securities because reserves have better intraday liquidity and are easier to monetize in a stress episode. The different shares of reserves in the overall HQLA portfolio across banks likely reflects differences in business models, risk tolerance, and once again, bank-dependent internal liquidity stress test models for the resolution planning requirements (Ihrig, Vojtech, and Weinbach (2019)).

Overall, the factors discussed above determine the minimum overall level of reserves that banks may want to maintain to satisfy both the regulatory requirements and their liquidity needs. Any level of reserves above this minimum level could potentially be used to conduct intermediation transactions. Prior to the repo rate spike in September 2019, the whole banking system still had $\$ 1.4$ trillion reserves, but the amount of truly drainable reserves was approaching zero.

\section{Conclusion}

In this paper, we have documented the important role that U.S. GSIBs play in dollar funding intermediation. In particular, we find that U.S. GSIBs react to dollar liquidity shortages by reducing their stock of reserves at the Federal Reserve to substitute for repo borrowing and to lend out more in the FX swap market. Furthermore, we find that non-broker-dealer entities within the BHC provide internal funds to the broker-dealer arms, which on-lend these funds in the repo and FX swap markets. These activities are operative as a result of the ample reserve environment set by the Federal Reserve in the post-GFC period. However, as the Fed's balance sheet and the level of reserves decreased, 
reserve-draining intermediation activities of global banks became impaired, leading to the stress observed in the repo market in September 2019.

More generally, the interaction between financial regulations and monetary policy have become more complex post-GFC. Regulatory reforms that build the resilience of the financial system may increase balance sheet costs for global banks to intermediate dollar funding, which could undermine the effectiveness of U.S. monetary policy implementation. Maintaining ample reserves likely mitigates the trade-off between resilient regulatory policy and effective monetary policy. 


\section{References}

Adrian, T., E. Etula, and T. Muir (2014). Financial intermediaries and the cross-section of asset returns. Journal of Finance 69(6), 2557-2596.

Adrian, T. and H. S. Shin (2010). Liquidity and leverage. Journal of financial intermediation 19(3), 418-437.

Afonso, G., M. Cipriani, A. M. Copeland, A. Kovner, G. La Spada, and A. Martin (2020). The market events of mid-september 2019. FRB of New York Staff Report No.918.

Anderson, A., W. Du, and B. Schlusche (2019). Arbitrage capital of global banks. Working Paper.

Avalos, F., T. Ehlers, and E. Eren (2019, December). September stress in dollar repo markets: passing or structural? BIS Quarterly Review.

Brunnermeier, M. K. and L. H. Pedersen (2008). Market liquidity and funding liquidity. Review of Financial Studies 22(6), 2201-2238.

Campello, M. (2002). Internal capital markets in financial conglomerates: Evidence from small bank responses to monetary policy. Journal of Finance 57(6), 2773-2805.

Cenedese, G., P. Della Corte, and T. Wang (2019). Currency mispricing and dealer balance sheets. Bank of England working paper No.779.

Cetorelli, N. and L. Goldberg (2012). Banking globalization and monetary transmission. Journal of Finance 5, 1811-1843.

Diamond, D. W. and P. H. Dybvig (1983, June). Bank runs, deposit insurance, and liquidity. Journal of Political Economy 91(3), 401-419.

Drechsler, I., A. Savov, and P. Schnabl (2017, 05). The deposits channel of monetary policy. Quarterly Journal of Economics 132(4), 1819-1876.

Du, W., B. M. Hébert, and A. W. Huber (2019). Are intermediary constraints priced? NBER Working Paper No. 26009.

Du, W., J. Im, and J. Schreger (2018). The US treasury premium. Journal of International Economics 112, 167-181.

Du, W., A. Tepper, and A. Verdelhan (2018). Deviations from covered interest rate parity. Journal of Finance 73(3), 915-957.

Duffie, D. (2010). Presidential address: Asset price dynamics with slow-moving capital. Journal of finance $65(4), 1237-1267$.

Egelhof, J., A. Martin, and N. Zinsmeiste (2017). Regulatory incentives and quarterend dynamics in the repo market. Federal Reserve Bank of New York Libery Street Economics (blog).

Fender, I. and P. McGuire (2010). European banks' us dollar funding pressures. BIS Quarterly Review.

Gagnon, J. and B. Sack (2019). Recent market turmoil shows that the fed needs a more resilient monetary policy framework. Peterson Institute For International Economics.

Gorton, G. and A. Metrick (2012). Securitized banking and the run on repo. Journal of Financial Economics $104(3), 425-451$. 
Gorton, G. and G. Pennacchi (1990). Financial intermediaries and liquidity creation. Journal of Finance 45(1), 49-71.

Greenwood, R., S. G. Hanson, and G. Y. Liao (2018). Asset price dynamics in partially segmented markets. Review of Financial Studies 31(9), 3307-3343.

Hamilton, J. D. (1997). Measuring the liquidity effect. American Economic Review, 80-97.

Hanson, S. G., A. Shleifer, J. C. Stein, and R. W. Vishny (2015). Banks as patient fixed-income investors. Journal of Financial Economics 117(3), 449-469.

He, Z., B. Kelly, and A. Manela (2017). Intermediary asset pricing: New evidence from many asset classes. Journal of Financial Economics 126(1), 1-35.

He, Z. and A. Krishnamurthy (2013). Intermediary asset pricing. American Economic Review 103(2), 732-70.

Ihrig, J. E., C. M. Vojtech, and G. C. Weinbach (2019). How have banks been managing the composition of high-quality liquid assets? Federal Reserve Bank of St. Louis Review $101(3), 177-201$.

Jiang, Z., A. Krishnamurthy, and H. Lustig (2018). Foreign safe asset demand for US Treasuries and the dollar. AEA Papers and Proceedings 108, 537-41.

Jiang, Z., A. Krishnamurthy, and H. Lustig (2019). Foreign safe asset demand and the dollar exchange rate. Stanford University Graduate School of Business Working Paper.

Kashyap, A. K., R. Rajan, and J. C. Stein (2002). Banks as liquidity providers: An explanation for the coexistence of lending and deposit-taking. Journal of Finance 57(1), $33-73$.

Kim, K., A. Martin, and E. Nosal (2018, December). Can the US Interbank Market be Revived? Finance and Economics Discussion Series 2018-088, Board of Governors of the Federal Reserve System (U.S.).

Krishnamurthy, A., S. Nagel, and D. Orlov (2014). Sizing up repo. Journal of Finance 69(6), 2381-2417.

Kroeger, A., J. McGowan, and A. Sarkar (2018). The pre-crisis monetary policy implementation framework. Economic Policy Review (24-2), 38-70.

Liao, G. Y. (2020). Credit migration and covered interest rate parity. Journal of Financial Economics.

Liao, G. Y. and T. Zhang (2020). Hedging channel of exchange rate determination. International Finance Discussion Papers.

McGuire, P. and G. Von Peter (2009). The US dollar shortage in global banking and the international policy response. BIS working paper.

Pozsar, Z. (2017). Sterilization and the fracking of reserves. Credit Suisse Global Money Notes No.10.

Pozsar, Z. (2019). Collateral supply and o/n rates. Credit Suisse Global Money Notes No.22.

Roberts, D., A. Sarkar, and O. Shachar (2018). Bank liquidity creation, systemic risk, and basel liquidity regulations. Federal Reserve Bank of New York Staff Report No.852. 
Santoro, P. (2012). The evolution of treasury cash management during the financial crisis. Current Issues in Economics and Finance 18(3).

Tarullo, D. K. (2019). Financial regulation: Still unsettled a decade after the crisis. Journal of Economic Perspectives 33(1), 61-80.

Walter, J. R. (2019). US Bank Capital Regulation: History and Changes Since the Financial Crisis. Economic Quarterly (1Q), 1-40. 
Figure 1: U.S. GSIBs balance sheet in dollars

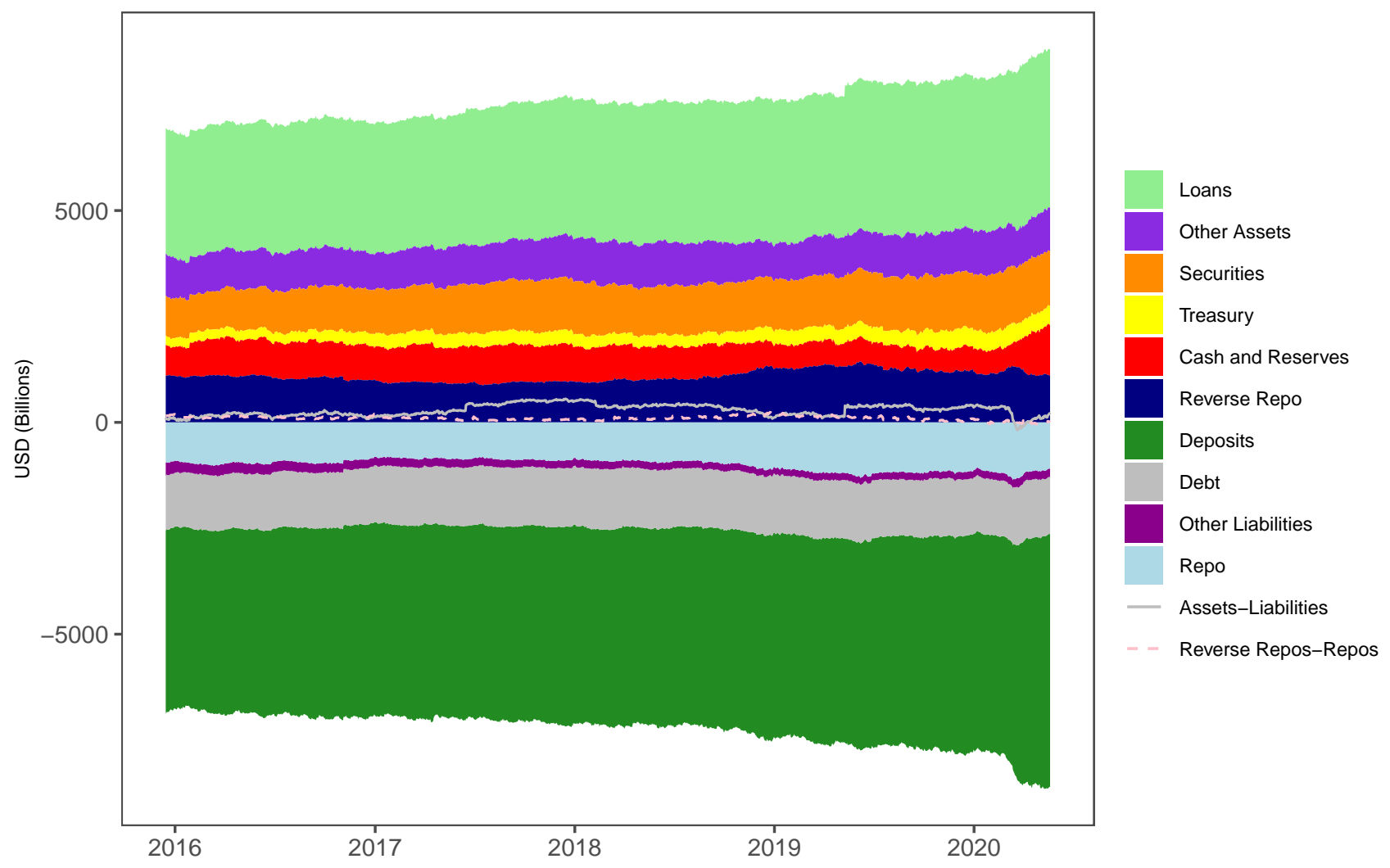

Notes: This figure presents the aggregate balance sheet for six U.S.GSIBs based on the FR 2052a data, including only items denominated in U.S. dollars. Items above zero are classified as assets and those below zero as liabilities. The solid line represents the difference between total assets and total liabilities, while the dashed line measures the net repo position of these banks. The sample period expands from December 2015 until May 2020 . 
Figure 2: U.S. GSIBs balance sheet in other currencies
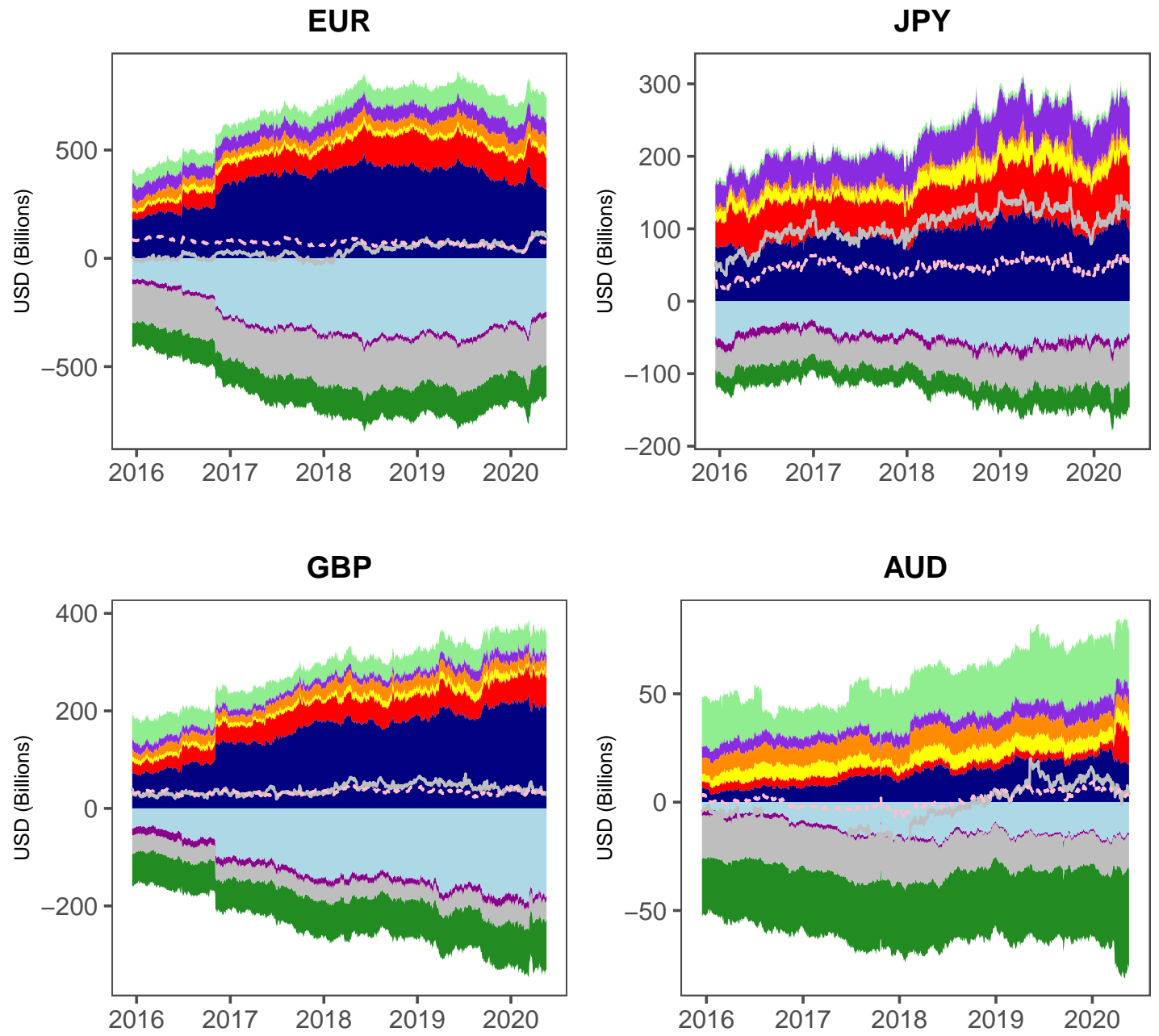

\begin{tabular}{l} 
Loans \\
Other Assets \\
Securities \\
Treasury \\
Cash and Reserves \\
Reverse Repo \\
Deposits \\
Debt \\
Other Liabilities \\
Repo \\
\hline- Assets-Liabilities \\
\hline- Reverse Repos-Repos
\end{tabular}

Notes: This figure presents the aggregate balance sheet for six U.S. GSIBs for items denominated in euros (EUR), Japanese Yen (JPY), British pounds (GBP), and Australian dollars (AUD) based on the FR 2052a data. Items above zero are classified as assets and those below zero as liabilities. The solid line represents the difference between total assets and total liabilities, while the dashed line measures the net repo position of these banks. The sample period expands from December 2015 until May 2020. 
Figure 3: U.S. GSIBs' dollar liquidity provision

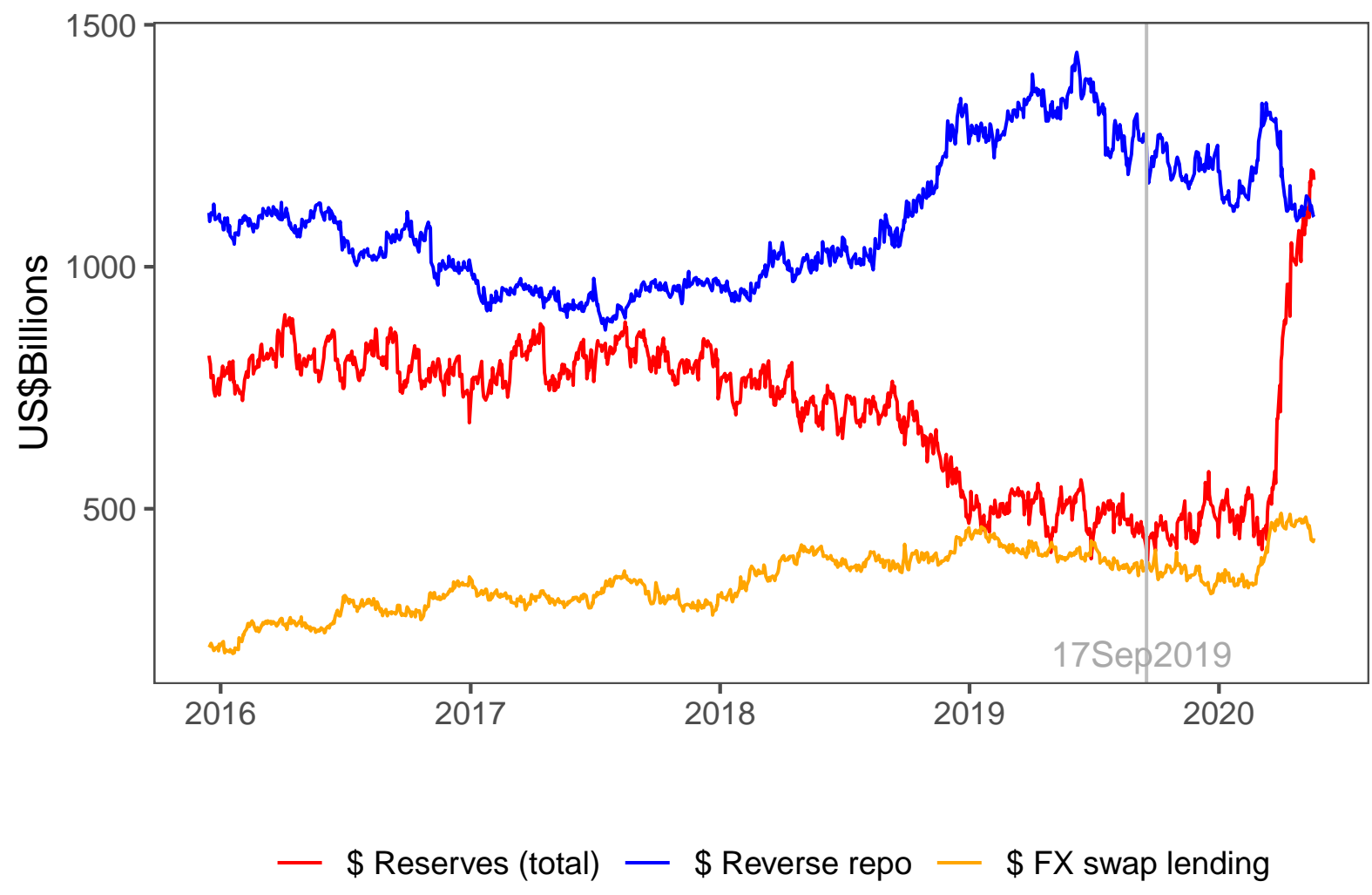

Notes: This figure shows the time series of U.S. GSIBs' total dollar reserves in red, dollar reverse repo lending in blue, and dollar FX swap lending in orange. The discussions of these short-term scalable components of bank assets are provided in Section 3. The vertical gray line shows the beginning of the Fed repo facility on September 17, 2019. The sample is measured daily from December 2015 to May 2020. 
Figure 4: Cash flows for dollar lending in repo and FX swap markets

(A) Dollar lending in the repo market

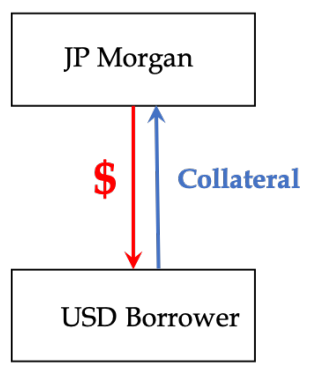

Time $t$

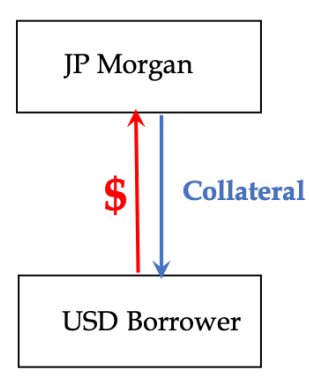

Time $t+1$

(B) Dollar lending in the FX swap market

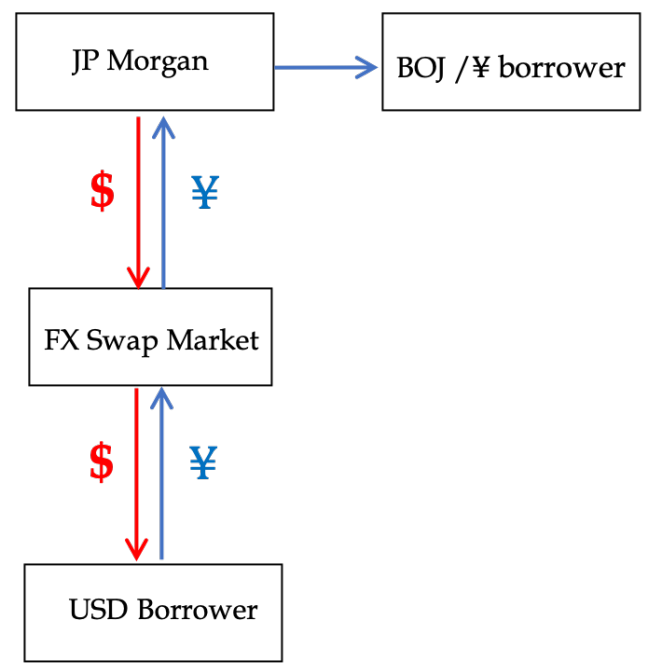

Time $t$

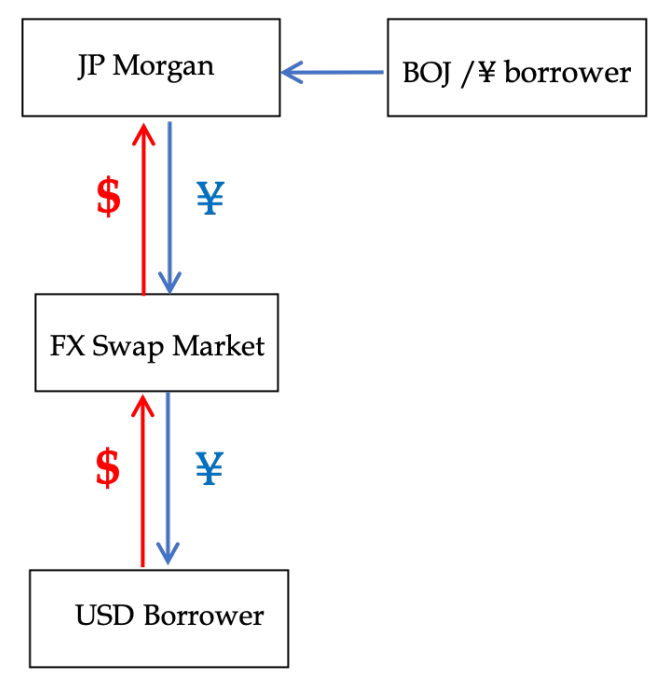

Time $t+1$

Notes: This figure shows a schematic representation of the dollar lending activities conducted by U.S. GSIBs. Panel (A) shows dollar lending in the repo market. Panel (B) shows dollar lending in the FX swap market. 
Figure 5: An illustration of different types of dollar intermediation

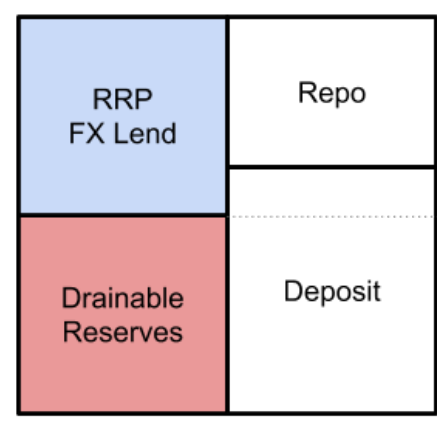

(A) Baseline

$\mathrm{T}=0$

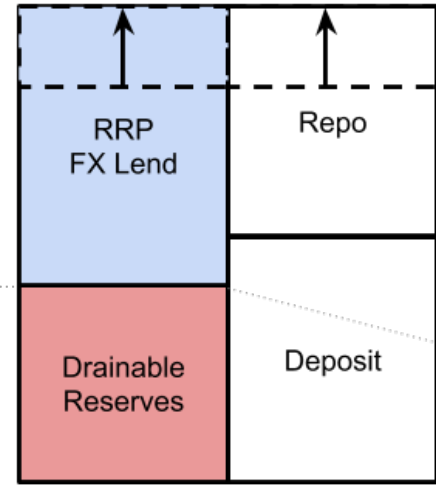

(B) Matched-Book $\mathrm{T}=1$

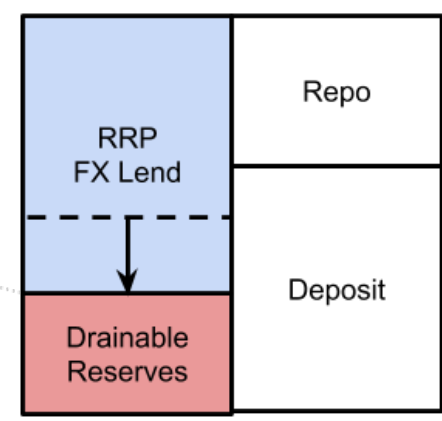

(C) Reserve-Draining $T=1$

Notes: This figure shows the aggregate short-term scalable balance sheet for dollar liquidity provision and two types of dollar funding intermediation. Panel (A) shows the baseline balance sheet. The asset items include the sum of the reverse repos and FX swap lending in dollars (shown in blue), and drainable reserve balances at the Federal Reserve beyond the reserve requirement and other regulatory demand (shown in red). The liability items include repos and deposits denominated in dollars. Panel (B) shows matched-book intermediation through which a bank increases repo borrowing by the same amount as the increase in short-term dollar lending in repo and FX swap markets. Panel (C) shows reserve-draining intermediation through which a bank reduces its drainable reserve balances to increase its short-term dollar lending, while leaving the overall size of the bank balance sheet unchanged. 
Figure 6: Intra-bank Transfer for Reserve-Draining Intermediation

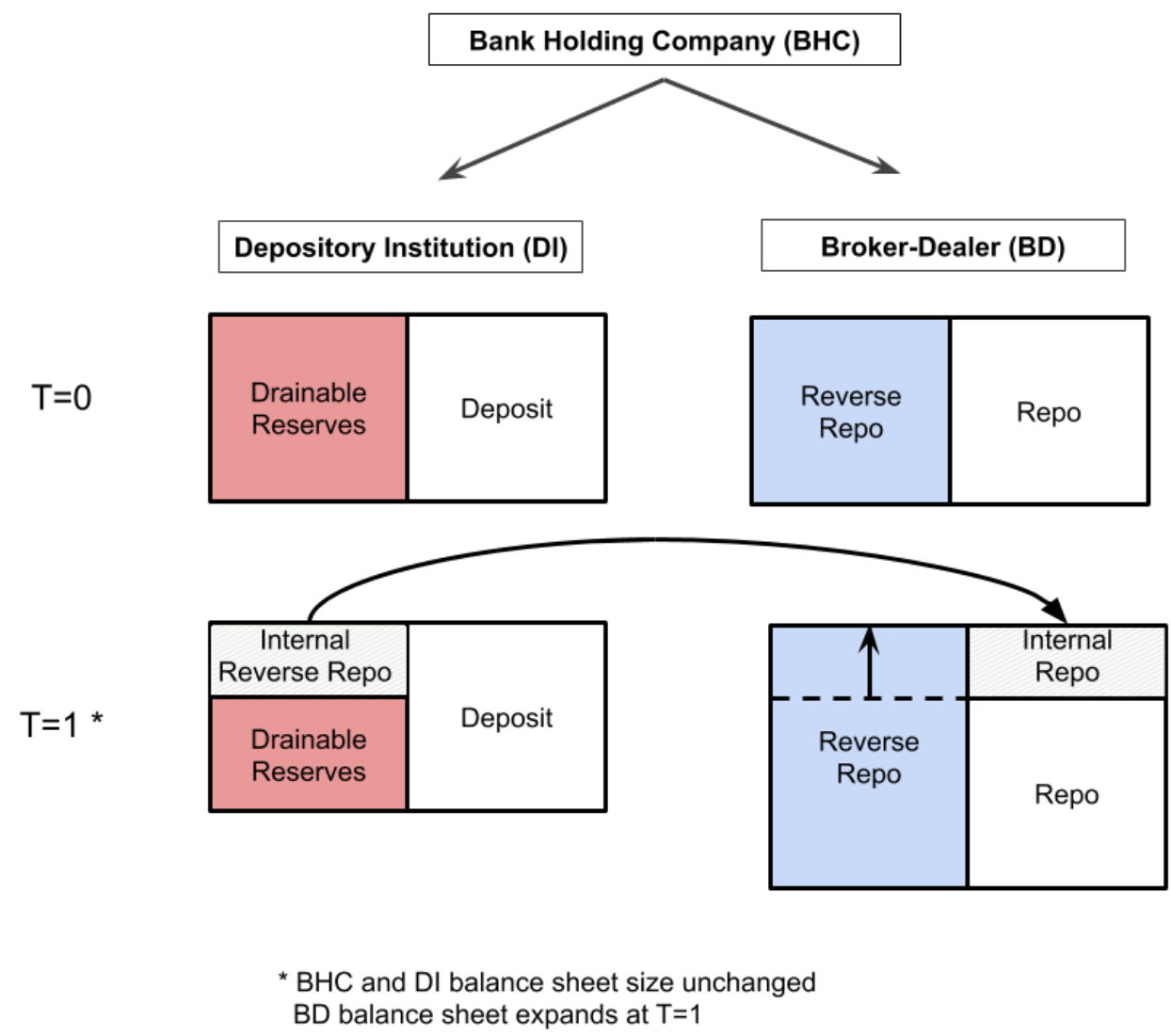

Notes: This figure illustrates the intra-office transfer between the depository institution (DI) and the broker-dealer (BD) subsidiary of the same bank-holding company (BHC) that enables reserve-draining intermediation. The top two diagrams show the baseline balance sheet for the DI and the BD at $T=0$. The bottom two diagrams show the new balance sheets after additional reserve-draining intermediation at $T=1$. The DI reduces its reserve balance, and transfers the proceeds to the $\mathrm{BD}$ through an internal reverse repo lending. The BD uses the additional funding from the internal repo position to expand its reverse repo position. Deposit and external repo positions remain unchanged. After netting out internal positions, the overall size of the BHC's balance sheet stays unchanged at $T=1$. 
Figure 7: Short-term intermediation spreads for dollar funding

(A) Repo intermediation spreads

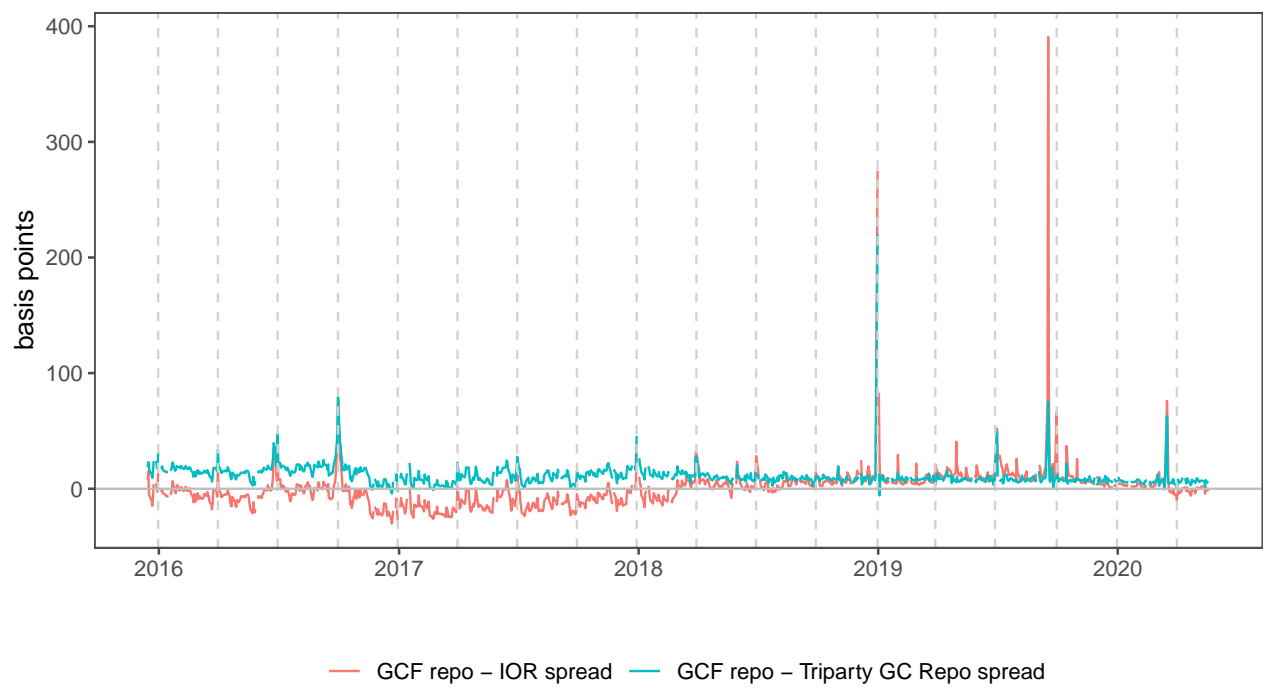

(B) FX swap intermediation spreads

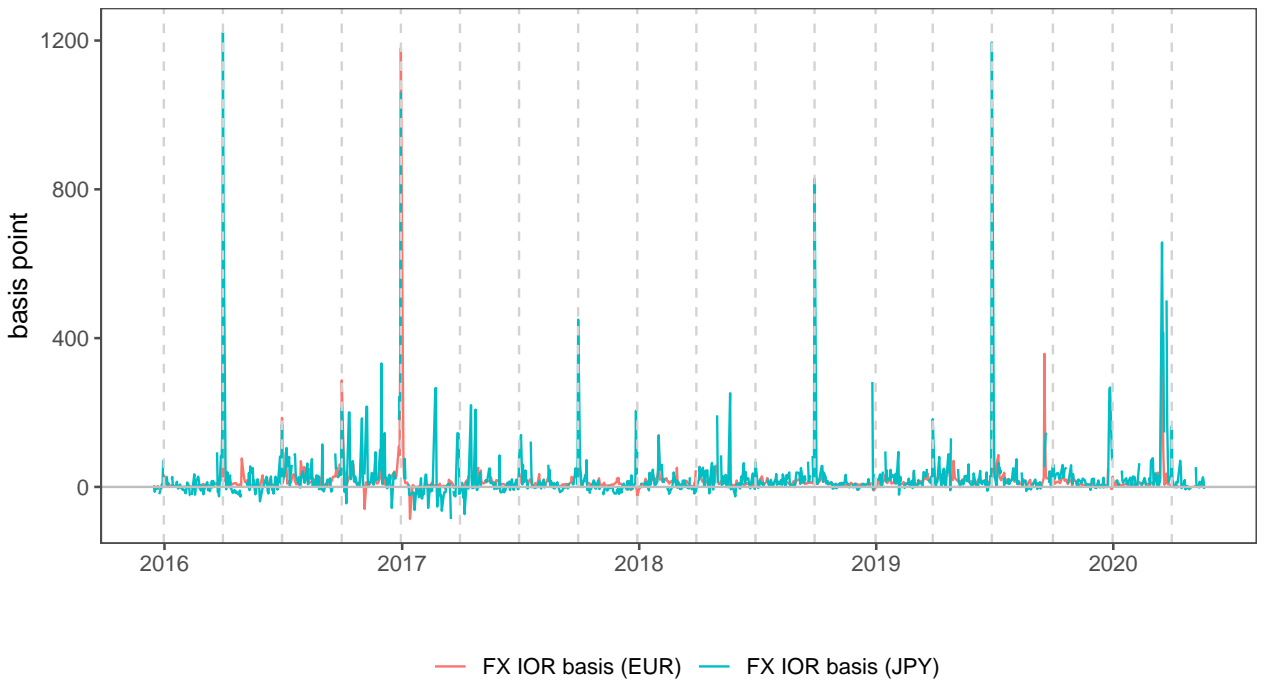

Notes: This figure shows various intermediation spreads for dollar funding intermediation. In Panel (A), we plot the difference between the GCF general collateral Treasury repo rate and interest on excess reserve (IOR) at the Federal Reserve (GCF repo - IOR spread"), and the difference between the GCF and Triparty Treasury general collateral repo spread ("GCF Repo - Triparty GC Repo Spread"). In Panel (B), we plot the spread of the implied dollar funding rate by swapping the ECB deposit rate over the Fed IOR (FX IOR Basis (EUR)), and the spread of the implied dollar funding rate by swapping the BOJ deposit rate over the Fed IOR (FX IOR Basis (JPY)). The dashed vertical lines denote quarter-ends. 
Figure 8: U.S. GSIBs' liquidity provision around quarter-ends
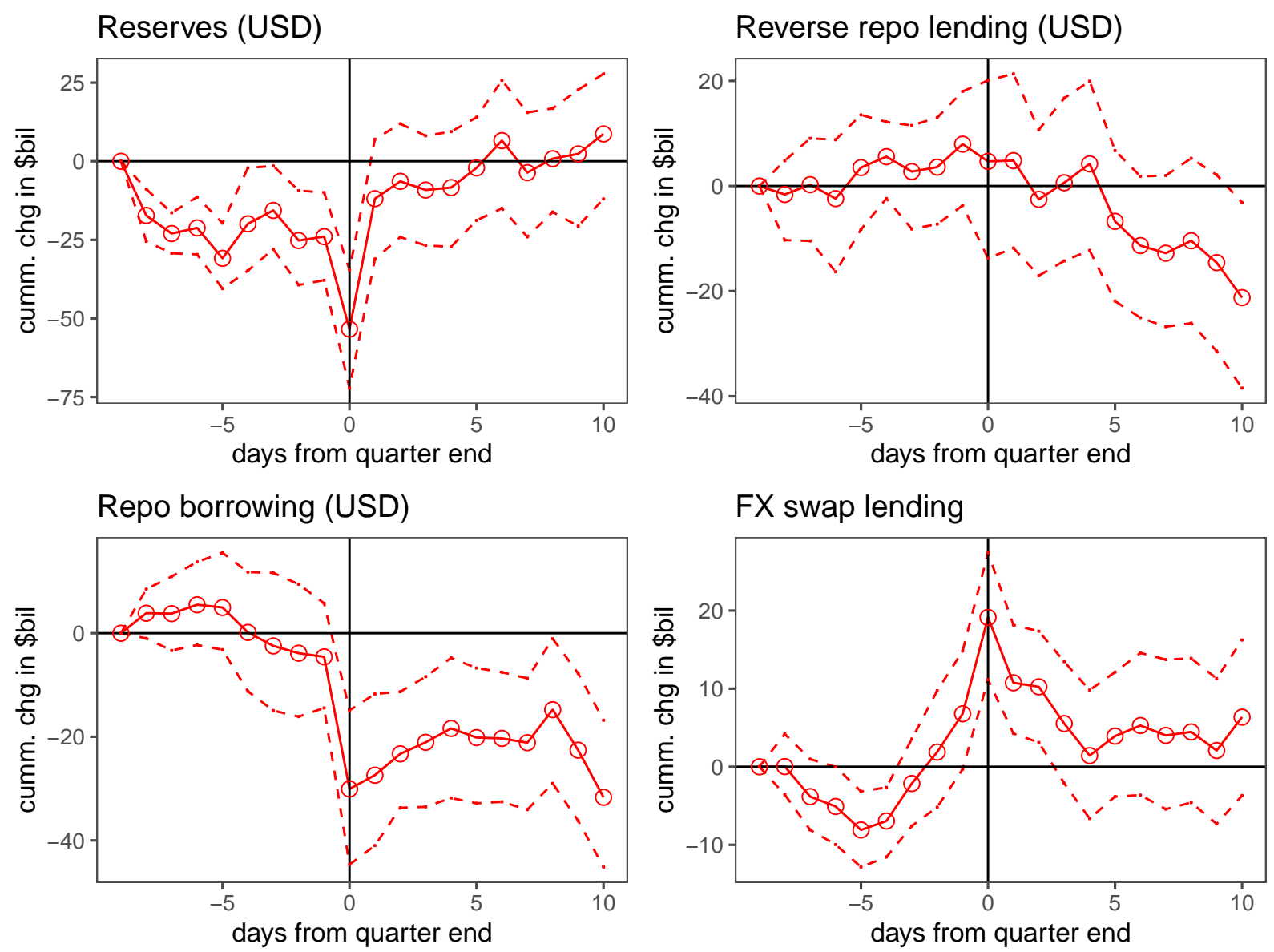

Notes: This figure shows quarter-end changes in U.S. GSIBs' dollar reserves, reverse repo lending, repo borrowing, and FX swap lending. The discussions of these liquidity measures are provided in Section 3. The dotted lines denote the $95 \%$ confidence interval with bootstrapped standard errors. 
Figure 9: Broker-dealer dollar repo borrowing and intra-bank transfers near quarter-ends
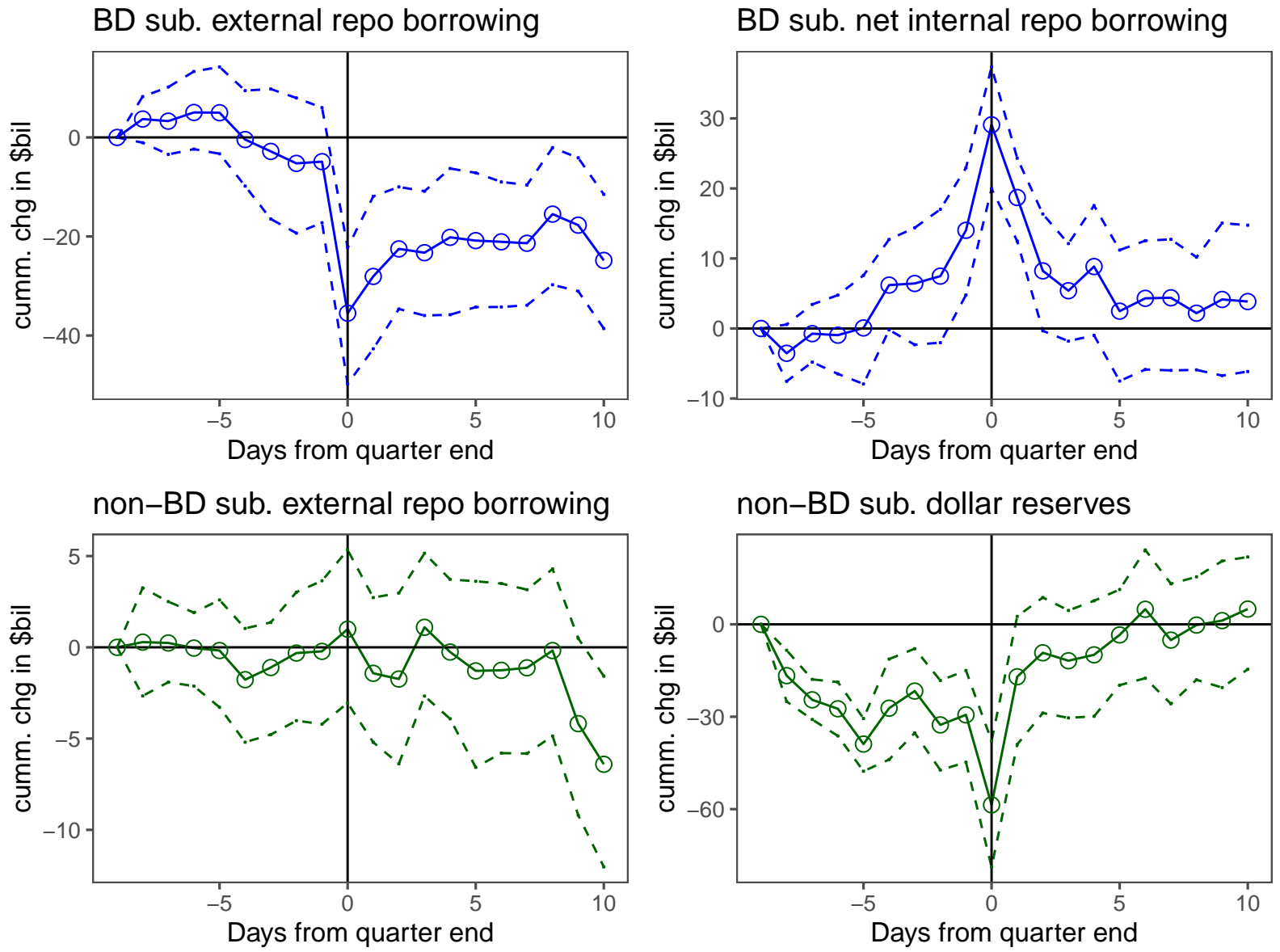

Notes: This figure shows quarter-end changes in dollar repo borrowing and reserve holdings for broker-dealer and non-broker-dealer entities. The top left panel shows brokerdealer entities' dollar repo borrowing from external sources. The top right panel shows changes in dollar net repo borrowing of broker-dealer entities from non-broker-dealer entities (largely depository institutions) within the bank holding company (internal). The bottom left and bottom right panels show, respectively, changes in the external dollar repo borrowing and dollar reserve holdings of the non-broker-dealer entities. The dotted lines denote the $95 \%$ confidence interval with bootstrapped standard errors. 
Figure 10: Dollar reserves by bank holding company entity type

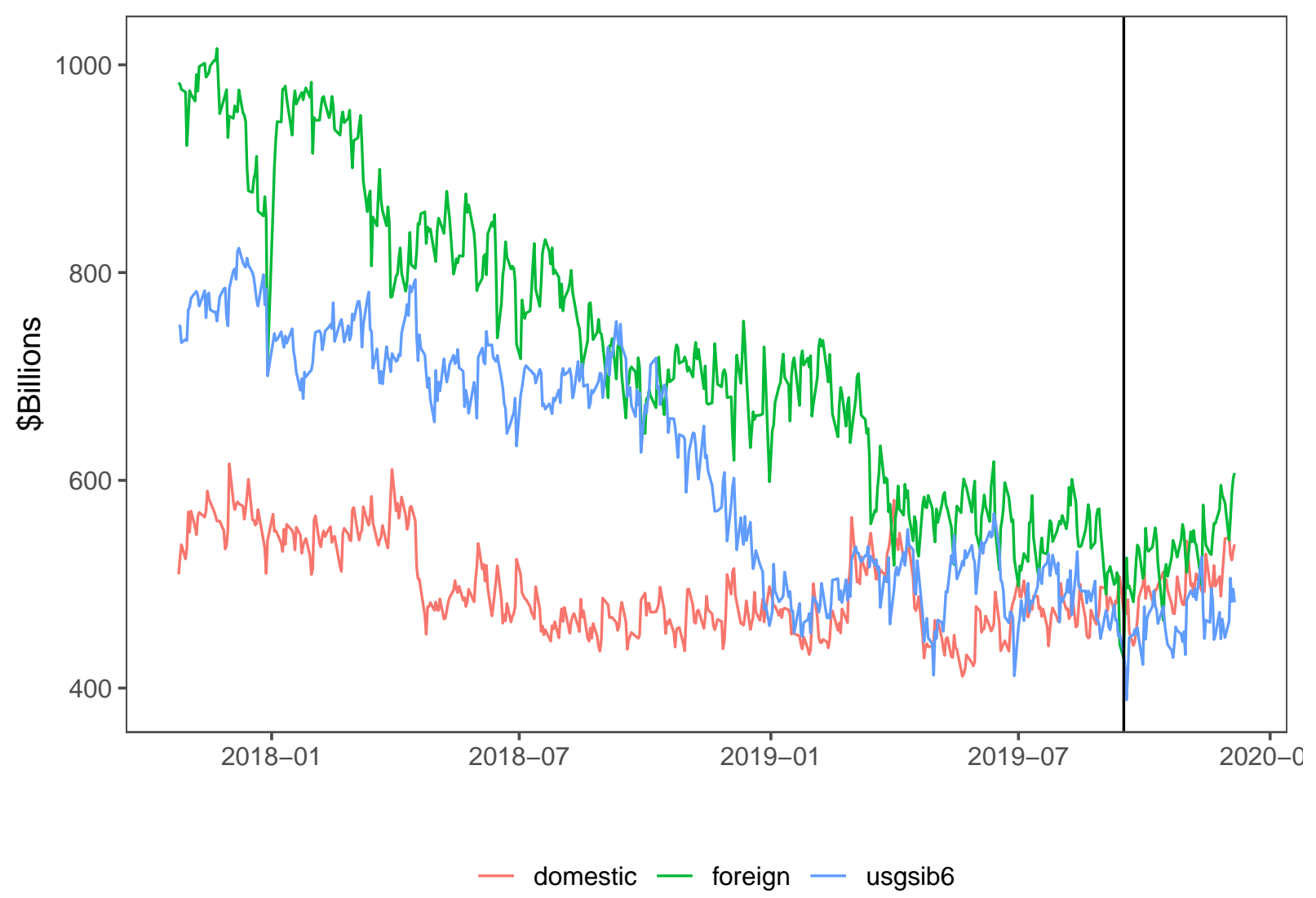

Notes: This figure shows the distribution of total reserve balances across different types of banks The blue line shows the reserve balances of the U.S. GSIBs in our sample. The red line shows the reserve balances of other U.S. banks. The green line shows the reserve balances of foreign banks. The vertical line denotes September 16, 2019. 
Figure 11: September 19 intraday overnight repo and FX-implied funding rates

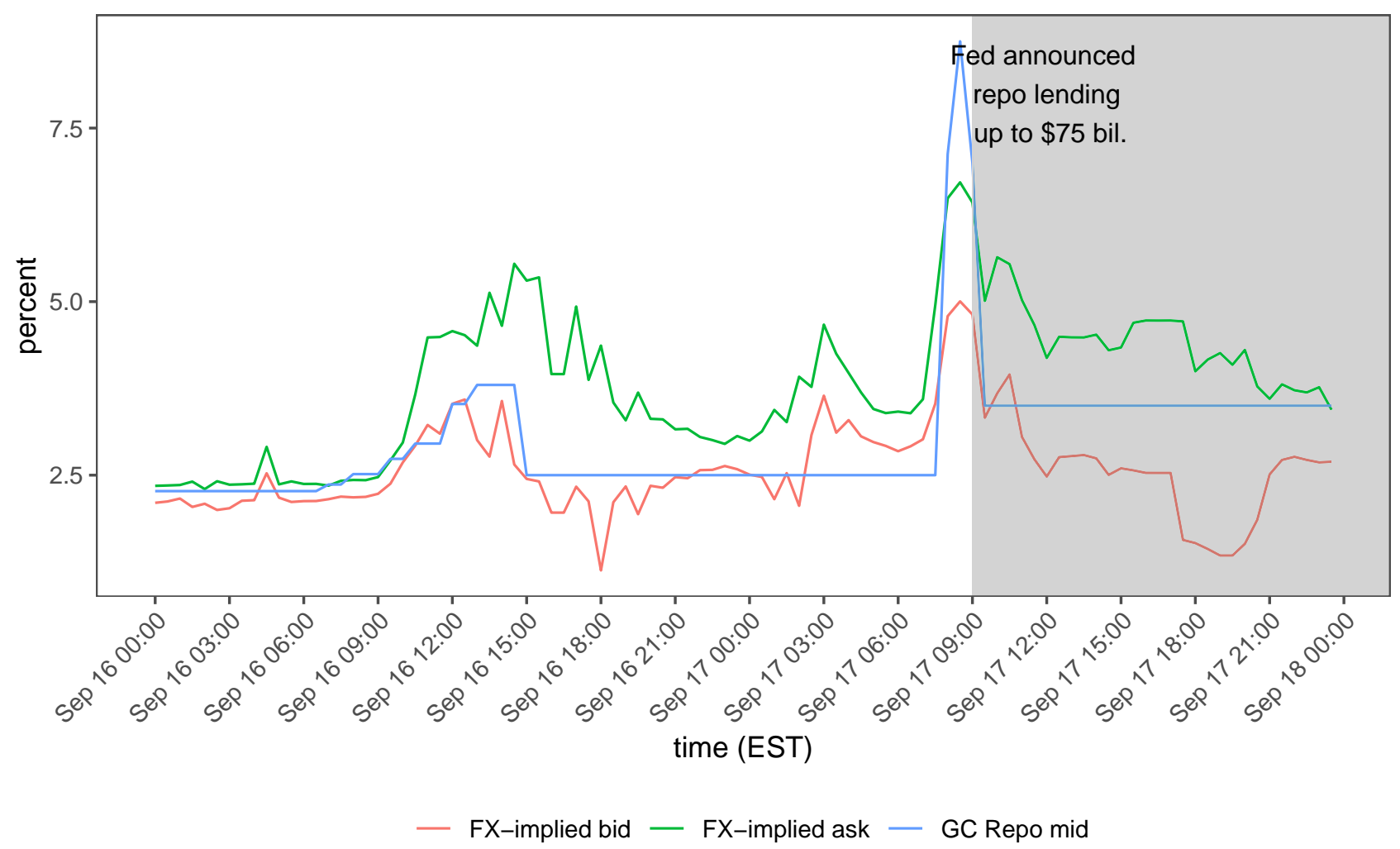

Notes: This figure shows the intraday repo rate and implied dollar funding rates from the FX swap market. The blue line shows the general collateral repo rate from the Thomson Reuters Tick History. The green and red lines show the bid and ask rate, respectively, for the implied dollar funding rate by swapping the deposit rate at the ECB into dollars on the overnight basis. The overnight implied FX swap rate is calculated based on the Bloomberg data with calculation details shown in Footnote 17. 
Figure 12: Treasury General Account and SOFR-IOR Spread

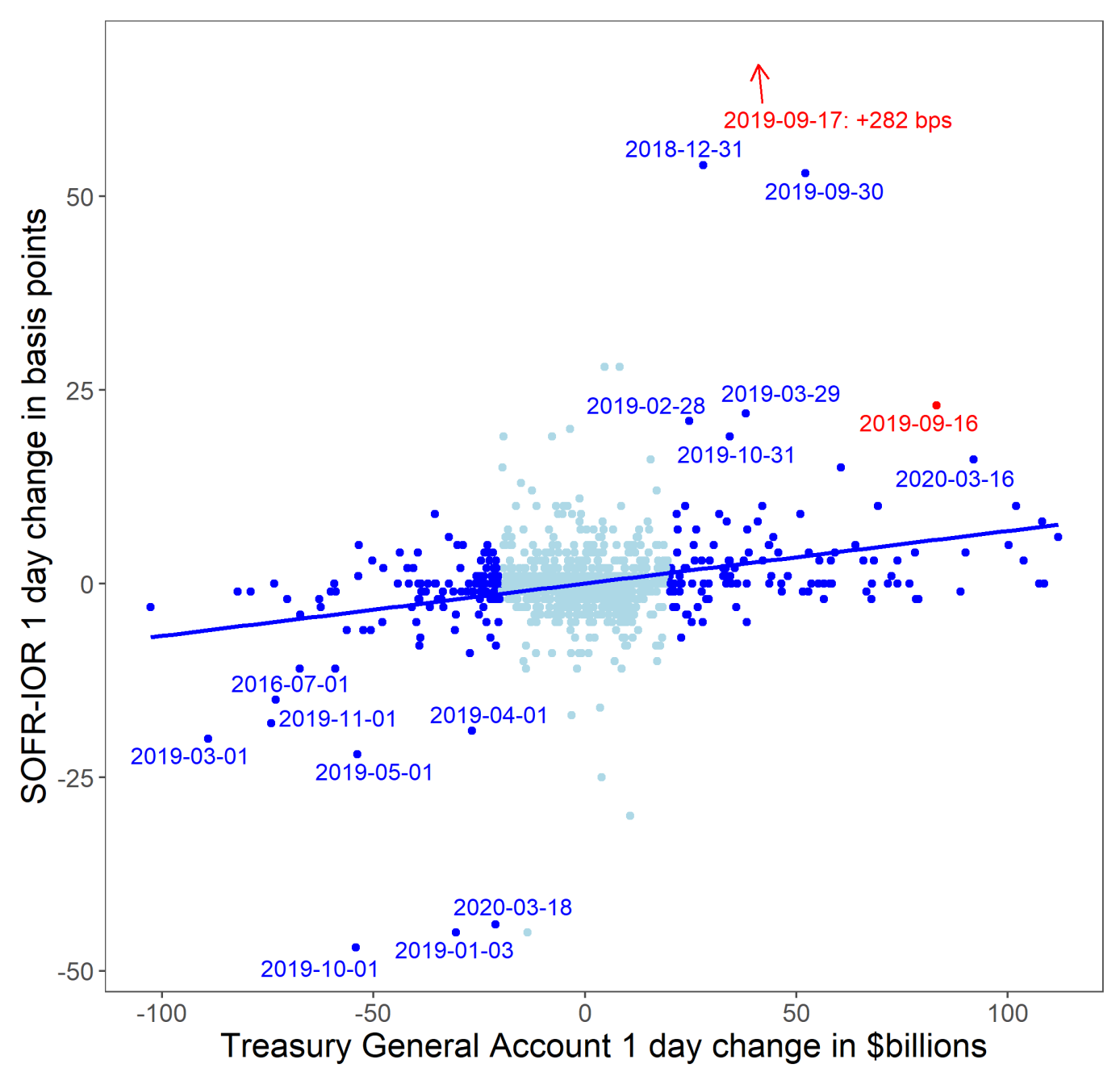

Notes: This figure shows a scatter plot between the daily changes in the spread between the secured overnight financing rate (SOFR) and the interest on excess reserves (IOR) at the Federal Reserve in basis points on the vertical axis, and the daily change in the Treasury General Account (TGA) balance in billions of dollar on the horizontal axis. Dark blue dots denote days with daily changes in the TGA balance greater than $\$ 20$ billion in absolute value. The light blue dots denote days with daily changes in the TGA balance less than or equal to $\$ 20$ billion. The straight line is the fitted regression line for large TGA change days, with the exception of September 17, 2019 and September 18, 2019 that are beyond the graph. The sample period is December 15, 2015 to May 18, 2020. 
Figure 13: Predicted and actual one-day change on September 16, 2019

(A) U.S. GSIBs' balance sheets

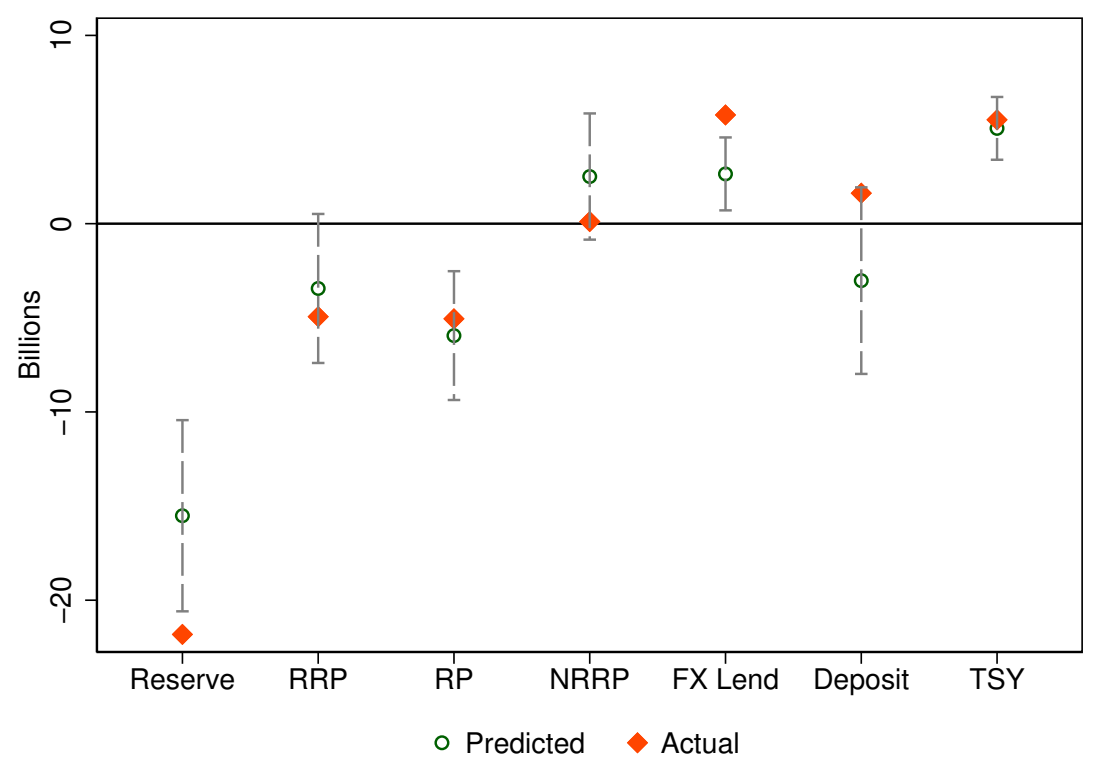

(B) Reserve balance of US GSIBs, foreign and other US banks

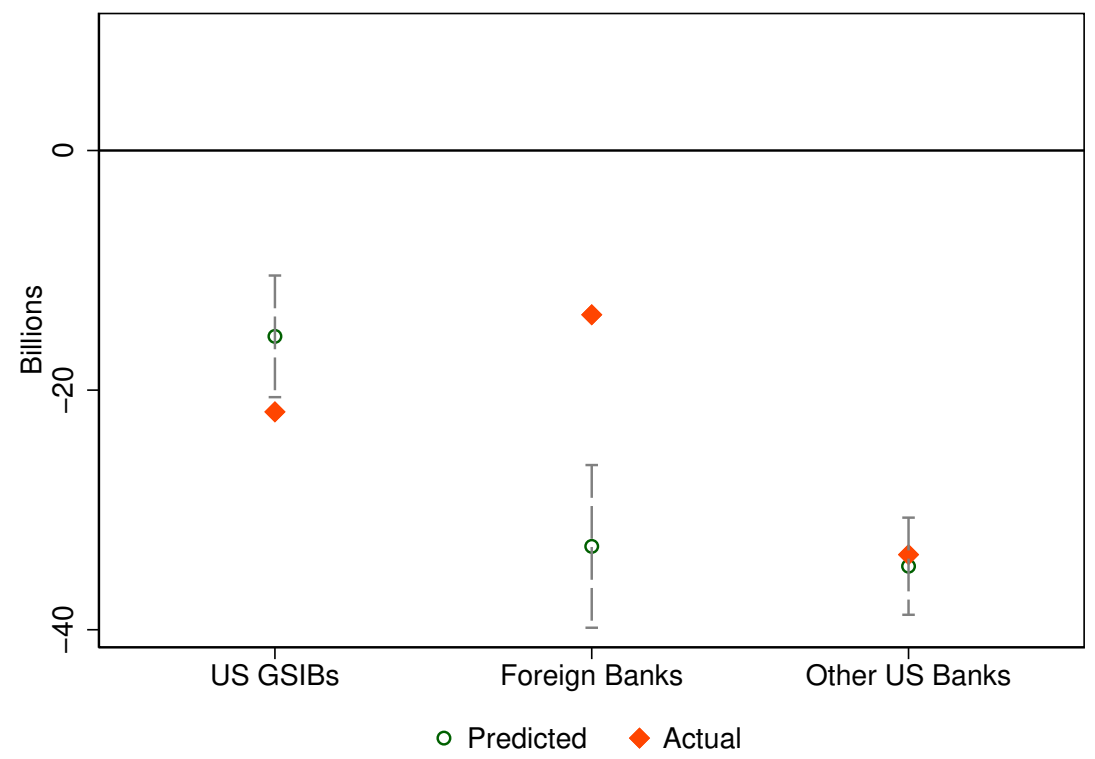

Notes: Panel A shows the predicted and actual one-day change in the intermediation activities of the U.S. GSIBs on September 16, 2019. The green dot shows the point estimate for the predicted one-day change based on the regression results in Table 2 and the $\$ 83$ billion TGA increase on September 16, 2019. The vertical dashed line denotes the 95 percent confidence interval for the point estimate of the predicted change. Panel B shows the predicted and actual one-day change in the reserve balance of U.S. GSIBs, foreign banks, and other U.S. banks. The green dot shows the point estimate for the predicted one-day change based on the regression results in Table 4. 
Figure 14: Broker-dealers Fed Repo Facility Usage and Internal-cash Substitution

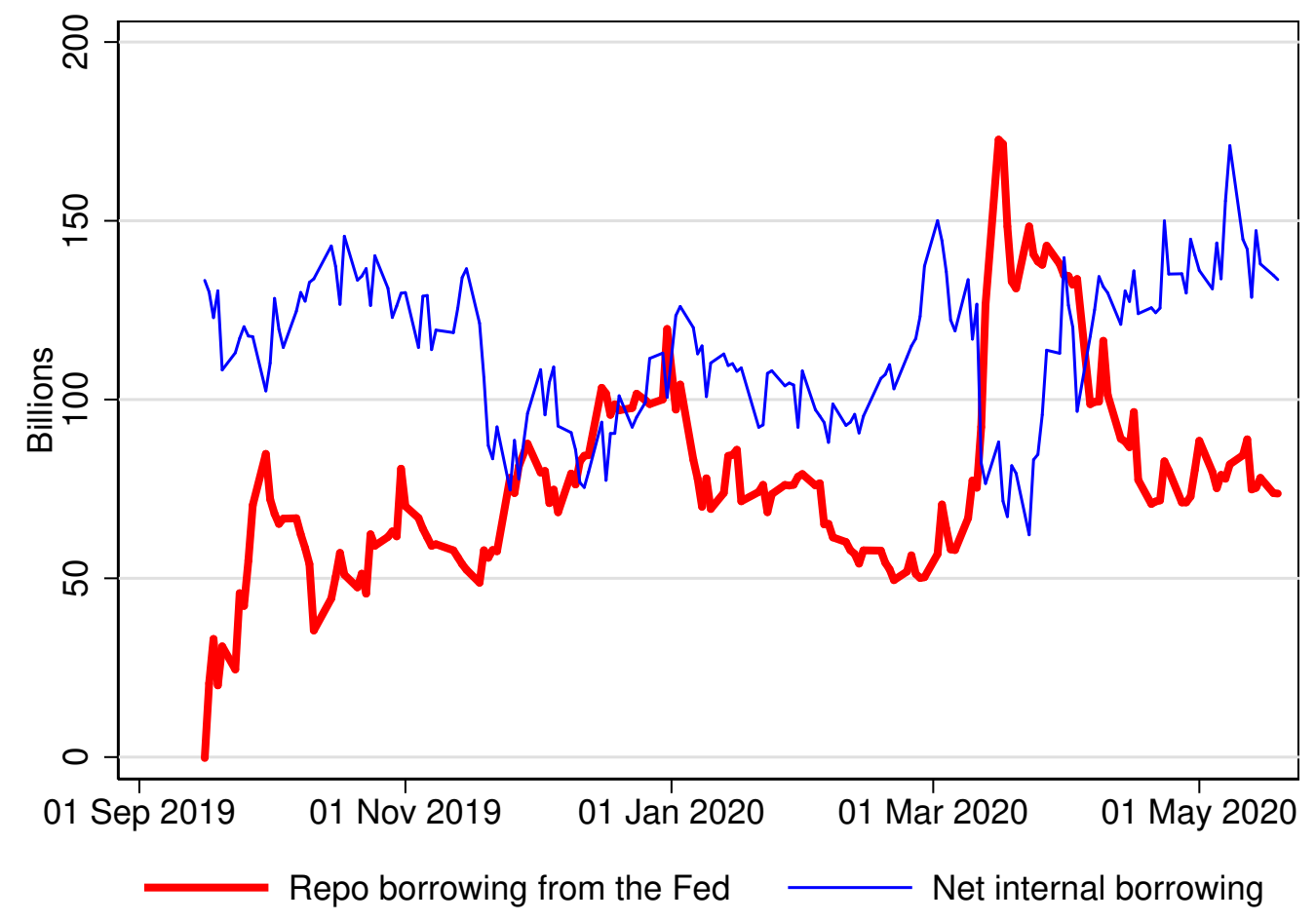

Notes: This figure shows the Fed repo facility draw and internal repo borrowing (from affiliated depository institutions) by broker-dealer arms of U.S. GSIBs since the establishment of the repo facility on September 16, 2019. 
Table 1: Impacts of Quarter-Ends, TGA, and SOMA Fluctuations on Intermediation Spreads

\begin{tabular}{|c|c|c|c|c|c|c|}
\hline & \multicolumn{6}{|c|}{ Dependent variable: } \\
\hline & (1) & $(2)$ & $(3)$ & $(4)$ & $(5)$ & (6) \\
\hline & $\triangle S O F R-I O R$ & $\triangle G C F-I O R$ & $\triangle T G C R-I O R$ & $\Delta G C F-\triangle T G C R$ & $\Delta E U R I O R$ & $\triangle J P Y I O R$ \\
\hline Qend $d_{t}$ & $\begin{array}{c}12.38^{* * *} \\
(2.604)\end{array}$ & $\begin{array}{c}30.36^{* *} \\
(13.56)\end{array}$ & $\begin{array}{c}8.006^{* * *} \\
(2.582)\end{array}$ & $\begin{array}{c}22.34^{*} \\
(11.51)\end{array}$ & $\begin{array}{c}137.7^{* *} \\
(59.92)\end{array}$ & $\begin{array}{c}417.2^{* * *} \\
(118.1)\end{array}$ \\
\hline Qstart $_{t}$ & $\begin{array}{c}-11.00^{* * *} \\
(3.692)\end{array}$ & $\begin{array}{c}-31.81^{* *} \\
(13.21)\end{array}$ & $\begin{array}{c}-6.353^{* *} \\
(2.599)\end{array}$ & $\begin{array}{c}-25.46^{*} \\
(14.38)\end{array}$ & $\begin{array}{c}-167.5^{*} \\
(85.93)\end{array}$ & $\begin{array}{c}-286.4^{* * *} \\
(98.26)\end{array}$ \\
\hline$\Delta T G A_{t}$ & $\begin{array}{c}0.0468 * * * \\
(0.00842)\end{array}$ & $\begin{array}{c}0.0717^{* * *} \\
(0.0155)\end{array}$ & $\begin{array}{c}0.0390 * * * \\
(0.00792)\end{array}$ & $\begin{array}{c}0.0328^{* * *} \\
(0.0123)\end{array}$ & $\begin{array}{c}0.249 * * * \\
(0.0579)\end{array}$ & $\begin{array}{c}0.411^{* * *} \\
(0.155)\end{array}$ \\
\hline$\Delta S O M A_{t}$ & $\begin{array}{c}-0.579^{* * *} \\
(0.146)\end{array}$ & $\begin{array}{c}-1.511^{* *} \\
(0.660)\end{array}$ & $\begin{array}{c}-0.479 * * * \\
(0.153)\end{array}$ & $\begin{array}{c}-1.032^{*} \\
(0.589)\end{array}$ & $\begin{array}{c}-2.884^{* *} \\
(1.420)\end{array}$ & $\begin{array}{c}1.801 \\
(2.375)\end{array}$ \\
\hline Constant & $\begin{array}{c}-0.238^{* *} \\
(0.121)\end{array}$ & $\begin{array}{c}-0.586^{* *} \\
(0.241)\end{array}$ & $\begin{array}{c}-0.197^{*} \\
(0.104)\end{array}$ & $\begin{array}{c}-0.378^{*} \\
(0.197)\end{array}$ & $\begin{array}{l}-0.495 \\
(0.665)\end{array}$ & $\begin{array}{l}-1.999 \\
(1.913)\end{array}$ \\
\hline$N$ & 933 & 930 & 933 & 930 & 901 & 835 \\
\hline$R^{2}$ & 0.294 & 0.285 & 0.227 & 0.198 & 0.248 & 0.376 \\
\hline
\end{tabular}

Notes: This table shows the regression results of the quarter-end dummies, TGA and SOMA fluctuations on daily changes in various intermediation spreads. The dependent variables are as follows: daily changes in the SOFR-IOR spread (Column 1), daily changes in the GCF repo-IOR spread (Column 2), daily changes in the Triparty (TGCR) repo-IOR spread (Column 3), daily changes in the GCF-TGCR repo spread (Column 4), daily changes spread between the overnight implied dollar rate by swapping the ECB deposit rate and the Fed IOR (Column 5), and daily changes in the spread between the overnight implied dollar rate by swapping the BOJ deposit rate and the Fed IOR (Column 6). The independent variables are as follows: $Q e n d_{t}$, a dummy variable indicating the last business day of the quarter; $Q$ start $_{t}$ a dummy variable indicating the first business day of the quarter; $\triangle T G A$, daily changes in the TGA balance; $\triangle S O M A$, daily changes in the Fed portfolio holdings of Treasury securities. Robust standard errors are reported in the parentheses with significance levels denoted by ${ }^{*} \mathrm{p}<0.1 ;{ }^{* *} \mathrm{p}<0.05 ;{ }^{* * *} \mathrm{p}<0.01$. 
Table 2: Impact of TGA, SOMA, and quarter-end constraints on Intermediation Activities

\begin{tabular}{|c|c|c|c|c|c|c|c|}
\hline & \multicolumn{7}{|c|}{ Dependent variable: } \\
\hline & (1) & $(2)$ & (3) & $(4)$ & $(5)$ & $(6)$ & $(7)$ \\
\hline & $\Delta R S V_{t}$ & $\Delta R R P_{t}$ & $\Delta R P_{t}$ & $\Delta N R R P_{t}$ & $\Delta F X_{t}$ & $\Delta$ Deposit $_{t}$ & $\Delta T S Y_{t}^{\text {outright }}$ \\
\hline Qend $_{t}$ & $\begin{array}{c}-26.200^{* * *} \\
(7.420)\end{array}$ & $\begin{array}{l}-6.570 \\
(7.270)\end{array}$ & $\begin{array}{c}-29.500^{* * *} \\
(4.810)\end{array}$ & $\begin{array}{c}23.000^{* * *} \\
(5.190)\end{array}$ & $\begin{array}{c}10.600^{* * *} \\
(3.150)\end{array}$ & $\begin{array}{c}1.780 \\
(4.470)\end{array}$ & $\begin{array}{c}3.230 \\
(2.830)\end{array}$ \\
\hline Qstart $_{t}$ & $\begin{array}{c}42.000^{* * *} \\
(5.480)\end{array}$ & $\begin{array}{l}-6.780 \\
(5.320)\end{array}$ & $\begin{array}{c}0.916 \\
(4.200)\end{array}$ & $\begin{array}{c}-7.700^{*} \\
(4.250)\end{array}$ & $\begin{array}{c}-8.420^{* *} \\
(3.270)\end{array}$ & $\begin{array}{c}29.900^{* * *} \\
(4.670)\end{array}$ & $\begin{array}{l}-0.745 \\
(1.520)\end{array}$ \\
\hline$\Delta T G A_{t}$ & $\begin{array}{c}-0.181^{* * *} \\
(0.036)\end{array}$ & $\begin{array}{c}-0.041^{*} \\
(0.025)\end{array}$ & $\begin{array}{c}-0.078^{* * *} \\
(0.021)\end{array}$ & $\begin{array}{l}0.037^{*} \\
(0.022)\end{array}$ & $\begin{array}{c}0.031^{* * *} \\
(0.012)\end{array}$ & $\begin{array}{l}-0.034 \\
(0.038)\end{array}$ & $\begin{array}{c}0.060^{* * *} \\
(0.010)\end{array}$ \\
\hline$\Delta S O M A_{t}$ & $\begin{array}{c}0.492 \\
(0.305)\end{array}$ & $\begin{array}{c}-1.150^{* * *} \\
(0.302)\end{array}$ & $\begin{array}{l}-0.359 \\
(0.257)\end{array}$ & $\begin{array}{c}-0.794^{* * *} \\
(0.249)\end{array}$ & $\begin{array}{l}-0.178 \\
(0.116)\end{array}$ & $\begin{array}{c}-0.895^{* * *} \\
(0.241)\end{array}$ & $\begin{array}{l}-0.090 \\
(0.056)\end{array}$ \\
\hline Constant & $\begin{array}{l}-0.482 \\
(0.610)\end{array}$ & $\begin{array}{l}-0.052 \\
(0.472)\end{array}$ & $\begin{array}{c}0.553 \\
(0.412)\end{array}$ & $\begin{array}{l}-0.605 \\
(0.399)\end{array}$ & $\begin{array}{c}0.082 \\
(0.229)\end{array}$ & $\begin{array}{l}-0.196 \\
(0.607)\end{array}$ & $\begin{array}{c}0.102 \\
(0.201)\end{array}$ \\
\hline $\begin{array}{l}N \\
R^{2}\end{array}$ & $\begin{array}{c}932 \\
0.142\end{array}$ & $\begin{array}{c}932 \\
0.044\end{array}$ & $\begin{array}{c}932 \\
0.104\end{array}$ & $\begin{array}{c}932 \\
0.086\end{array}$ & $\begin{array}{c}932 \\
0.067\end{array}$ & $\begin{array}{c}932 \\
0.073\end{array}$ & $\begin{array}{c}932 \\
0.046\end{array}$ \\
\hline
\end{tabular}

Notes: This table shows regression results of one-day changes in the TGA account $\left(\Delta T G A_{t}\right)$, net SOMA purchase $\left(\Delta S O M A_{t}\right)$, and quarter-end $\left(\right.$ Qend $\left._{t}\right)$ and quarter-starts $\left(\right.$ Qstart $\left._{t}\right)$ on daily changes in the U.S. GSIBs intermediation activities. The dependent variables are as follows: changes in reserves (Column 1), changes in dollar reverse repos (Column 2), changes in dollar repos (Column 3), changes in net dollar reverse repos, or the difference between reverse repos and repos in dollars (Column 4), changes in dollar lending in the FX swap market (Column 5), changes in dollar deposits (Column 6), and changes in outright Treasury holdings (Column 7). Qend is a dummy variable indicating the last business day of the

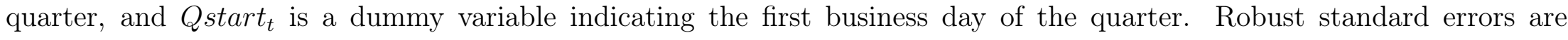
reported in parentheses with significance levels denoted by ${ }^{*} \mathrm{p}<0.1 ;{ }^{* *} \mathrm{p}<0.05 ;{ }^{* * *} \mathrm{p}<0.01$. 
Table 3: TGA fluctuations and intra-bank transfers

\begin{tabular}{|c|c|c|c|c|}
\hline & \multicolumn{2}{|c|}{ Broker-Dealers } & \multicolumn{2}{|c|}{ Non-Broker Dealers } \\
\hline & $\stackrel{(1)}{\text { External } \Delta R P_{t}}$ & $\begin{array}{c}(2) \\
\text { Net Internal } \Delta R P_{t}\end{array}$ & $\begin{array}{c}(3) \\
\text { External } \Delta R P_{t}\end{array}$ & $\begin{array}{c}(4) \\
\Delta \text { Reservest }^{(4)}\end{array}$ \\
\hline Qend $_{t}$ & $\begin{array}{c}-30.800^{* * *} \\
(4.930)\end{array}$ & $\begin{array}{c}14.600^{* * *} \\
(3.190)\end{array}$ & $\begin{array}{c}1.240 \\
(1.500)\end{array}$ & $\begin{array}{l}-26.200^{* * *} \\
(7.420)\end{array}$ \\
\hline Qstart $_{t}$ & $\begin{array}{l}3.640 \\
(3.850)\end{array}$ & $\begin{aligned}- & 11.800^{* * *} \\
& (2.420)\end{aligned}$ & $\begin{array}{c}-2.720^{* *} \\
(1.300)\end{array}$ & $\begin{array}{c}42.000^{* * *} \\
(5.480)\end{array}$ \\
\hline$\Delta T G A_{t}$ & $\begin{array}{c}-0.069^{* * *} \\
(0.020)\end{array}$ & $\begin{array}{c}0.020 \\
(0.016)\end{array}$ & $\begin{array}{l}-0.010 \\
(0.008)\end{array}$ & $\begin{array}{c}-0.181^{* * *} \\
(0.036)\end{array}$ \\
\hline$\Delta S O M A_{t}$ & $\begin{array}{l}-0.345 \\
(0.232)\end{array}$ & $\begin{array}{c}-0.307^{* * *} \\
(0.114)\end{array}$ & $\begin{array}{l}-0.014 \\
(0.099)\end{array}$ & $\begin{array}{c}0.492 \\
(0.305)\end{array}$ \\
\hline Constant & $\begin{array}{c}0.495 \\
(0.384)\end{array}$ & $\begin{array}{l}-0.157 \\
(0.309)\end{array}$ & $\begin{array}{c}0.058 \\
(0.147)\end{array}$ & $\begin{array}{l}-0.482 \\
(0.610)\end{array}$ \\
\hline $\begin{array}{l}N \\
R^{2}\end{array}$ & 932 & 932 & 932 & 932 \\
\hline & 0.123 & 0.066 & 0.008 & 0.142 \\
\hline
\end{tabular}

Notes: This table shows regression results of daily changes in the TGA balances and Fed SOMA holdings on daily changes in the repo borrowing and intra-office transfers between the broker-dealer entities and non-broker-dealer entities. Columns 1-2 show regression results for changes in broker-dealer entities' external repo borrowing from a third party outside the same bank and net internal repo borrowing from non-broker-dealer entities of the same bank, respectively. Column 3 shows results for changes in external repo borrowing of the non-broker-dealer entities, and Column 4 shows results for changes in the Fed reserve position of the non-broker-dealers. Robust standard errors are reported in parentheses with significance levels denoted by ${ }^{*} \mathrm{p}<0.1 ;{ }^{* *} \mathrm{p}<0.05 ;{ }^{* * *} \mathrm{p}<0.01$. 
Table 4: Impact of TGA, SOMA, and quarter-end constraints on reserve distribution

\begin{tabular}{|c|c|c|c|c|}
\hline & \multicolumn{4}{|c|}{ Dependent variable: } \\
\hline & $\begin{array}{c}\Delta R S V_{t}^{U S G I S B s} \\
(1)\end{array}$ & $\begin{array}{c}\Delta R S V_{t}^{\text {Foreign }} \\
(2)\end{array}$ & $\begin{array}{c}\Delta R S V_{t}^{\text {Domestic }} \\
(3)\end{array}$ & $\begin{array}{c}\Delta O N R R P_{t} \\
(4)\end{array}$ \\
\hline Qend $_{t}$ & $\begin{array}{c}-28.000^{* * *} \\
(7.240)\end{array}$ & $\begin{array}{c}-101.000^{* * *} \\
(20.200)\end{array}$ & $\begin{array}{c}25.500^{* * *} \\
(4.510)\end{array}$ & $\begin{array}{c}95.000^{* * *} \\
(16.800)\end{array}$ \\
\hline Qstart $_{t}$ & $\begin{array}{c}42.900^{* * *} \\
(5.460)\end{array}$ & $\begin{array}{c}82.800^{* * *} \\
(18.700)\end{array}$ & $\begin{array}{c}1.050 \\
(6.380)\end{array}$ & $\begin{array}{c}-119.000^{* * *} \\
(19.000)\end{array}$ \\
\hline$\Delta T G A_{t}$ & $\begin{array}{c}-0.186^{* * *} \\
(0.035)\end{array}$ & $\begin{array}{c}-0.406^{* * *} \\
(0.044)\end{array}$ & $\begin{array}{c}-0.406^{* * *} \\
(0.033)\end{array}$ & $\begin{array}{c}0.055 \\
(0.043)\end{array}$ \\
\hline$\Delta S O M A_{t}$ & $\begin{array}{l}0.573^{* *} \\
(0.286)\end{array}$ & $\begin{array}{c}2.570^{* * *} \\
(0.613)\end{array}$ & $\begin{array}{c}-0.692^{* * *} \\
(0.203)\end{array}$ & $\begin{array}{c}-1.230^{* *} \\
(0.537)\end{array}$ \\
\hline Constant & $\begin{array}{l}-0.363 \\
(0.590)\end{array}$ & $\begin{array}{c}0.688 \\
(0.717)\end{array}$ & $\begin{array}{c}-0.893^{*} \\
(0.488)\end{array}$ & $\begin{array}{l}-0.198 \\
(0.644)\end{array}$ \\
\hline$N$ & 931 & 931 & 931 & 931 \\
\hline$R^{2}$ & 0.159 & 0.384 & 0.268 & 0.425 \\
\hline
\end{tabular}

Notes: This table shows regression results of one-day changes in the TGA account $\left(\triangle T G A_{t}\right)$, net SOMA purchases $\left(\triangle S O M A_{t}\right)$, and quarter-end $\left(\right.$ Qend $\left._{t}\right)$ and quarter-starts $\left(\right.$ Qstart $\left._{t}\right)$ on daily changes in reserve balances for financial institutions and in the balance of the Federal Reserve's ON RRP facility. Column 1 shows regression results for changes in reserve balances for the six U.S. GSIBs in our sample, while column 2 shows results for foreign banks with U.S. branches and subsidiaries. Column 3 shows results for other U.S. banks not classified in the other two groups. Column 4 shows results for changes in the ON RRP facility. Qend $d_{t}$ is a dummy variable indicating the last business day of the quarter, and start $_{t}$ is a dummy variable indicating the first business day of the quarter. The sample period is December 15, 2015 until August 31, 2019. Robust standard errors are reported in parentheses with significance levels denoted by ${ }^{*} \mathrm{p}<0.1 ;{ }^{* *} \mathrm{p}<0.05 ;{ }^{* *} \mathrm{p}<0.01$. 
Table 5: U.S. GSIBs' Fed Repo Line Usage and Intermediation Activities

\begin{tabular}{lccccc}
\hline \hline & \multicolumn{5}{c}{ Dependent variable: } \\
\cline { 2 - 6 } & $\Delta R S V_{t}$ & $\Delta R R P_{t}$ & $\Delta R P_{t}^{\text {exFed }}$ & $\Delta N R R P_{t}^{\text {exFed }}$ & $\Delta F X_{t}$ \\
& $(1)$ & $(2)$ & $(3)$ & $(4)$ & $(5)$ \\
\hline$\Delta$ FedRepo & -0.014 & $0.291^{*}$ & $-0.446^{* *}$ & $0.784^{* * *}$ & $0.254^{* * *}$ \\
& $(0.229)$ & $(0.153)$ & $(0.185)$ & $(0.171)$ & $(0.096)$ \\
& & & & & \\
Constant & $4.960^{* *}$ & -0.832 & -0.769 & -0.055 & 0.127 \\
& $(2.340)$ & $(1.510)$ & $(1.140)$ & $(1.400)$ & $(0.715)$ \\
& & & & & \\
\hline $\mathrm{N}$ & 158 & 158 & 158 & 158 & 158 \\
$\mathrm{R}^{2}$ & 0.00002 & 0.021 & 0.079 & 0.151 & 0.066 \\
\hline \hline
\end{tabular}

Notes: This table shows the relationship between U.S. GSIBs' draw on the Fed repo facility $(\Delta F e d R e p o)$ and their various intermediation activities. The dependent variables are as follows: changes in reserves (Column 1), changes in dollar reverse repos (Column 2 ), changes in dollar repos excluding borrowings from the Fed repo facility (Column 3), changes in net dollar reverse repos excluding borrowings from the Fed repo facility (Column 4), changes in dollar lending in the FX swap market (Column 5). The sample period is from October 1, 2019 to May 18, 2020. Robust standard errors are reported in the parentheses with significance levels denoted by ${ }^{*} \mathrm{p}<0.1 ;{ }^{* *} \mathrm{p}<0.05 ;{ }^{* * *} \mathrm{p}<0.01$. 


\section{Internet Appendix \\ "U.S. Banks and Global Liquidity" \\ Ricardo Correa Wenxin Du Gordon Liao}

\section{A FR 2052a and FR Y9-C Comparison}

This comparison between the LCR assessment data and the FR Y-9C data serves two important functions. First, it verifies that the daily balance sheet snapshots assembled from the liquidity monitoring reports are of high quality and broadly match the public filings reported on quarter-ends. Second, the comparison highlights an advantage of the LCR monitoring data for assessing the gross amount of intermediation in dollar liquidity. As the FR Y-9C data defers to Generally Accepted Accounting Principles (GAAP) standards in the netting treatment of certain balance sheet items, matched-book exposures in repurchase agreements (repos) are significantly lower as reported in this form. For instance, the gross exposure in repo borrowing aggregated across the six GSIBs is around $\$ 1.8$ trillion at the end of 2018 according to the LCR data, but only around $\$ 800$ billion according to the FR Y-9C. The former more accurately reflect the volume of repo intermediation from other sources. ${ }^{1}$

Figure A1 shows that repo are reverse repo positions are significantly larger in FR2052a than in Y9-C. The net reverse repo positions from the two sources have similar trends. The other main asset and liability items from the two sources are broadly in line with each other.

\footnotetext{
${ }^{1}$ Daily triparty repo volume was around $\$ 2.2$ trillion and GCF repo was around $\$ 700$ billion at the end of 2018, according to the Federal Reserve Bank of New York. Additionally, sizable bilateral repo borrowings also make up a large part of the banks' repo exposure.
} 


\section{B Intraday rate movements during the September 2019 event}

This section describes the intraday movements in several rates during the September 16 and 17 event shown in Figure 11.

Even though the GC repo rate spiked to its high on Tuesday September 17, the repo market was already experiencing significant strains on Monday after the TGA balance increase. The morning of Monday, September 16th started with elevated but orderly secured funding rates. Both GC repo and FX implied dollar rate were trading around $2.5 \%$, which is around 20 basis points higher than the previous trading day's close and 40 basis points higher than the interest on reserve. The bid-ask spread in FX swapped dollar funding was also relatively tight. The GC repo rate increased steadily throughout the day peaking around $4.5 \%$ (mid) by late afternoon, when the market closed for the day. The timing of the repo rate increase in late morning and early afternoon suggests that auction settlement-related financing is likely a driver of the repo rate increase. ${ }^{2}$

The elevated secured funding rates carried over to Tuesday from the day before. Despite the lack of additional Treasury settlement or tax payment on Tuesday (the TGA balance only increased by $\$ 8$ billion on Tuesday), the GC repo borrowing rate quickly increased to a high of $10 \%$ by early-morning, when the bulk of the repo volume occurs, and the FX-implied funding rate reacted in lock step. Shortly after 9 a.m, the Federal Reserve Bank of New York announced that it would conduct repo operations and ultimately lent $\$ 53$ billion to primary dealers in overnight repo. The secured funding rates declined sharply thereafter.

\footnotetext{
${ }^{2}$ Since the repo market starts trading early in the morning, a large fraction of trades were done before 9 a.m., around this time, $\$ 78$ of new treasury issuance was settled through the Bank of New York Mellon (BNYM) (Since 2017, BNYM has been the sole provider of U.S. government securities settlement and triparty repo services for broker-dealers.). Primary dealers typically draw down or overdraft their clearing accounts at BNYM to fund the treasury settlement, and, over the course of the day, these dealers sell the new bonds in exchange for cash to "refill" their clearing account by 3:30 pm (Pozsar, 2019). A fraction of the newly issued treasury bonds were sold off to real-money investors, and the remaining portion of the new issuance were bought by levered investors or remained in dealer's inventory, both of which required repo financing.
} 


\section{Dealer security financing needs}

In this section, we present suggestive evidence that dealers' own security financing needs also contributed to the September 2019 liquidity crunch in addition to the breakdown of reserve-based intermediation.

Decomposing the balance sheet shifts by subsidiary, we find that the decline in reserves in depository institutions coincided with an increase in repo borrowing by the brokerdealer affiliates to finance the holdings of Treasury securities. Dealer accumulation of Treasury securities is likely related to reduced demand from real money institutions at Treasury auctions as the Treasury yield curve flattened and inverted throughout this period. Figure A9 shows that these broker-dealer reached their highest level of external repo financing (net reverse repo reached their lowest level) immediately prior to the repo rate spike. This financing need coincided with an increase in primary dealers' accumulation of coupon securities throughout 2018 and early 2019, as shown in Figure A10. ${ }^{3}$

Two additional trends that are typically associated with funding strains also emerged around the same time. First, broker-dealer were increasingly reliant on worse collaterals to finance their borrowings. Panel A in Figure A11 shows that broker-dealers have historically net lend out cash against Treasurys collateral, but net borrowed cash against non-Treasury collaterals. In 2019, broker-dealers reduced the net lending collateralized by Treasurys and increased the reliance on funding using non-Treasurys as collateral. An increasing fraction of the borrowing were backed by equities and Government Sponsored Enterprise (GSE) bonds. Second, dealers became more engaged in maturity transformation in 2019. Panel B in Figure A11 shows that while dealers continue to net lend the same amount of termed repo with maturity greater than one-week, they have started to borrow with short maturity repo contracts. Dealers became net borrowers of short-maturity repo, as opposed to net lender in earlier period.

\footnotetext{
${ }^{3}$ Primary dealers shown in Figure A10 include dealers beside those affiliated with the six GSIBs.
} 
The maturity and collateral mismatch observed in 2019 bear resemblance to the hallmarks of broker-dealer's repo financing just prior to the financial crisis. The key difference is that this time, the funding pressure arises from the need to finance Treasury securities, rather than illiquid securities.

\section{FX swap exposure in the bank trading book}

Figure A12 plots the foreign currency funding gap for the four major currencies, and our estimated FX swap exposure in the bank's trading book based on information included in the FR Y-14 data. We can observe that a positive foreign currency funding gap in euros, yen and sterling is indeed matched by a short position in the foreign currency and a long

position in dollars in the FX swap market. Since the FR Y-14 data only capture FX swap exposure in the trading book, it is not surprising that these exposures are lower than the overall foreign currency funding gap. In the case of the euro, the correlation between the overall euro funding gap and the estimated short-euro-long-dollar FX swap position in the trading book is about $70 \%$. 
Figure A1: Comparison of FR 2052a and FR Y-9C
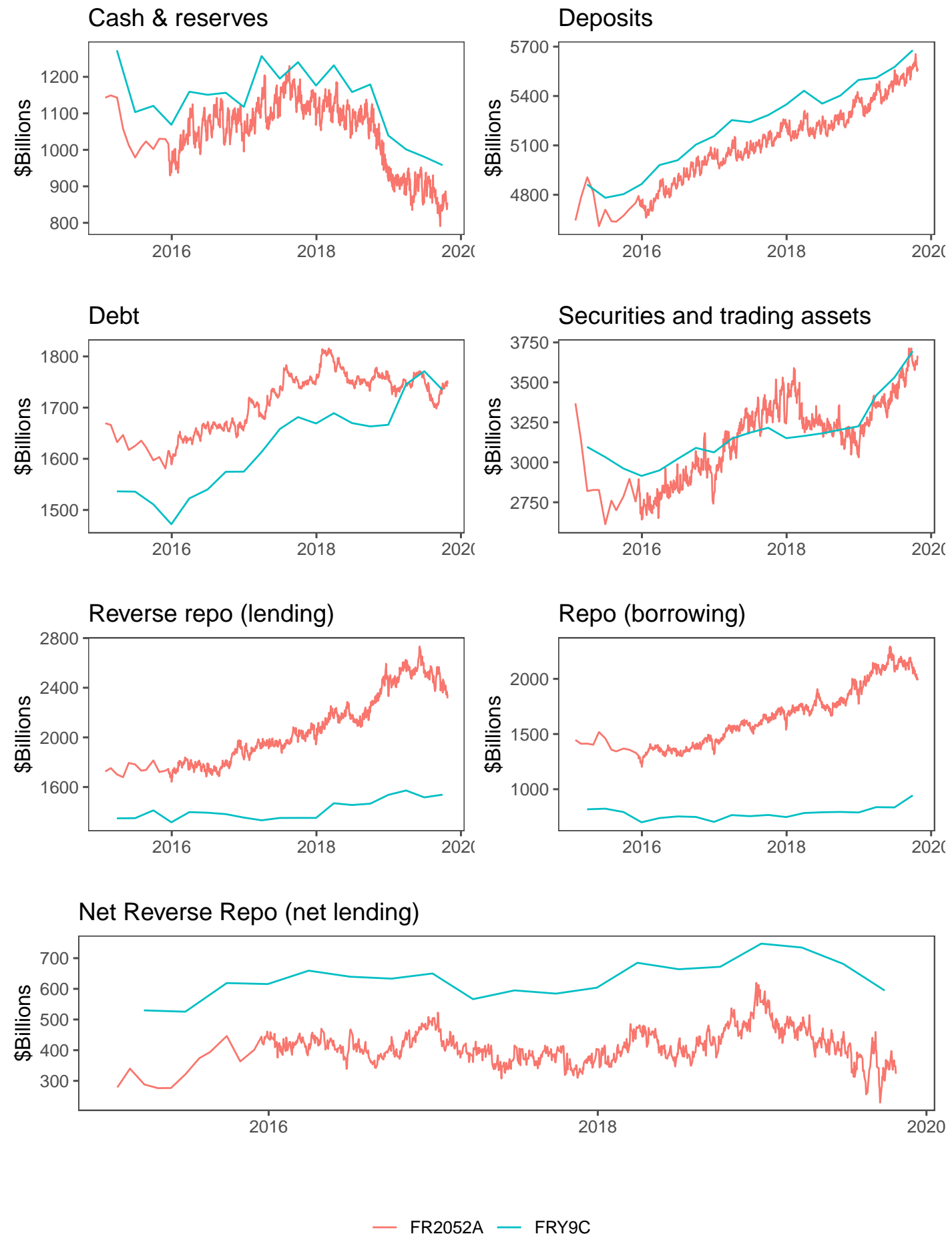

Notes: This figure provides a comparison between the balance sheet items constructed from various inflow and outflow product categories in FR 2052a and the reported balance sheet items in FR Y9-C. 
Figure A2: Fluctuations in the Treasury General Account Balance

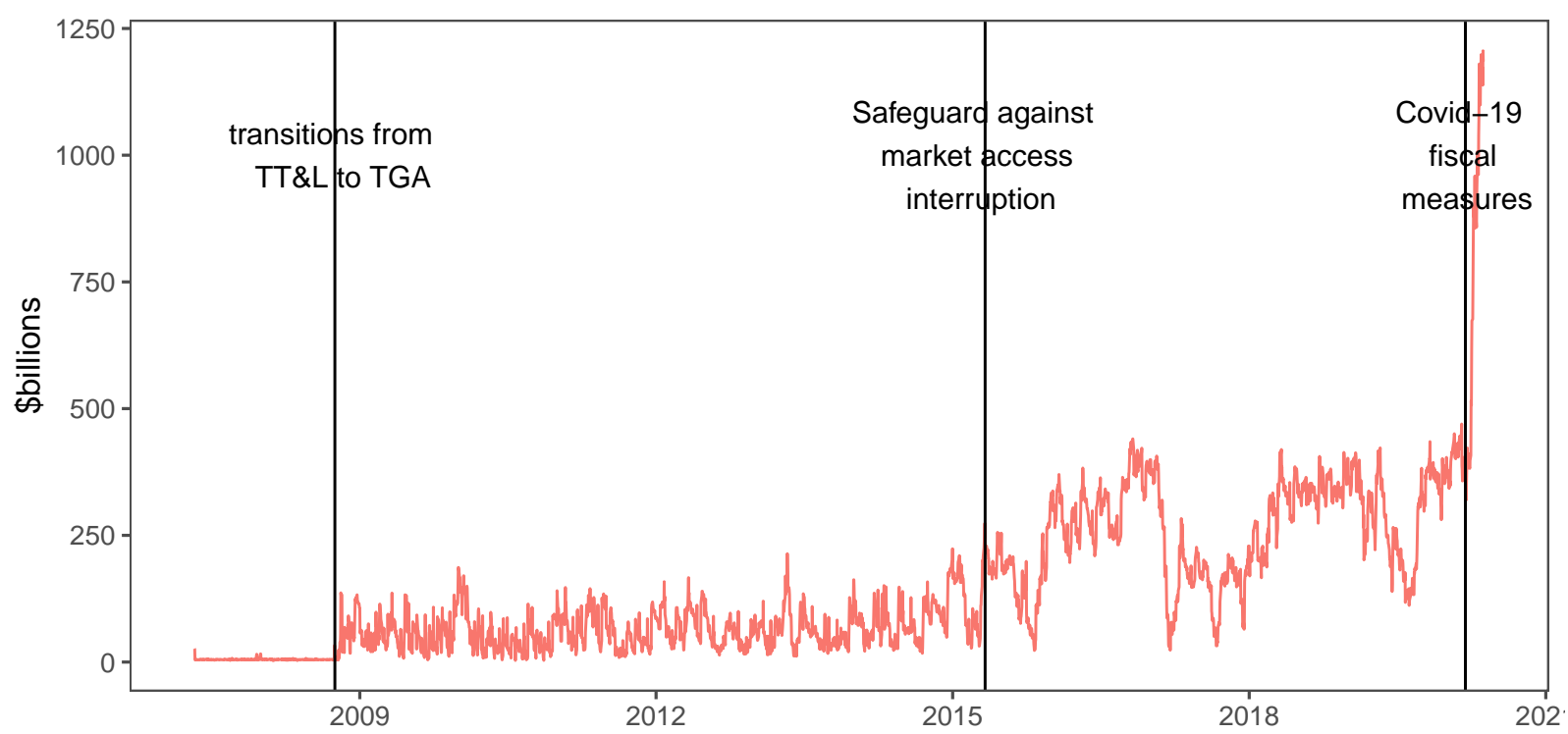

Notes: This figure shows time series of the Treasury General Account (TGA) balance. Prior to 2009, the U.S. Treasury they held most of its balances in commercial banks through the Treasury Tax and Loan Program. In May 2015, the Treasury expanded its TGA balance to protect against a potential interruption in market access. In March 2020, Increased fiscal spending relating to the COVID-19 pandemic further prompted large increase in the TGA account. 
Figure A3: Period-end short-term intermediation spreads
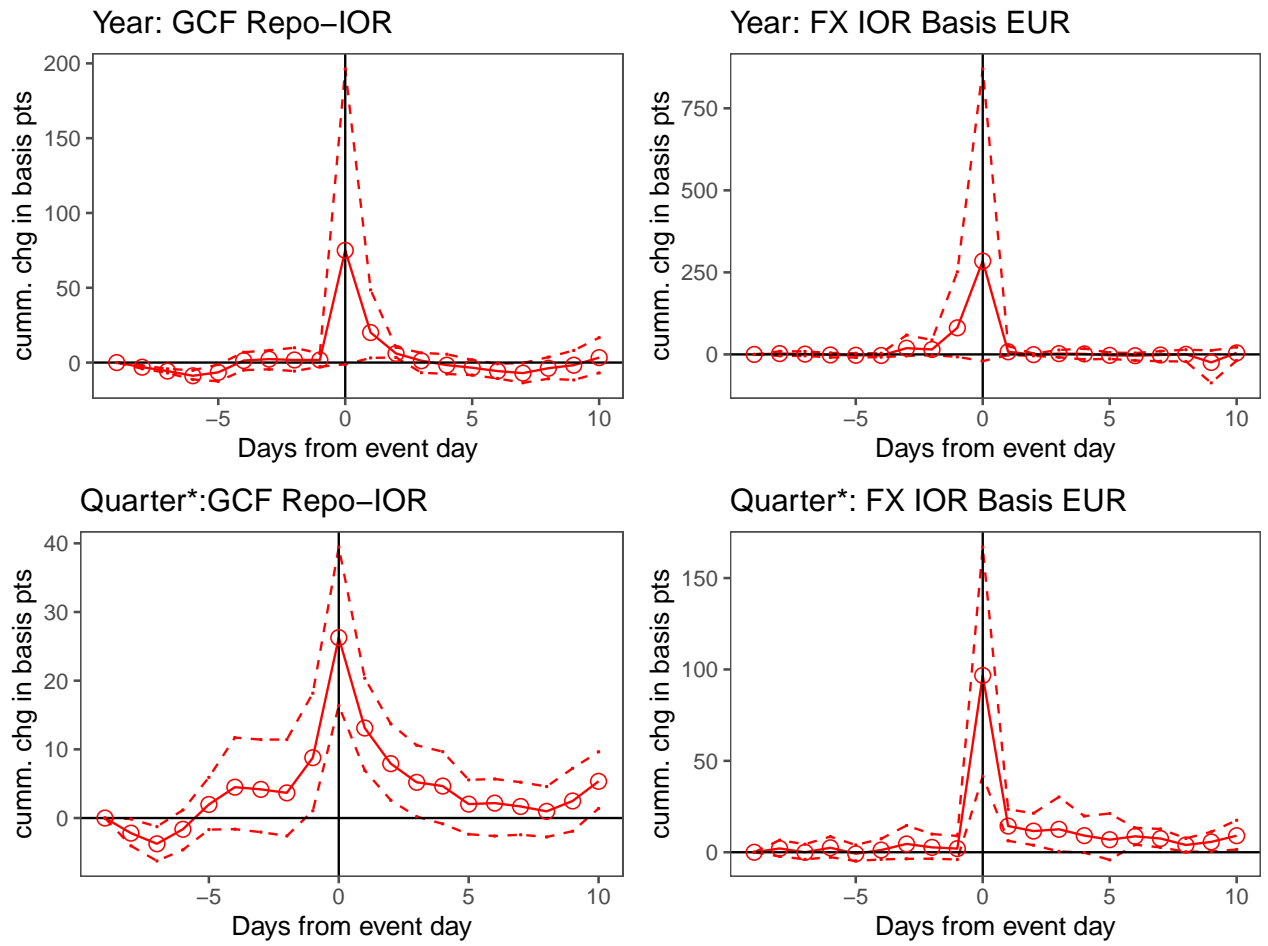

Month*:GCF Repo-IOR

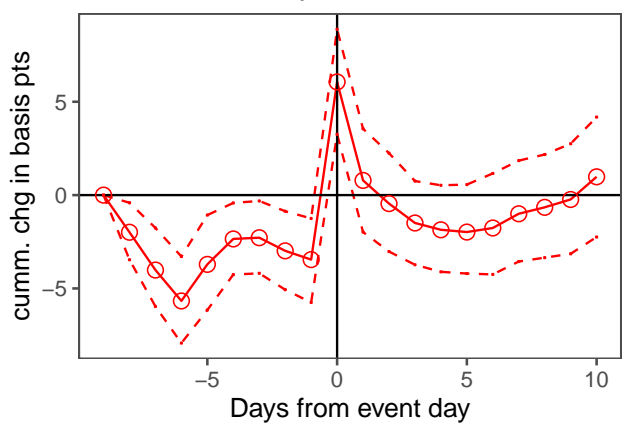

Month*: FX IOR basis EUR

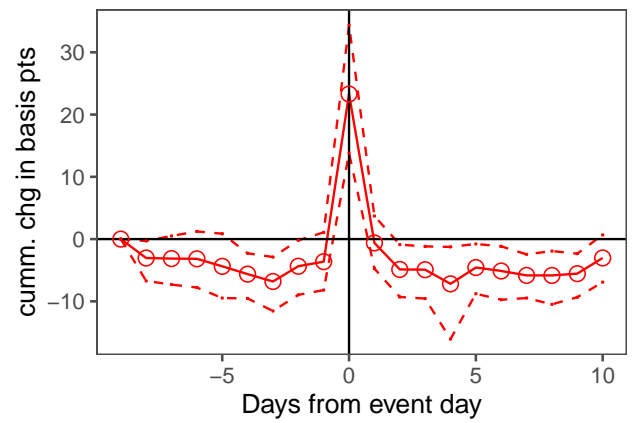

Notes: This figure shows the period-end effects on short-term funding spreads. The left column shows the spread between the GCF repo rate and the interest on reserve (IOR) at the Federal Reserve. The right column shows the EUR overnight FX IOR basis, measured as the spread of the implied dollar funding rate by swapping the ECB deposit rate minus the Fed IOR. The sample period is from December 2015 to September 2019. Quarter-ends refer to quarter-ends that are not year-ends. Month-ends refer to month-ends that are not quarter-ends. The dotted lines denote the $95 \%$ confidence interval with bootstrapped standard errors. 
Figure A4: U.S. GSIBs' liquidity provision around year-ends
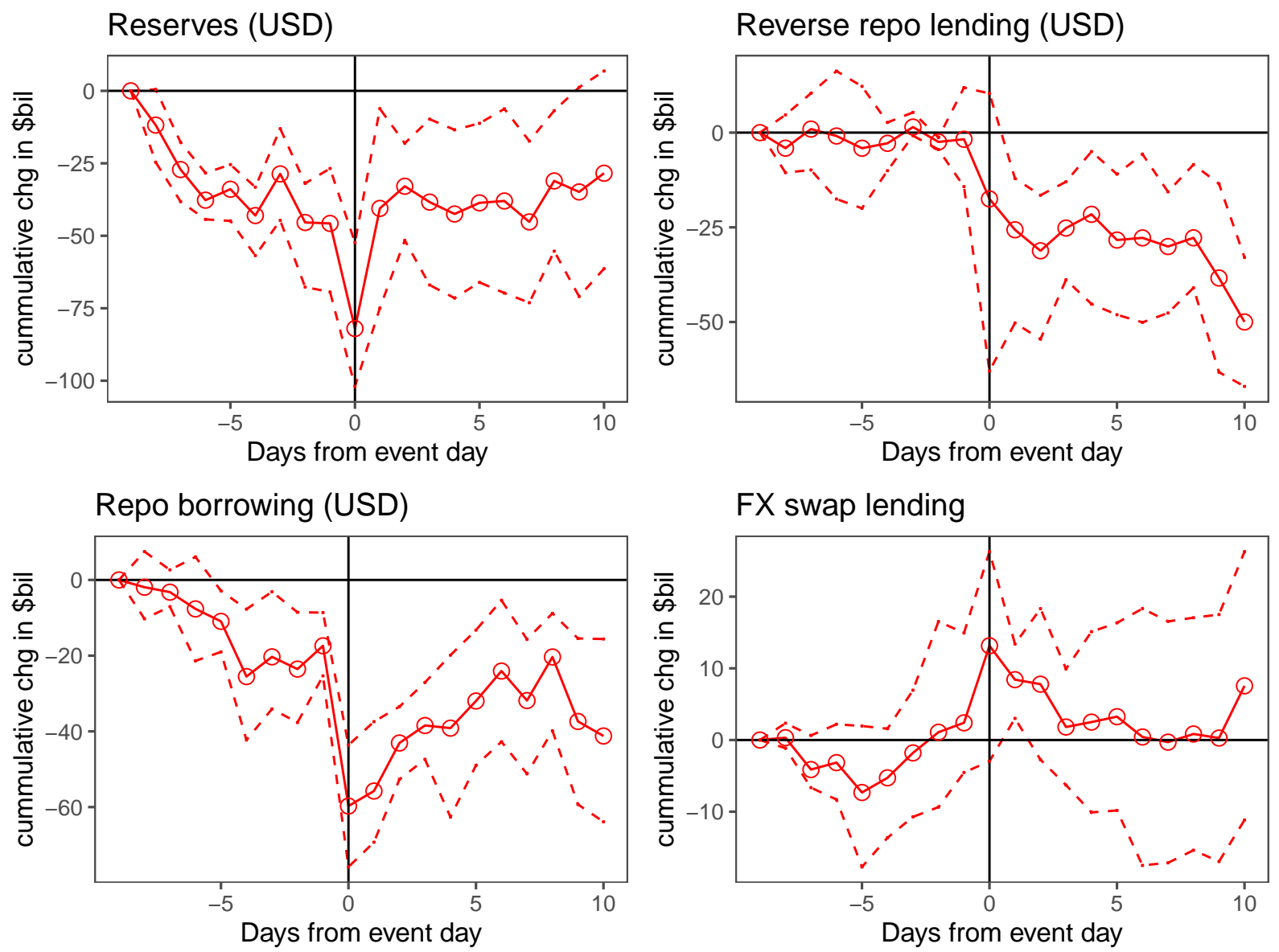

Notes: This figure shows year-end changes in U.S. GSIBs' dollar reserves, reverse repo lending, repo borrowing, and FX swap lending. The discussions of these liquidity measures are provided in Section 3. The dotted lines denote the $95 \%$ confidence interval with bootstrapped standard errors. 
Figure A5: U.S. GSIBs' liquidity provision around month-ends
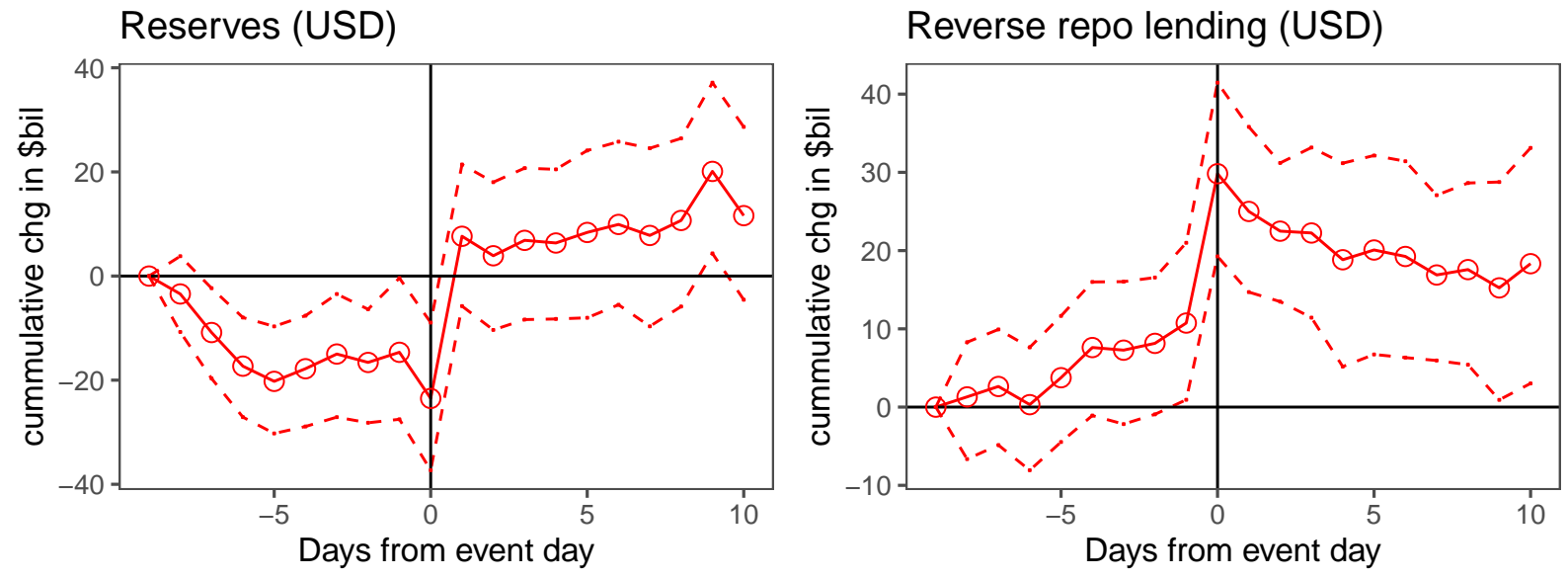

Repo borrowing (USD)

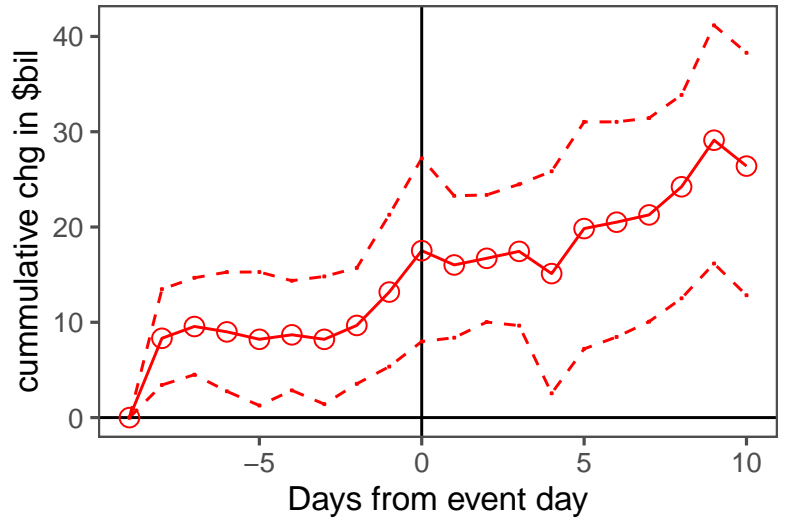

FX swap lending

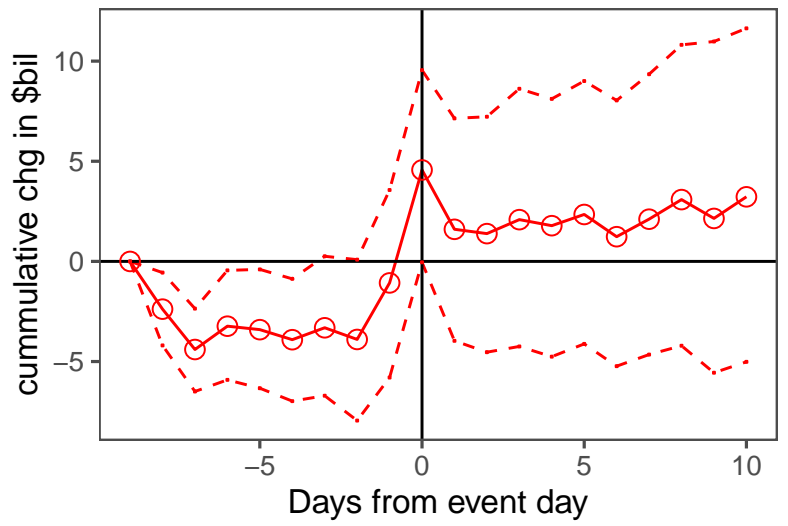

Notes: This figure shows month-end changes in U.S. GSIBs' dollar reserves, reverse repo lending, repo borrowing, and FX swap lending. The discussions of these liquidity measures are provided in Section 3. Month-ends are defined as month-ends that do not coincide quarter-ends. The dotted lines denote the $95 \%$ confidence interval with bootstrapped standard errors. 
Figure A6: Foreign banks' liquidity provision around quarter-ends
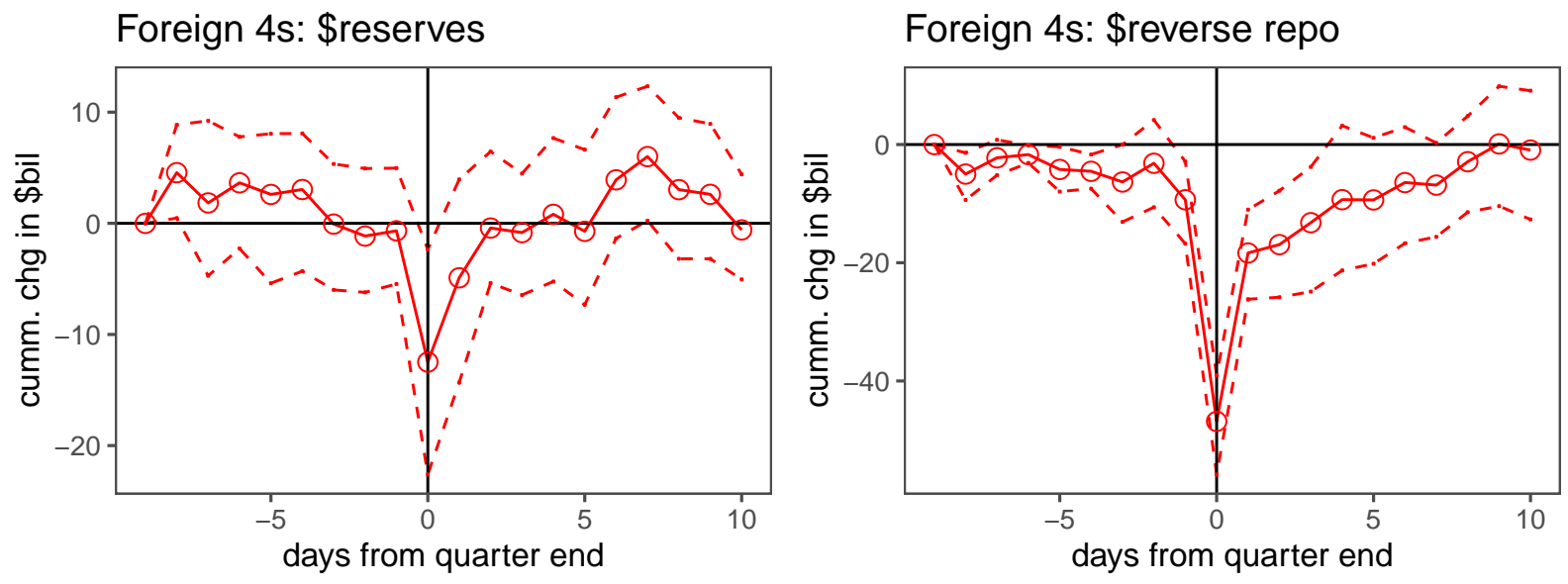

Foreign 4s: \$repo

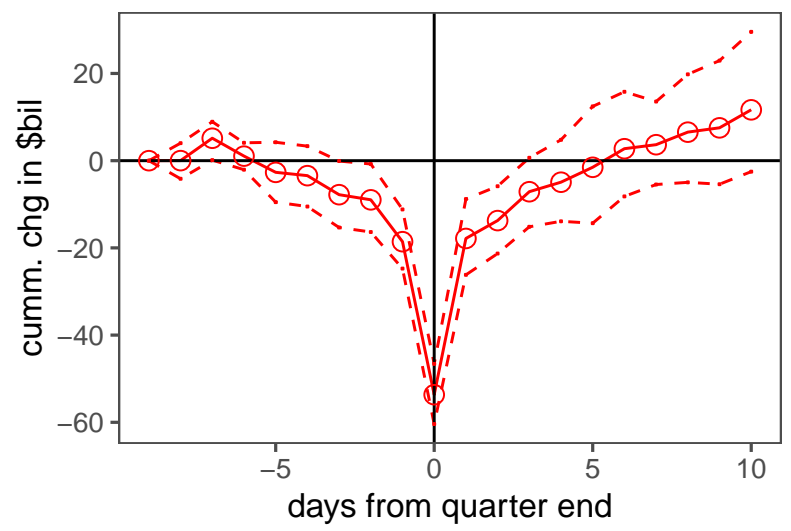

Foreign 4s: \$NRRP

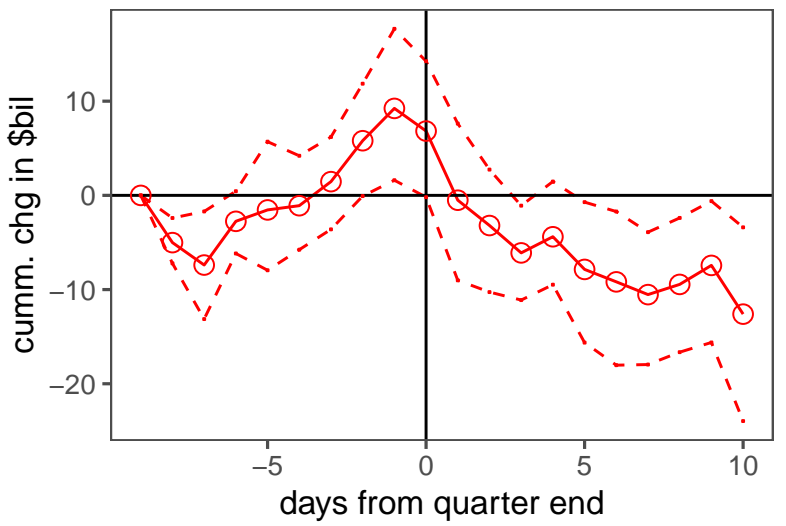

Notes: This figure shows quarter-end changes in foreign banks' dollar reserves, reverse repo lending, repo borrowing, and net reverse repo lending. The positions are aggregated across four foreign banking offices in the U.S. with daily reporting requirements for FR2052a. The discussions of these liquidity measures are provided in Section 3. The dotted lines denote the $95 \%$ confidence interval with bootstrapped standard errors. 
Figure A7: Evolution of the Federal Reserve Balance Sheet Post-GFC

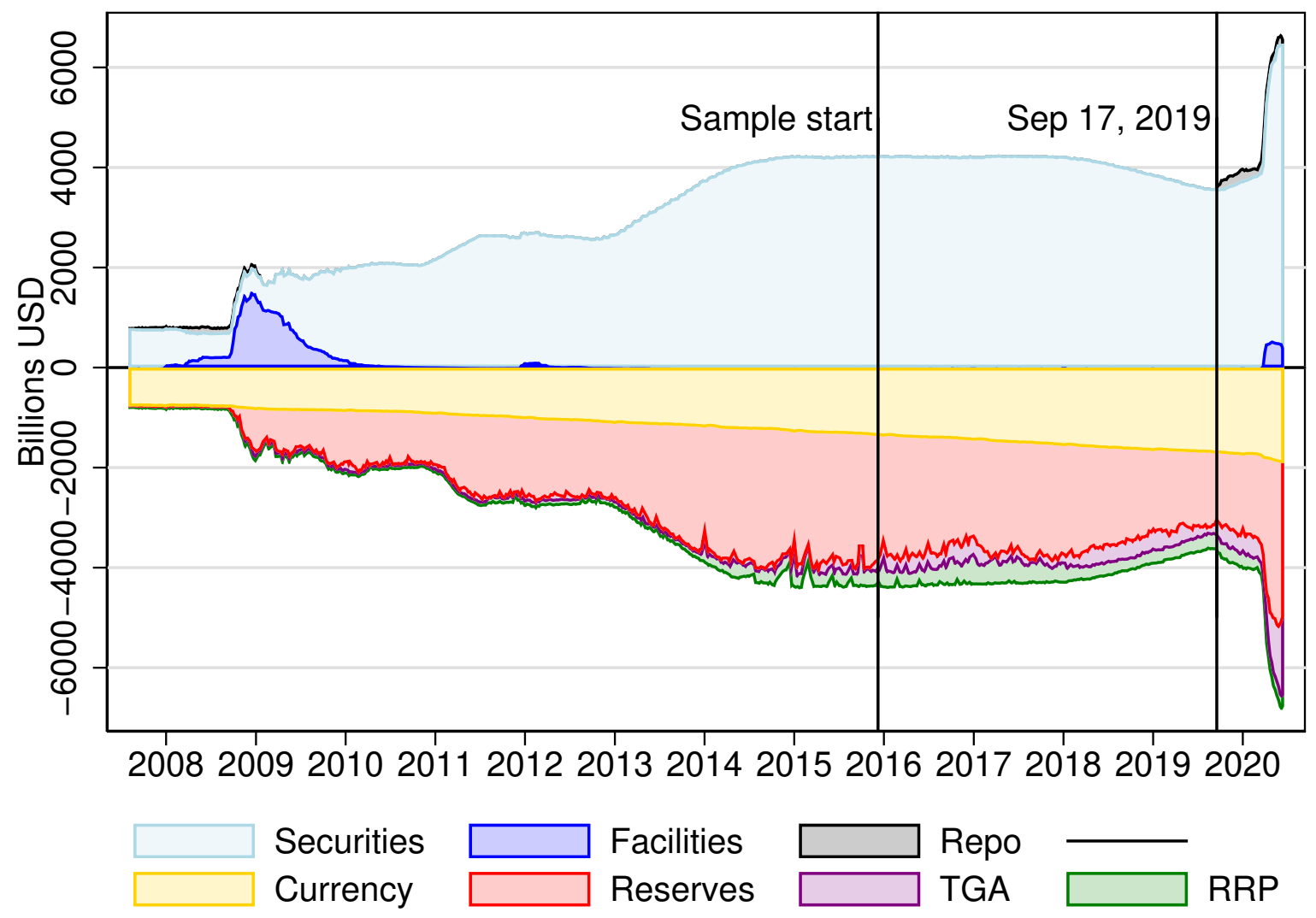

Notes: This figure plots major assets and liability items of the Federal Reserve postGFC. "Securities" refers to outright securities holdings, "Facilities" denotes liquidity facility, including central bank swap lines; "Repo" denotes the repo facility; "Currency" denotes currency in circulation; "Reserves" denotes total bank reserves; "TGA" denotes the Treasury general account; and "RRP" denotes the reverse repo facility. 
Figure A8: Dollar Funding Spreads Since September 2019

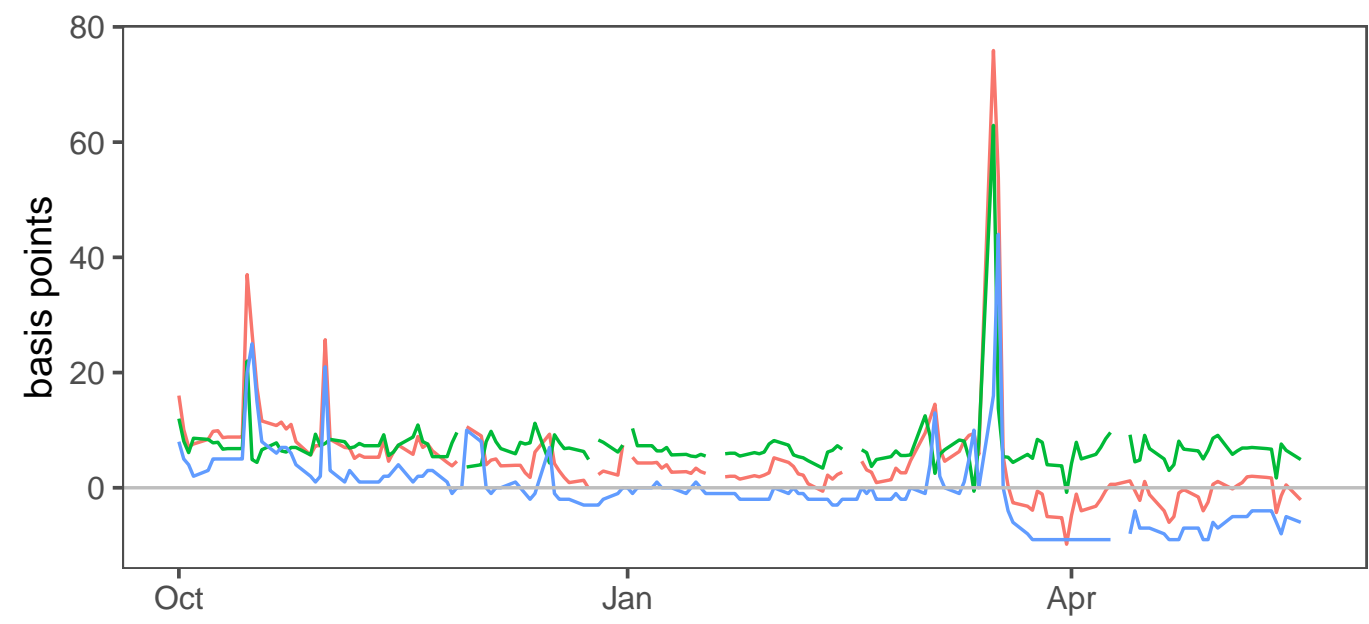

- GCF repo - IOR - GCF repo - Triparty GC repo - SOFR - IOR

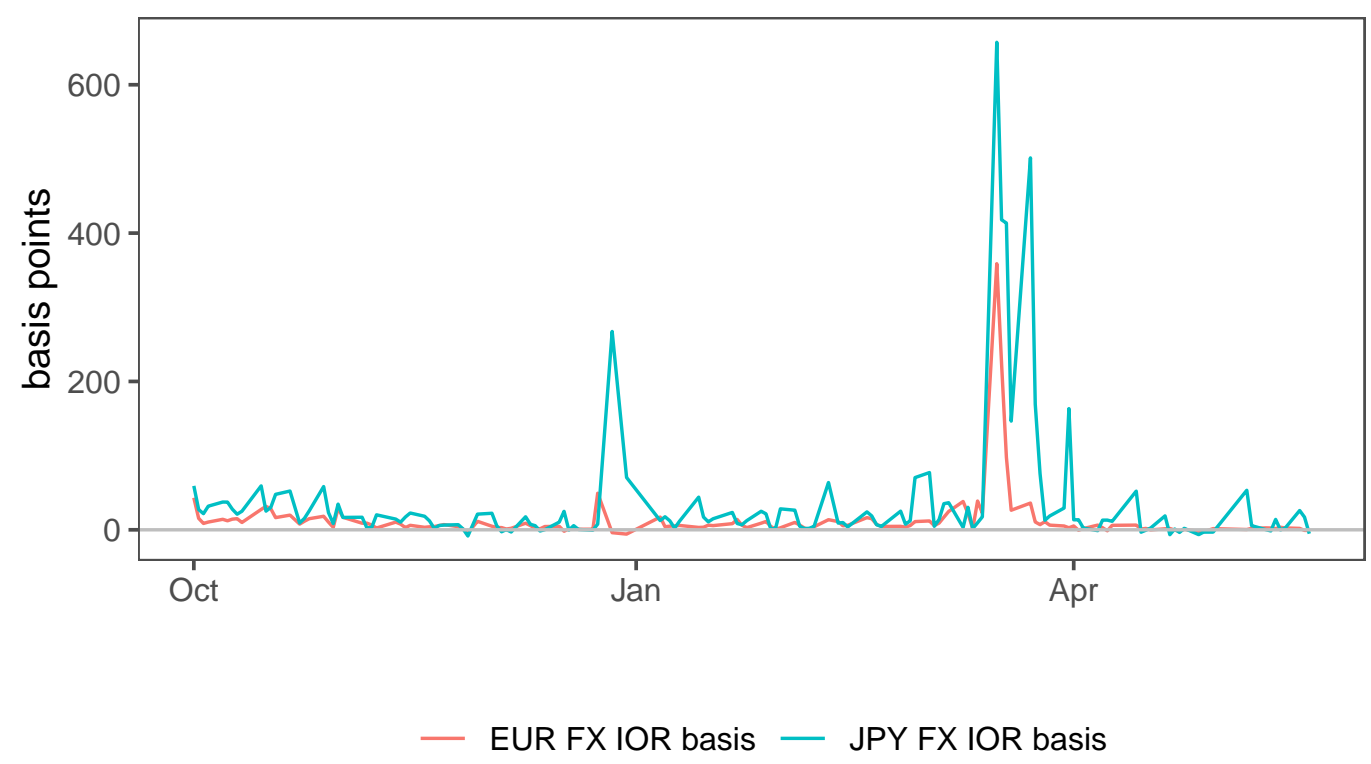

Notes: This figure shows the funding spreads since post the repo rate spike in September 2019. In the top panel, we plot the spread between the GCF general collateral Treasury repo rate and interest on excess reserve (IOR) at the Federal Reserve ("GCF repo-IOR"), the spread between the GCF and Triparty Treasury general collateral repo spread ("GCF Repo - Triparty GC Repo Spread"), and the spreaad between the Secured Overnight Financing Rate (SOFR) and the IOR ("SOFR-IOR"). In the bottom panel, we plot the spread of the implied dollar funding rate by swapping the ECB deposit rate over the Fed IOR ("EUR FX IOR basis"), and the spread of the implied dollar funding rate by swapping the BOJ deposit rate over the Fed IOR ("JPY FX IOR basis"). 
Figure A9: Broker-dealer dollar net reverse repo

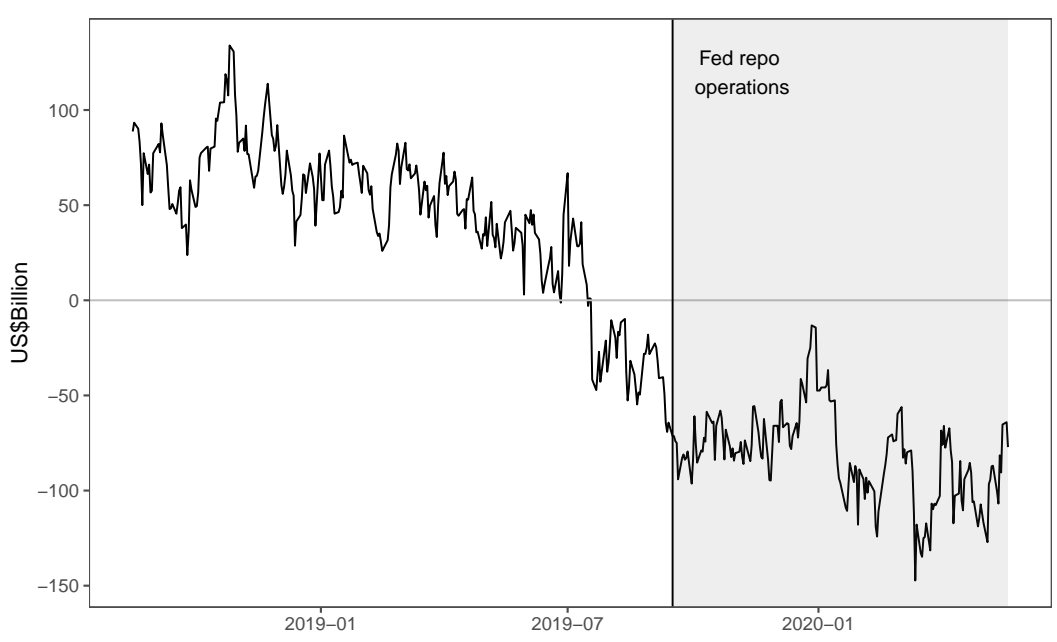

Notes: This figure shows the net reverse repo position (reverse repos minus repos) denominated in dollars for the broker-dealer entities of U.S. GSIBs in our sample. The shaded area denotes the period since the Fed introduced the repo facility on September 17, 2019.

Figure A10: Prime dealers treasury holdings

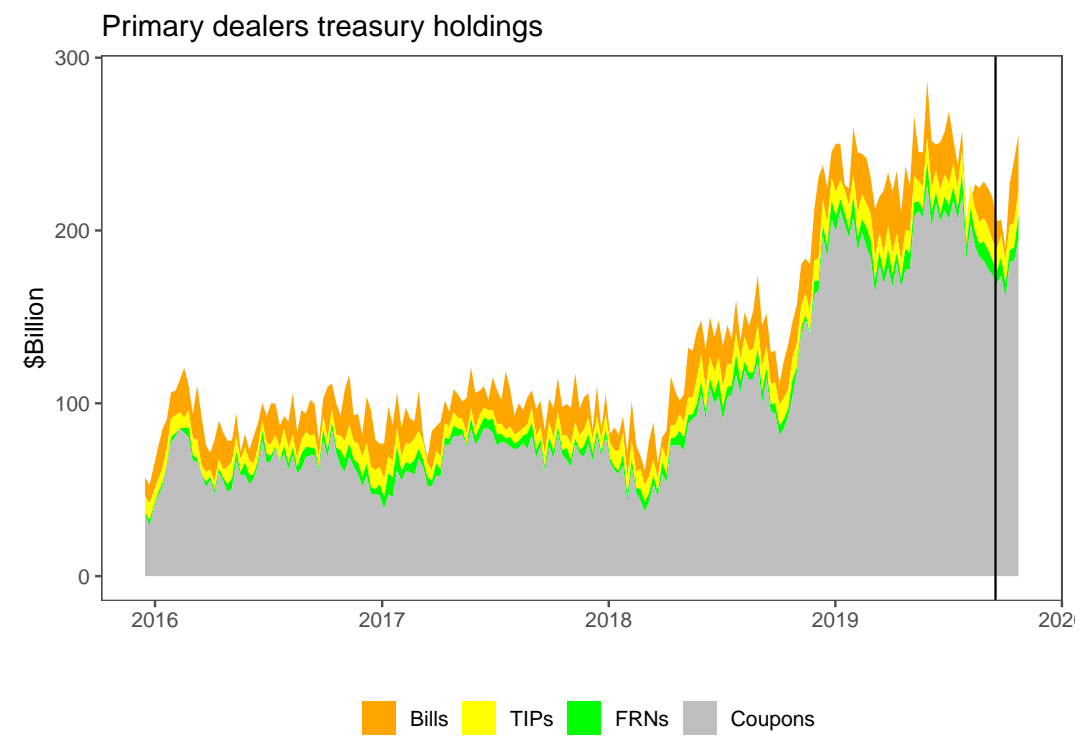

Notes: This figure shows the net Treasury holdings for all prime dealers (including primary dealers within our sample U.S. GSIBs and all other primary dealers). The data is from weekly public release of FR 2004 filings. 
Figure A11: Broker-dealer dollar net reverse repo by collateral and maturity

(A) Collateral breakdown

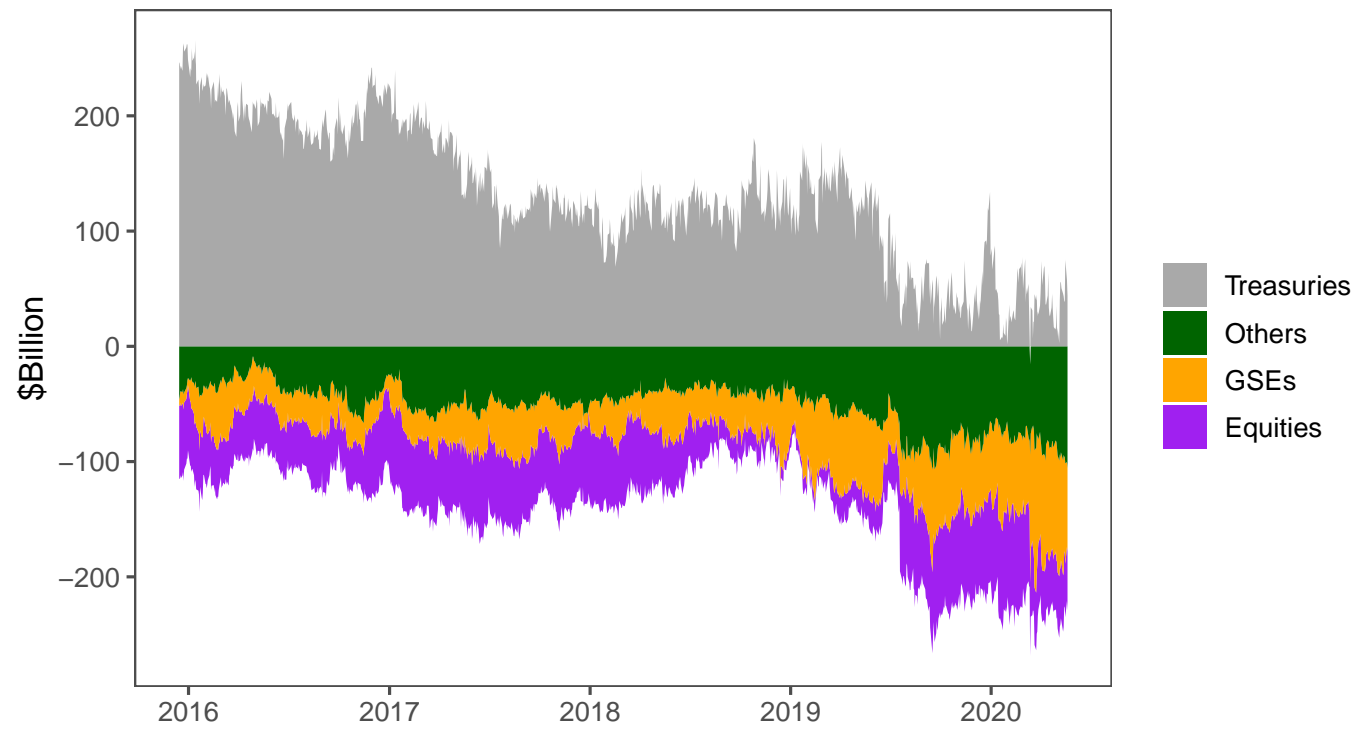

(B) Maturity breakdown:

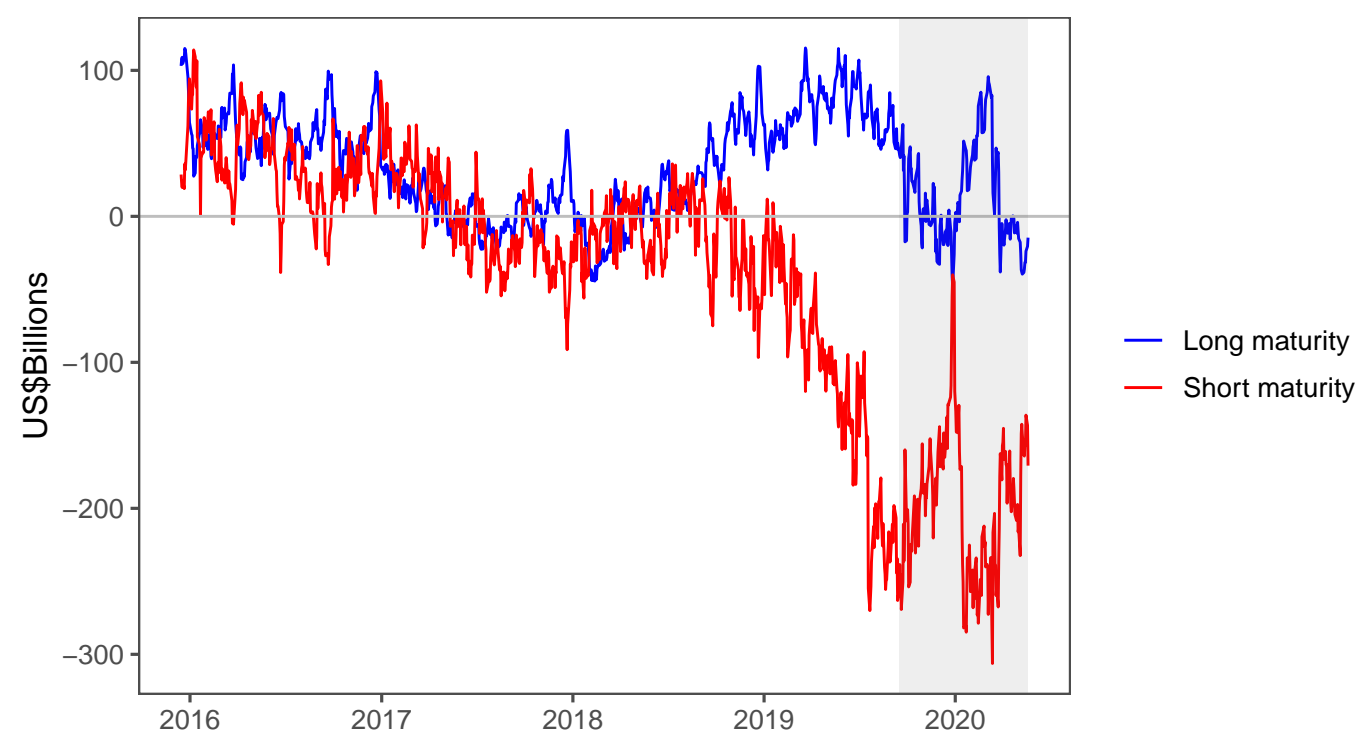

Notes: Panel (A) shows collateral breakdown of the net reverse repo position for the broker-dealer entities of the U.S. GSIBs. For a given collateral type, a positive number indicates that the broker-dealers are lending more than borrowing against the collateral. Panel (B) shows the maturity breakdown of the net reverse repo position for the brokerdealer entities of the U.S. GSIBs. Long-maturity refers to contracts with maturity greater than one week, and short-maturity refers to contracts with maturities of one week or less. 
Figure A12: U.S. GSIBs funding gaps by currency and FX swaps
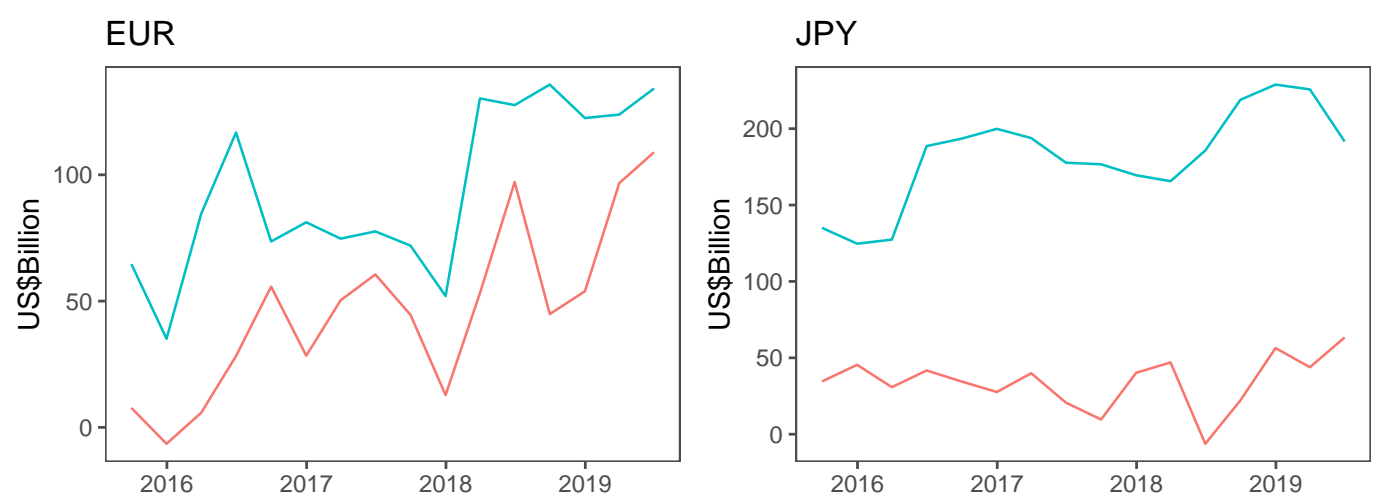

\section{GBP}
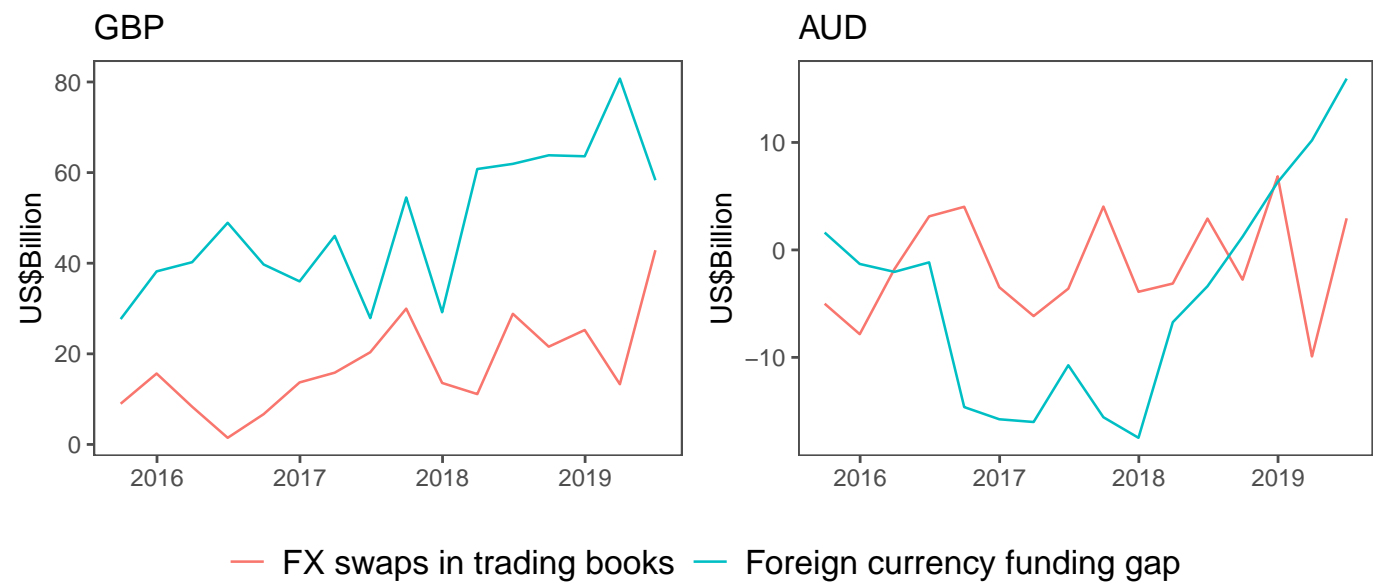

Notes: This figures shows the quarterly foreign currency funding gap as the difference between foreign currency assets and liabilities for U.S. GSIBs in blue based on the FR 2052a data for the EUR, JPY, GBP and AUD. The red line shows and the estimated FX swap exposure that goes long in dollars and short in the respective foreign currency from the Y14 data. 
Table A1: Impacts of Quarter-Ends, TGA, and SOMA Fluctuations on Intermediation Spreads: Post September 2019

\begin{tabular}{|c|c|c|c|c|c|c|}
\hline & \multicolumn{6}{|c|}{ Dependent variable: } \\
\hline & $\begin{array}{c}\Delta S O F R-I O R \\
(1)\end{array}$ & $\begin{array}{c}\triangle G C F-I O R \\
(2)\end{array}$ & $\begin{array}{c}\Delta T G C R-I O R \\
(3)\end{array}$ & $\begin{array}{c}\Delta G C F-T G C R \\
(4)\end{array}$ & $\begin{array}{c}\Delta E U R I O R \\
(5)\end{array}$ & $\begin{array}{c}\triangle J P Y I O R \\
(6)\end{array}$ \\
\hline$Q$ start $_{t}$ & $\begin{array}{l}-14.300 \\
(12.500)\end{array}$ & $\begin{array}{l}-12.400 \\
(13.700)\end{array}$ & $\begin{array}{l}-0.172 \\
(0.131)\end{array}$ & $\begin{array}{c}4.870^{* * *} \\
(1.360)\end{array}$ & $\begin{array}{l}-1.440 \\
(9.460)\end{array}$ & $\begin{array}{l}-29.400 \\
(42.500)\end{array}$ \\
\hline $\operatorname{Qend}_{t}$ & $\begin{array}{l}-1.650 \\
(1.970)\end{array}$ & $\begin{array}{l}-3.680 \\
(6.380)\end{array}$ & $\begin{array}{l}-0.001 \\
(0.029)\end{array}$ & $\begin{array}{l}-3.600 \\
(3.790)\end{array}$ & $\begin{array}{c}6.690 \\
(21.700)\end{array}$ & $\begin{array}{c}138.000^{* *} \\
(58.500)\end{array}$ \\
\hline$\Delta T G A_{t}$ & $\begin{array}{c}0.045^{* * *} \\
(0.017)\end{array}$ & $\begin{array}{l}0.086^{* *} \\
(0.036)\end{array}$ & $\begin{array}{l}0.0004^{* *} \\
(0.0002)\end{array}$ & $\begin{array}{c}0.046 \\
(0.028)\end{array}$ & $\begin{array}{c}0.223 \\
(0.177)\end{array}$ & $\begin{array}{c}0.533 \\
(0.367)\end{array}$ \\
\hline$\Delta S O M A_{t}$ & $\begin{array}{l}-0.010 \\
(0.036)\end{array}$ & $\begin{array}{l}-0.027 \\
(0.042)\end{array}$ & $\begin{array}{l}-0.0001 \\
(0.0004)\end{array}$ & $\begin{array}{l}-0.023 \\
(0.032)\end{array}$ & $\begin{array}{l}-0.141 \\
(0.148)\end{array}$ & $\begin{array}{l}-0.955^{*} \\
(0.526)\end{array}$ \\
\hline Constant & $\begin{array}{l}-0.213 \\
(0.435)\end{array}$ & $\begin{array}{l}-0.241 \\
(0.482)\end{array}$ & $\begin{array}{l}-0.002 \\
(0.005)\end{array}$ & $\begin{array}{l}-0.035 \\
(0.311)\end{array}$ & $\begin{array}{c}0.512 \\
(1.250)\end{array}$ & $\begin{array}{c}6.600 \\
(5.090)\end{array}$ \\
\hline $\mathrm{N}$ & 155 & 157 & 155 & 155 & 150 & 134 \\
\hline $\mathrm{R}^{2}$ & 0.153 & 0.154 & 0.180 & 0.055 & 0.051 & 0.110 \\
\hline
\end{tabular}

Notes: This table shows the post-September 2019 regression results of the quarter-end dummies, TGA and SOMA fluctuations on daily changes in various intermediation spreads. The dependent variables are as follows: daily changes in the SOFR-IOR spread (Column 1), daily changes in the GCF repo-IOR spread (Column 2), daily changes in the Triparty (TGCR) repo-IOR spread (Column 3), daily changes in the GCF-TGCR repo spread (Column 4), daily changes spread between the overnight implied dollar rate by swapping the ECB deposit rate and the Fed IOR (Column 5), and daily changes in the spread between the overnight implied dollar rate by swapping the BOJ deposit rate and the Fed IOR (Column 6). The independent variables are as follows: $Q e n d_{t}$, a dummy variable indicating the last business day of the quarter; $Q$ start $_{t}$ a dummy variable indicating the first business day of the quarter; $\triangle T G A$, daily changes in the TGA balance; $\triangle S O M A$, daily changes in the Fed portfolio holdings of Treasury securities. The sample period is from October 1, 2019 to May 18, 2020. Robust standard errors are reported in the parentheses with significance levels denoted by ${ }^{*} \mathrm{p}<0.1 ;{ }^{* *} \mathrm{p}<0.05 ;{ }^{* * *} \mathrm{p}<0.01$. 
Table A2: Impact of Quarter-Ends, TGA, and SOMA Fluctuations on Intermediation Activities: Post September 2019

\begin{tabular}{|c|c|c|c|c|c|c|c|}
\hline & \multicolumn{7}{|c|}{ Dependent variable: } \\
\hline & $\begin{array}{c}\Delta R S V_{t} \\
(1)\end{array}$ & $\begin{array}{c}\Delta R R P_{t} \\
(2) \\
\end{array}$ & $\begin{array}{c}\Delta R P_{t} \\
(3) \\
\end{array}$ & $\begin{array}{c}\Delta N R R P_{t} \\
(4) \\
\end{array}$ & $\begin{array}{c}\Delta F X_{t} \\
(5)\end{array}$ & $\begin{array}{c}\Delta \text { Deposit }_{t} \\
(6)\end{array}$ & $\begin{array}{c}\Delta T S Y_{t}^{\text {outright }} \\
(7) \\
\end{array}$ \\
\hline Qend $_{t}$ & $\begin{array}{c}-43.700^{* * *} \\
(12.100)\end{array}$ & $\begin{array}{l}-10.900 \\
(33.800)\end{array}$ & $\begin{array}{c}-29.200^{* * *} \\
(6.430)\end{array}$ & $\begin{array}{c}18.300 \\
(27.800)\end{array}$ & $\begin{array}{c}8.600^{* * *} \\
(2.430)\end{array}$ & $\begin{array}{c}-40.000^{* * *} \\
(4.800)\end{array}$ & $\begin{array}{l}-5.210 \\
(6.270)\end{array}$ \\
\hline$Q_{\text {start }}$ & $\begin{array}{c}49.000^{* * *} \\
(8.500)\end{array}$ & $\begin{array}{l}-28.700 \\
(21.300)\end{array}$ & $\begin{array}{c}-24.500^{* * *} \\
(7.370)\end{array}$ & $\begin{array}{c}-4.270 \\
(18.100)\end{array}$ & $\begin{array}{l}-6.510 \\
(6.060)\end{array}$ & $\begin{array}{c}16.500 \\
(14.400)\end{array}$ & $\begin{array}{l}10.500^{*} \\
(5.820)\end{array}$ \\
\hline$\Delta T G A_{t}$ & $\begin{array}{c}-0.293^{* * *} \\
(0.075)\end{array}$ & $\begin{array}{l}0.109^{* *} \\
(0.045)\end{array}$ & $\begin{array}{c}0.010 \\
(0.032)\end{array}$ & $\begin{array}{l}0.100^{* *} \\
(0.048)\end{array}$ & $\begin{array}{c}0.070^{* * *} \\
(0.022)\end{array}$ & $\begin{array}{l}-0.053 \\
(0.078)\end{array}$ & $\begin{array}{c}0.035 \\
(0.026)\end{array}$ \\
\hline$\Delta S O M A_{t}$ & $\begin{array}{c}0.511^{* * *} \\
(0.131)\end{array}$ & $\begin{array}{c}-0.190^{* *} \\
(0.078)\end{array}$ & $\begin{array}{c}-0.105^{* *} \\
(0.051)\end{array}$ & $\begin{array}{l}-0.085 \\
(0.069)\end{array}$ & $\begin{array}{l}-0.019 \\
(0.044)\end{array}$ & $\begin{array}{c}0.305^{* * *} \\
(0.111)\end{array}$ & $\begin{array}{l}-0.068 \\
(0.043)\end{array}$ \\
\hline Constant & $\begin{array}{l}-0.191 \\
(2.230)\end{array}$ & $\begin{array}{c}1.770 \\
(1.700)\end{array}$ & $\begin{array}{c}1.350 \\
(1.400)\end{array}$ & $\begin{array}{c}0.421 \\
(1.690)\end{array}$ & $\begin{array}{c}0.029 \\
(0.851)\end{array}$ & $\begin{array}{c}2.990 \\
(2.040)\end{array}$ & $\begin{array}{c}0.788 \\
(0.710)\end{array}$ \\
\hline $\begin{array}{l}\mathrm{N} \\
\mathrm{R}^{2}\end{array}$ & $\begin{array}{c}157 \\
0.301\end{array}$ & $\begin{array}{c}157 \\
0.123\end{array}$ & $\begin{array}{c}157 \\
0.123\end{array}$ & $\begin{array}{c}157 \\
0.060\end{array}$ & $\begin{array}{c}157 \\
0.101\end{array}$ & $\begin{array}{c}157 \\
0.101\end{array}$ & $\begin{array}{c}157 \\
0.061\end{array}$ \\
\hline
\end{tabular}

Notes: This table shows the post-Septmeber 2019 regression results of one-day changes in the TGA account $\left(\Delta T G A_{t}\right)$, net SOMA purchase $\left(\triangle S O M A_{t}\right)$, and quarter-end $\left(Q e n d_{t}\right)$ and quarter-starts $\left(Q_{\text {start }}\right)$ on daily changes in the U.S. GSIBs intermediation activities. The dependent variables are as follows: changes in reserves (Column 1), changes in dollar reverse repos (Column 2), changes in dollar repos (Column 3), changes in net dollar reverse repos, or the difference between reverse repos and repos in dollars (Column 4), changes in dollar lending in the FX swap market (Column 5), changes in dollar deposits (Column 6), and changes in outright Treasury holdings (Column 7). Qend is a dummy variable indicating the last business day of the quarter, and Q start $_{t}$ is a dummy variable indicating the first business day of the quarter. The sample period is from October 1, 2019 to May 18, 2020. Robust standard errors are reported in parentheses with significance levels denoted by ${ }^{*} \mathrm{p}<0.1 ;{ }^{* *} \mathrm{p}<0.05 ;{ }^{* * *} \mathrm{p}<0.01$. 
Table A3: Comparisons of FX Lending Measures

\begin{tabular}{|c|c|c|c|c|c|c|}
\hline & \multicolumn{6}{|c|}{ Dependent variable: } \\
\hline & $\begin{array}{c}\Delta F X_{t} \\
(1)\end{array}$ & $\begin{array}{c}\Delta F X_{t}^{\text {all }} \\
(2)\end{array}$ & $\begin{array}{c}\Delta F X_{t} \\
(3)\end{array}$ & $\begin{array}{c}\Delta F X_{t}^{\text {all }} \\
(4)\end{array}$ & $\begin{array}{c}\Delta F X_{t} \\
(5)\end{array}$ & $\begin{array}{c}\Delta F X_{t}^{\text {all }} \\
(6)\end{array}$ \\
\hline$\Delta T G A_{t}$ & $\begin{array}{c}0.040^{* * *} \\
(0.013)\end{array}$ & $\begin{array}{l}0.030^{* *} \\
(0.012)\end{array}$ & $\begin{array}{c}0.031^{* * *} \\
(0.012)\end{array}$ & $\begin{array}{c}0.021^{*} \\
(0.012)\end{array}$ & & \\
\hline$\Delta T G A_{t}^{\text {Other }}$ & & & & & $\begin{array}{c}0.045^{* * *} \\
(0.015)\end{array}$ & $\begin{array}{l}0.029^{* *} \\
(0.014)\end{array}$ \\
\hline$\Delta T S Y_{t}^{\text {Issuance }}$ & & & & & $\begin{array}{c}0.004 \\
(0.018)\end{array}$ & $\begin{array}{c}0.007 \\
(0.019)\end{array}$ \\
\hline$\Delta S O M A_{t}$ & & & $\begin{array}{l}-0.178 \\
(0.116)\end{array}$ & $\begin{array}{c}-0.197^{*} \\
(0.113)\end{array}$ & $\begin{array}{c}-0.217^{*} \\
(0.118)\end{array}$ & $\begin{array}{c}-0.217^{*} \\
(0.115)\end{array}$ \\
\hline Qend $_{t}$ & & & $\begin{array}{c}10.600^{* * *} \\
(3.150)\end{array}$ & $\begin{array}{c}8.480^{* * *} \\
(2.360)\end{array}$ & $\begin{array}{c}11.400^{* * *} \\
(3.170)\end{array}$ & $\begin{array}{c}8.900^{* * *} \\
(2.420)\end{array}$ \\
\hline Qstart $_{t}$ & & & $\begin{array}{c}-8.420^{* *} \\
(3.270)\end{array}$ & $\begin{array}{c}-8.640^{* * *} \\
(2.700)\end{array}$ & $\begin{array}{c}-8.270^{* *} \\
(3.290)\end{array}$ & $\begin{array}{c}-8.560^{* * *} \\
(2.710)\end{array}$ \\
\hline Constant & $\begin{array}{c}0.191 \\
(0.238)\end{array}$ & $\begin{array}{c}0.181 \\
(0.242)\end{array}$ & $\begin{array}{c}0.082 \\
(0.229)\end{array}$ & $\begin{array}{c}0.103 \\
(0.239)\end{array}$ & $\begin{array}{c}0.188 \\
(0.233)\end{array}$ & $\begin{array}{c}0.157 \\
(0.239)\end{array}$ \\
\hline $\mathrm{N}$ & 932 & 932 & 932 & 932 & 932 & 932 \\
\hline $\mathrm{R}^{2}$ & 0.012 & 0.007 & 0.067 & 0.049 & 0.070 & 0.050 \\
\hline
\end{tabular}

Notes: This table shows regression results of one-day changes in the TGA account $\left(\Delta T G A_{t}\right)$, net SOMA purchase $\left(\Delta S O M A_{t}\right)$, and quarter-end $\left(\right.$ Qend $\left._{t}\right)$ and quarter-starts $\left(\right.$ start $\left._{t}\right)$ on daily changes in two measures of dollar lending in the FX swap market. The benchmark measure $\Delta F X_{t}$ is defined by Equation 1. The alternative measure $\Delta F X_{t}^{\text {all }}$ is defined by Equation 2. Column 5 and 6 shows additional breakdown of TGA into changes in net Treasury issuance $\left(\Delta T S Y_{t}^{\text {Issue }}\right)$ and other components of $\operatorname{TGA}\left(\Delta T G A_{t}^{\text {Other }}\right)$. Robust standard errors are reported in parentheses with significance levels denoted by ${ }^{*} \mathrm{p}<0.1 ;{ }^{* *} \mathrm{p}<0.05 ;{ }^{* * *} \mathrm{p}<0.01$. 
Table A4: Impacts of Quarter-Ends, Different Components of TGA, and SOMA Fluctuations on Intermediation Spreads

\begin{tabular}{|c|c|c|c|c|c|c|}
\hline & $\begin{array}{c}(1) \\
\Delta S O F R-I O R\end{array}$ & $\begin{array}{c}(2) \\
\Delta G C F-I O R \\
\end{array}$ & $\begin{array}{c}(3) \\
\Delta T G C R-I O R \\
\end{array}$ & $\begin{array}{c}(4) \\
\Delta G C F-\Delta T G C R\end{array}$ & $\begin{array}{c}(4) \\
\Delta E U R I O R\end{array}$ & $\begin{array}{c}(5) \\
\triangle J P Y I O R\end{array}$ \\
\hline Qend $d_{t}$ & $\begin{array}{c}11.20^{* * *} \\
(2.720)\end{array}$ & $\begin{array}{c}29.19^{* *} \\
(14.21)\end{array}$ & $\begin{array}{l}7.112^{* * *} \\
(2.707)\end{array}$ & $\begin{array}{l}22.05^{*} \\
(12.01)\end{array}$ & $\begin{array}{c}146.7^{* *} \\
(60.27)\end{array}$ & $\begin{array}{c}424.8^{* * *} \\
(118.2)\end{array}$ \\
\hline Qstart $_{t}$ & $\begin{array}{c}-11.22^{* * *} \\
(3.674)\end{array}$ & $\begin{array}{c}-32.03^{* *} \\
(13.16)\end{array}$ & $\begin{array}{c}-6.524^{* *} \\
(2.580)\end{array}$ & $\begin{array}{l}-25.52^{*} \\
(14.35)\end{array}$ & $\begin{array}{l}-166.3^{*} \\
(85.24)\end{array}$ & $\begin{array}{c}-284.7^{* * *} \\
(98.02)\end{array}$ \\
\hline$\Delta T G A_{t}^{\text {Other }}$ & $\begin{array}{c}0.0255^{* *} \\
(0.0102)\end{array}$ & $\begin{array}{l}0.0506^{*} \\
(0.0259)\end{array}$ & $\begin{array}{l}0.0229 * * \\
(0.00976)\end{array}$ & $\begin{array}{c}0.0276 \\
(0.0215)\end{array}$ & $\begin{array}{c}0.404^{* * *} \\
(0.0927)\end{array}$ & $\begin{array}{c}0.544^{* * *} \\
(0.208)\end{array}$ \\
\hline$\Delta T S Y_{t}^{\text {Issue }}$ & $\begin{array}{c}0.0859 * * * \\
(0.0106)\end{array}$ & $\begin{array}{l}0.111^{* * *} \\
(0.0203)\end{array}$ & $\begin{array}{c}0.0687^{* * *} \\
(0.00949)\end{array}$ & $\begin{array}{c}0.0424^{* *} \\
(0.0166)\end{array}$ & $\begin{array}{l}-0.0218 \\
(0.0719)\end{array}$ & $\begin{array}{c}0.158 \\
(0.145)\end{array}$ \\
\hline$\Delta S O M A_{t}$ & $\begin{array}{c}-0.523^{* * *} \\
(0.152)\end{array}$ & $\begin{array}{c}-1.456^{* *} \\
(0.688)\end{array}$ & $\begin{array}{c}-0.436 * * * \\
(0.160)\end{array}$ & $\begin{array}{l}-1.019^{*} \\
(0.612)\end{array}$ & $\begin{array}{c}-3.348^{* *} \\
(1.523)\end{array}$ & $\begin{array}{c}1.338 \\
(2.391)\end{array}$ \\
\hline Constant & $\begin{array}{c}-0.391^{* * *} \\
(0.119)\end{array}$ & $\begin{array}{c}-0.738^{* * *} \\
(0.195)\end{array}$ & $\begin{array}{c}-0.313^{* * *} \\
(0.0988)\end{array}$ & $\begin{array}{c}-0.415^{* * *} \\
(0.159)\end{array}$ & $\begin{array}{c}0.643 \\
(0.651)\end{array}$ & $\begin{array}{l}-1.052 \\
(2.094)\end{array}$ \\
\hline $\begin{array}{l}N \\
R^{2}\end{array}$ & $\begin{array}{c}933 \\
0.311\end{array}$ & $\begin{array}{c}930 \\
0.288\end{array}$ & $\begin{array}{c}933 \\
0.242\end{array}$ & $\begin{array}{c}930 \\
0.198\end{array}$ & $\begin{array}{c}901 \\
0.255\end{array}$ & $\begin{array}{c}835 \\
0.378\end{array}$ \\
\hline
\end{tabular}

Notes: This table shows the regression results of the quarter-end dummies, different components of TGA fluctuations, SOMA fluctuations on daily changes in various intermediation spreads. The dependent variables are as follows: daily changes in the SOFR-IOR spread (Column 1), daily changes in the GCF repo-IOR spread (Column 2), daily changes in the Triparty (TGCR) repo-IOR spread (Column 3), daily changes in the GCF-TGCR repo spread (Column 4), daily changes spread between the overnight implied dollar rate by swapping the ECB deposit rate and the Fed IOR (Column 5), and daily changes in the spread between the overnight implied dollar rate by swapping the BOJ deposit rate and the Fed IOR (Column 6). The independent variables are as follows: $Q e n d_{t}$, a dummy variable indicating the last business day of the quarter; $Q s t a r t_{t}$ a dummy variable indicating the first business day of the quarter; $\Delta T G A_{t}^{\text {Other }}$, daily changes in TGA balance unrelated to net Treasury issuance; $\left(\Delta T S Y_{t}^{\text {Issue }}\right)$, net treasury issuance; and $\triangle S O M A$, daily changes in the Fed portfolio holdings of Treasury securities. Robust standard errors are reported in parentheses with significance levels denoted by ${ }^{*} \mathrm{p}<0.1 ;{ }^{* *} \mathrm{p}<0.05$; ${ }^{* * *} \mathrm{p}<0.01$ 
Table A5: Impacts of Quarter-Ends, Different Components of TGA, and SOMA Fluctuations on Intermediation Activities

\begin{tabular}{|c|c|c|c|c|c|c|c|}
\hline & \multicolumn{7}{|c|}{ Dependent variable: } \\
\hline & $\begin{array}{c}\Delta R S V_{t} \\
(1) \\
\end{array}$ & $\begin{array}{c}\Delta R R P_{t} \\
(2)\end{array}$ & $\begin{array}{c}\Delta R P_{t} \\
(3) \\
\end{array}$ & $\begin{array}{c}\Delta N R R P_{t} \\
(4)\end{array}$ & $\begin{array}{c}\Delta F X_{t} \\
(5)\end{array}$ & $\begin{array}{c}\Delta \text { Deposit }_{t} \\
(6)\end{array}$ & $\begin{array}{c}\Delta T S Y_{t}^{\text {outright }} \\
(7)\end{array}$ \\
\hline$\Delta T G A_{t}^{\text {Other }}$ & $\begin{array}{c}-0.232^{* * *} \\
(0.045)\end{array}$ & $\begin{array}{c}-0.127^{* * *} \\
(0.029)\end{array}$ & $\begin{array}{c}-0.116^{* * *} \\
(0.027)\end{array}$ & $\begin{array}{l}-0.011 \\
(0.027)\end{array}$ & $\begin{array}{c}0.045^{* * *} \\
(0.015)\end{array}$ & $\begin{array}{c}-0.128^{* * *} \\
(0.045)\end{array}$ & $\begin{array}{c}0.071^{* * *} \\
(0.012)\end{array}$ \\
\hline$\Delta T S Y_{t}^{\text {Issue }}$ & $\begin{array}{c}-0.087^{*} \\
(0.053)\end{array}$ & $\begin{array}{c}0.118^{* * *} \\
(0.040)\end{array}$ & $\begin{array}{l}-0.008 \\
(0.033)\end{array}$ & $\begin{array}{c}0.126^{* * *} \\
(0.037)\end{array}$ & $\begin{array}{c}0.004 \\
(0.018)\end{array}$ & $\begin{array}{c}0.139^{* * *} \\
(0.046)\end{array}$ & $\begin{array}{c}0.039^{* * *} \\
(0.014)\end{array}$ \\
\hline$\Delta S O M A_{t}$ & $\begin{array}{l}0.627^{* *} \\
(0.308)\end{array}$ & $\begin{array}{c}-0.926^{* * *} \\
(0.284)\end{array}$ & $\begin{array}{l}-0.258 \\
(0.256)\end{array}$ & $\begin{array}{c}-0.667^{* * *} \\
(0.240)\end{array}$ & $\begin{array}{c}-0.217^{*} \\
(0.118)\end{array}$ & $\begin{array}{c}-0.647^{* * *} \\
(0.220)\end{array}$ & $\begin{array}{c}-0.120^{* *} \\
(0.060)\end{array}$ \\
\hline Qend $_{t}$ & $\begin{array}{c}-29.100^{* * *} \\
(7.470)\end{array}$ & $\begin{array}{c}-11.400 \\
(7.180)\end{array}$ & $\begin{array}{c}-31.700^{* * *} \\
(4.960)\end{array}$ & $\begin{array}{c}20.300^{* * *} \\
(5.130)\end{array}$ & $\begin{array}{c}11.400^{* * *} \\
(3.170)\end{array}$ & $\begin{array}{l}-3.440 \\
(4.260)\end{array}$ & $\begin{array}{c}3.850 \\
(2.870)\end{array}$ \\
\hline Qstart $_{t}$ & $\begin{array}{c}41.500^{* * *} \\
(5.450)\end{array}$ & $\begin{array}{l}-7.690 \\
(5.110)\end{array}$ & $\begin{array}{c}0.515 \\
(4.170)\end{array}$ & $\begin{array}{c}-8.200^{* *} \\
(4.150)\end{array}$ & $\begin{array}{c}-8.270^{* *} \\
(3.290)\end{array}$ & $\begin{array}{c}28.900^{* * *} \\
(4.410)\end{array}$ & $\begin{array}{l}-0.626 \\
(1.500)\end{array}$ \\
\hline Constant & $\begin{array}{l}-0.848 \\
(0.628)\end{array}$ & $\begin{array}{l}-0.673 \\
(0.480)\end{array}$ & $\begin{array}{c}0.279 \\
(0.421)\end{array}$ & $\begin{array}{c}-0.952^{* *} \\
(0.408)\end{array}$ & $\begin{array}{c}0.188 \\
(0.233)\end{array}$ & $\begin{array}{l}-0.874 \\
(0.647)\end{array}$ & $\begin{array}{c}0.182 \\
(0.207)\end{array}$ \\
\hline $\begin{array}{l}\mathrm{N} \\
\mathrm{R}^{2}\end{array}$ & $\begin{array}{c}932 \\
0.148\end{array}$ & $\begin{array}{c}932 \\
0.074\end{array}$ & $\begin{array}{c}932 \\
0.111\end{array}$ & $\begin{array}{c}932 \\
0.098\end{array}$ & $\begin{array}{c}932 \\
0.070\end{array}$ & $\begin{array}{c}932 \\
0.096\end{array}$ & $\begin{array}{c}932 \\
0.048\end{array}$ \\
\hline
\end{tabular}

Notes: This table shows regression results of one-day changes in the TGA account unrelated to net Treasury issuance $\left(\Delta T G A_{t}^{\text {Other }}\right)$, net treasury issuance $\left(\Delta T S Y_{t}^{\text {Issue }}\right)$, net SOMA purchase $\left(\triangle S O M A_{t}\right)$ on daily changes in the U.S. GSIBs intermediation activities. The dependent variables are as follows: changes in reserves (Column 1), changes in dollar reverse repos (Column 2), changes in dollar repos (Column 3), changes in net dollar reverse repos, or the difference between reverse repos and repos in dollars (Column 4), changes in dollar lending in the FX swap market (Column 5), changes in dollar deposits (Column 6), and changes in outright Treasury holdings (Column 7). Qend is a dummy variable indicating the last business day of the quarter, and Qstart $_{t}$ is a dummy variable indicating the first business day of the quarter. Robust standard errors are reported in parentheses with significance levels denoted by ${ }^{*} \mathrm{p}<0.1 ;{ }^{* *} \mathrm{p}<0.05 ;{ }^{* * *} \mathrm{p}<0.01$. 
Table A6: Comparisons of Outright versus Repo-financed Treasury Holdings

\begin{tabular}{lccc}
\hline \hline & \multicolumn{3}{c}{ Dependent variable: } \\
\cline { 2 - 4 } & $\Delta T S Y_{t}^{\text {all }}$ & $\Delta T S Y_{t}^{\text {outright }}$ & $\Delta T S Y_{t}^{\text {fin. }}$ \\
& $(1)$ & $(2)$ & $(3)$ \\
\hline$\Delta T G A_{t}^{\text {Other }}$ & $0.063^{* * *}$ & $0.071^{* * *}$ & -0.007 \\
& $(0.013)$ & $(0.012)$ & $(0.009)$ \\
$\Delta T S Y_{t}^{\text {Issue }}$ & $0.071^{* * *}$ & $0.039^{* * *}$ & $0.032^{* *}$ \\
& $(0.016)$ & $(0.014)$ & $(0.012)$ \\
& & & \\
$\Delta S O M A_{t}$ & $-0.306^{* * *}$ & $-0.120^{* *}$ & $-0.186^{* *}$ \\
& $(0.095)$ & $(0.060)$ & $(0.085)$ \\
Qend & & & \\
& -0.612 & 3.850 & $-4.470^{* *}$ \\
Qstart $_{t}$ & $(2.940)$ & $(2.870)$ & $(1.900)$ \\
& -1.480 & -0.626 & -0.852 \\
Constant $^{*}$ & $(1.800)$ & $(1.500)$ & $(1.420)$ \\
& 0.159 & 0.182 & -0.023 \\
& $(0.223)$ & $(0.207)$ & $(0.149)$ \\
$\mathrm{N}$ & & & \\
$\mathrm{R}^{2}$ & 932 & 932 & 932 \\
\hline \hline
\end{tabular}

Notes: This table shows regression results of one-day changes in the TGA account unrelated to net Treasury issuance $\left(\Delta T G A_{t}^{\text {Other }}\right)$, net treasury issuance $\left(\Delta T S Y_{t}^{\text {Issue }}\right)$, net SOMA purchase $\left(\triangle S O M A_{t}\right)$, and quarter-end dummies on daily changes in Treasury holding-related positions. The dependent variables are as follows: $\Delta T S Y_{t}^{\text {All }}$, daily changes in total Treasury holdings of U.S. GSIBs, including outright holdings and repo-financed Treasury holdings (Column 1); $\Delta T S Y_{t}^{\text {outright }}$, daily changes in outright Treasury holdings (Column 2); and $\Delta T S Y_{t}^{\text {fin }}$, daily changes in repo-financed Treasury holdings (Column 3). Qend $_{t}$, is a dummy variable indicating the last business day of the quarter, and Qstart is a dummy variable indicating the first business day of the quarter. Robust standard errors are reported in parentheses with significance levels denoted by ${ }^{*} \mathrm{p}<0.1 ;{ }^{*} \mathrm{p}<0.05$; ${ }^{* * *} \mathrm{p}<0.01$. 